\title{
Factors Affecting the Strength of Road Base Stabilized with Cement Slurry or Dry Cement in Conjunction with Full-Depth Reclamation
}

Paul A. Dixon

Brigham Young University - Provo

Follow this and additional works at: https://scholarsarchive.byu.edu/etd

Part of the Civil and Environmental Engineering Commons

\section{BYU ScholarsArchive Citation}

Dixon, Paul A., "Factors Affecting the Strength of Road Base Stabilized with Cement Slurry or Dry Cement in Conjunction with Full-Depth Reclamation" (2011). Theses and Dissertations. 2629.

https://scholarsarchive.byu.edu/etd/2629

This Thesis is brought to you for free and open access by BYU ScholarsArchive. It has been accepted for inclusion in Theses and Dissertations by an authorized administrator of BYU ScholarsArchive. For more information, please contact scholarsarchive@byu.edu, ellen_amatangelo@byu.edu. 
Factors Affecting the Strength of Road Base Stabilized with Cement Slurry or Dry Cement in Conjunction

with Full-Depth Reclamation

\section{Paul A. Dixon}

A thesis submitted to the faculty of

Brigham Young University

in partial fulfillment of the requirements for the degree of

Master of Science

W. Spencer Guthrie, Chair

Fernando S. Fonseca

Grant G. Schultz

Department of Civil and Environmental Engineering

Brigham Young University

June 2011

Copyright () 2011 Paul A. Dixon

All Rights Reserved 



\author{
ABSTRACT \\ Factors Affecting the Strength of Road Base Stabilized with \\ Cement Slurry or Dry Cement in Conjunction \\ with Full-Depth Reclamation \\ Paul A. Dixon \\ Department of Civil and Environmental Engineering \\ Master of Science
}

Full-depth reclamation (FDR) in conjunction with cement stabilization is an established practice for rehabilitating deteriorating asphalt roads. Conventionally, FDR uses dry cement powder applied with a pneumatic spreader, creating undesirable fugitive cement dust. The cement dust poses a nuisance and, when inhaled, a health threat. Consequently, FDR in conjunction with conventional cement stabilization cannot generally be used in urban areas.

To solve the problem of fugitive cement dust, the use of cement slurry, prepared by combining cement powder and water, has been proposed to allow cement stabilization to be utilized in urban areas. However, using cement slurry introduces several factors not associated with using dry cement that may affect road base strength, dry density (DD), and moisture content (MC).

The objectives of this research were to 1) identify construction-related factors that influence the strength of road base treated with cement slurry in conjunction with FDR and quantify the effects of these factors and 2) compare the strength of road base treated with cement slurry with that of road base treated with dry cement. To achieve the research objectives, road base taken from an FDR project was subjected to extensive full-factorial laboratory testing. The 7-day unconfined compressive strength (UCS), DD, and MC were measured as dependent variables, while independent variables included cement content; slurry water batching temperature; cement slurry aging temperature; cement slurry aging time; presence of a setretarding, water-reducing admixture; and aggregate-slurry mixing time.

This research suggests that, when road base is stabilized with cement slurry in conjunction with FDR, the slurry water batching temperature; haul time; environmental temperature; and presence of a set-retarding, water-reducing admixture will not significantly affect the strength of CTB, provided that those factors fall within the limits explored in this research and are applied to a road base with similar properties. Cement content and cementaggregate mixing time are positively correlated with the strength of CTB regardless of cement form. Additionally, using cement slurry will result in slightly lower strength values than using dry cement.

Key words: cement slurry, cement stabilization, cement-stabilized aggregate base, cementtreated aggregate base, cement-treated base (CTB), deep in-situ recycling, full-depth reclamation (FDR), reclaimed asphalt pavement (RAP), recycled asphalt pavement (RAP), soil-cement 



\section{ACKNOWLEDGMENTS}

I am grateful to the Portland Cement Association (PCA) and their generous sponsorship of this research through their Education Foundation Fellowship, project index number F08-02. I thank the PCA personnel who have provided support, including Steve Kosmatka, Wayne Adaska, Greg Halsted, Don Clem, and Carmaline Spurrier, among others. I am grateful to BYU students Amy Crook, Jeremy Dye, Jeff Hoki, Adam Homewood, Charles Hope, Shar Montgomery, Tyler Quick, Maile Rogers, Scott Shea, Chase Thomas, Wendy Thompson, and Bryan Wilson for their help; I am especially grateful to David Young for being an excellent, diligent assistant in the laboratory. I thank BYU laboratory technicians David Anderson, Rodney Mayo, Robert Paulsen, and Benjamin Holdaway for their extensive laboratory support. I thank Dennis Eggett for his statistical work on this research and Grant G. Schultz and Fernando S. Fonseca for serving on my graduate committee. I am grateful to my parents, my siblings, and their spouses for the moral support and genuine interest they expressed in my progress. Most of all, I express deepest appreciation for my graduate advisor, professor, mentor, and friend, W. Spencer Guthrie, for believing in me, teaching me, and helping me see and realize my true potential, both technically and outside of academia. 

LIST OF TABLES ......................................................................................................... vii

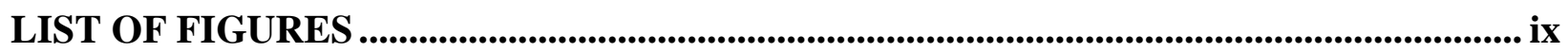

1 INTRODUCTION...................................................................................................................... 1

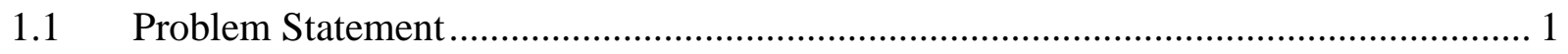

1.2 Scope

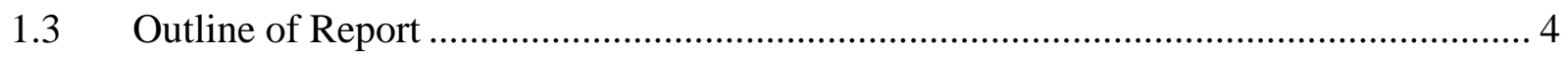

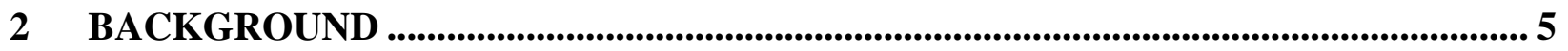

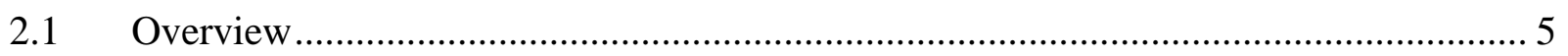

2.2 Construction Process................................................................................................... 5

2.3 Construction Factors ............................................................................................... 10

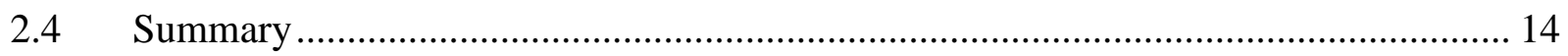

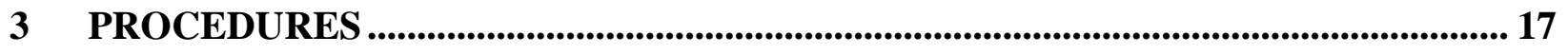

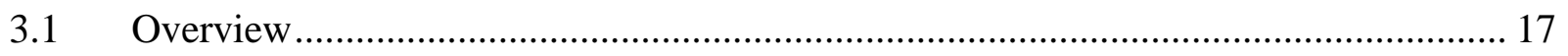

3.2 Experimental Design............................................................................................ 17

3.3 Material Characterization ..................................................................................... 19

$3.4 \quad$ Specimen Preparation ......................................................................................... 21

3.4.1 Aggregate and Water Proportioning ....................................................................... 21

3.4.2 Cement Slurry Preparation and Aging ..................................................................... 24

3.4.3 Aggregate and Cement Mixing ................................................................................. 28

3.4.4 Specimen Compaction and Curing ……………................................................. 31

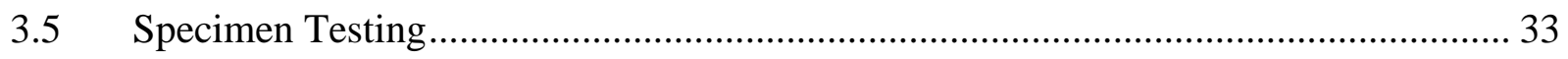

3.6 Data Analyses …………………………………............................................... 36

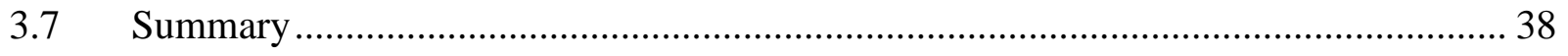




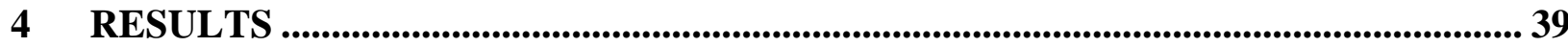

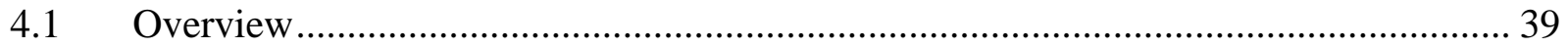

4.2 Material Characterization ........................................................................................ 39

4.3 Evaluation of Road Base Stabilized with Cement Slurry ............................................... 42

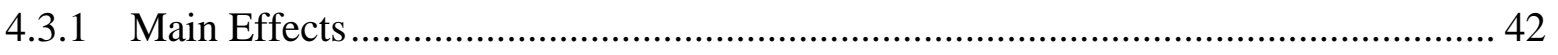

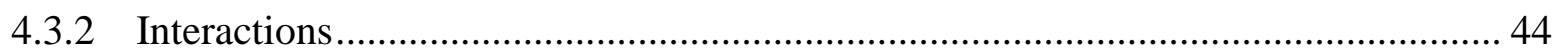

4.4 Evaluation of Road Base Stabilized with Either Slurry or Dry Cement......................... 47

4.4.1 Main Effects .......................................................................................................... 55

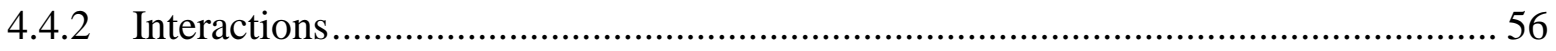

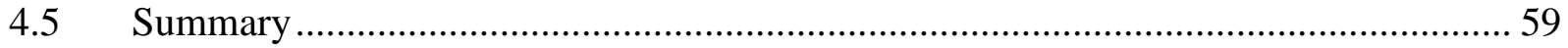

5 CONCLUSION …….......................................................................................................... 61

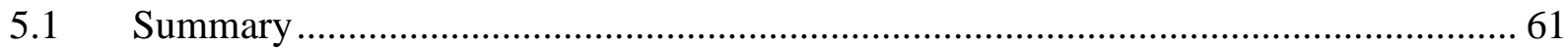

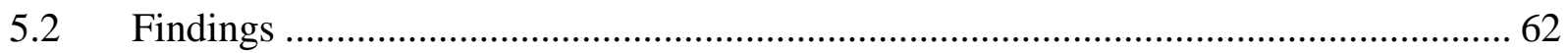

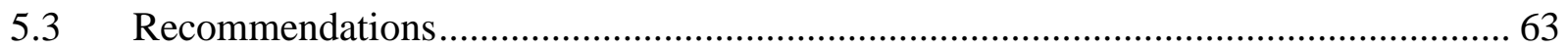

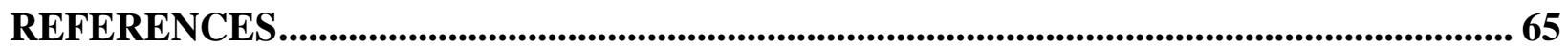

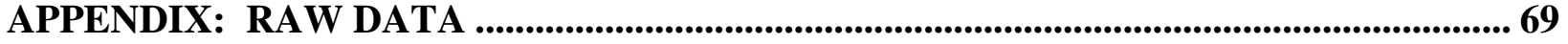




\section{LIST OF TABLES}

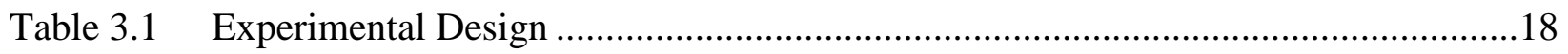

Table 4.1 Particle-Size Distribution ..............................................................................40

Table 4.2 OMC and MDD Values ...............................................................................42

Table 4.3 ANOVA Results for Road Base Treated with Cement Slurry ...............................43

Table 4.4 Least Squares Means for Main Effects of Experimental Factors on UCS, DD, and MC of Road Base Treated with Cement Slurry.

Table 4.5 Least Squares Means for Interactions between Experimental Factors for UCS of Road Base Treated with Cement Slurry

Table 4.6 Least Squares Means for Interactions between Experimental Factors for DD of Road Base Treated with Cement Slurry

Table 4.7 Least Squares Means for Interactions between Experimental Factors for MC of Road Base Treated with Cement Slurry......

Table 4.8 ANOVA Results for Road Base Treated with Dry Cement or Cement Slurry

Table 4.9 Least Squares Means for Main Effects of Experimental Factors on UCS, DD, and MC of Road Base Treated with Dry Cement or Cement Slurry

Table 4.10 Least Squares Means for Interactions between Experimental Factors for UCS of Road Base Treated with Dry Cement or Cement Slurry....

Table A.1 Raw Data 


\section{LIST OF FIGURES}

Figure 2.1 Schematic showing a reclaimer drum grinding distressed asphalt pavement and mixing with underlying road base ...........................................6

Figure 2.2 Grinding a failed asphalt pavement and mixing with underlying road base .............6

Figure 2.3 Fugitive cement dust associated with applying dry cement using a pneumatic spreader

Figure 2.4 Spreading dry cement using a pneumatic spreader with an enclosure for dust reduction

Figure 2.5 Application of cement slurry in an FDR project using a slurry spreader

Figure 2.6 Application of cement slurry in an FDR project directly from the chute of a ready-mix truck

Figure 2.7 Mixing cement with road base while injecting water.........................................9

Figure 2.8 Compaction following mixing of cement and road base....................................10

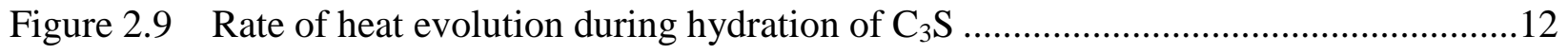

Figure 3.1 Aerial view of Redwood Drive and surrounding area........................................19

Figure 3.2 Operation of the sieving machine for bulk material separation .............................20

Figure 3.3 Road base separated after bulk sieving .........................................................21

Figure 3.4 Aggregate during washed sieving for road base classification .............................22

Figure 3.5 Particle separation using hydrometer for road base classification .........................22

Figure 3.6 Proportioning of road base aggregate for testing …........................................23

Figure 3.7 Road base moistening in sealed plastic cylinders..............................................24

Figure 3.8 Conditioned, deionized water used to make cement slurry ..................................25

Figure 3.9 Addition of a set-retarding, water-reducing admixture to cement slurry water

Figure 3.10 Addition of cement to water to prepare cement slurry. .27

Figure 3.11 Initial mixing to prepare cement slurry .27 
Figure 3.12 Slurry aging in a covered mixer in a temperature-controlled environmental chamber .....

Figure 3.13 Adding cement slurry to aggregate................................................................29

Figure 3.14 Cement slurry with aggregate before mixing .....................................................30

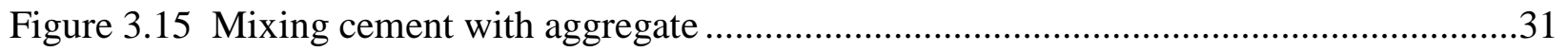

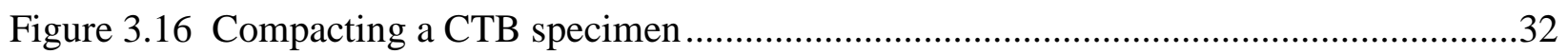

Figure 3.17 CTB specimens ready for 7 days of curing at room temperature...........................33

Figure 3.18 Hardening of gypsum caps in preparation for 7-day UCS testing............................34

Figure 3.19 CTB specimen undergoing 7-day UCS testing ….............................................35

Figure 3.20 Specimens drying in a $140^{\circ} \mathrm{F}$ oven in order to obtain DD and MC .......................36

Figure 4.1 Particle-size distribution from washed-sieve analysis.......................................40

Figure 4.2 Moisture-density curve for road base containing 2 percent cement.........................41

Figure 4.3 Moisture-density curve for road base containing 6 percent cement........................41

Figure 4.4 Interaction between cement content and slurry aging temperature .........................45

Figure 4.5 Interaction between cement content and cement-aggregate mixing time.................46

Figure 4.6 Interaction between slurry aging temperature and slurry admixture.......................46

Figure 4.7 Interaction between cement content and cement-aggregate mixing time.................49

Figure 4.8 Interaction between water batching temperature and slurry aging temperature

Figure 4.9 Interaction between aging temperature and slurry admixture ...............................50

Figure 4.10 Interaction between water batching temperature and slurry admixture ...................50

Figure 4.11 Interaction between slurry aging temperature and cement content .........................52

Figure 4.12 Interaction between slurry aging temperature and water batching temperature

Figure 4.13 Interaction between slurry admixture and slurry aging temperature.......................53

Figure 4.14 Interaction between slurry admixture and water batching temperature ...................53 
Figure 4.15 Interaction between water batching temperature and cement content......................54

Figure 4.16 Interaction between slurry admixture and cement content...................................54

Figure 4.17 Interaction between cement content and cement form .......................................57

Figure 4.18 Interaction between cement content and cement-aggregate mixing time ................58 


\section{INTRODUCTION}

\subsection{Problem Statement}

Asphalt-surfaced pavements comprise approximately 94 percent of all paved roads in the United States (Huang 2004). Unfortunately, those responsible for maintaining asphalt roads often lack the resources necessary to maintain them adequately. Consequently, asphalt pavements commonly require extensive rehabilitation, creating the need for cost-effective rehabilitative solutions. Full-depth reclamation (FDR) in conjunction with cement stabilization is a cost-effective way to rehabilitate a deteriorating asphalt road.

Both cement stabilization and FDR have been utilized in roadway construction for decades. Cement stabilization for roads dates to at least 1915 when portland cement was mixed with shells and sand for a road in Sarasota, Florida (ACI 1990), and rational methods for testing and constructing soil-cement were developed by the Portland Cement Association (PCA) in 1935 (PCA 1992). Reclaiming was first performed with asphalt rippers and equipment such as travelling hammer mills and grid rollers to break up asphalt. Development of rotary mixers in the 1950s led to improved sizing of ripped asphalt material, and the development of cold-planing machines eventually led to the production of modern reclaimers, increasing FDR implementation (ARRA 2001). With increasing use of FDR, many agencies developed their own FDR mix design methods. Although few of these have been reported in the literature (ARRA 2001), PCA 
has offered publications describing the steps involved in FDR with cement stabilization since at least 1976 (PCA 1976).

At the present time, FDR in conjunction with cement stabilization is an established practice for rehabilitating asphalt roads in many locations. The FDR process converts a failed asphalt pavement into a cement-stabilized road base while simultaneously minimizing the removal and addition of aggregates and thereby providing an avenue by which agencies may cut road rehabilitation costs (Bemanian et al. 2006, Kearney and Huffman 1999, PCA 2002). Furthermore, because the addition of cement strengthens the road base, the rehabilitated pavement can last longer and/or accommodate heavier traffic.

Using dry cement in the FDR process effectively produces strong and durable road base. However, its application with a pneumatic spreader creates undesirable fugitive cement dust. The cement dust poses a nuisance and, when inhaled, a health threat. Therefore, despite the numerous benefits of cement treatment, FDR in conjunction with conventional cement stabilization cannot generally be used in urban areas.

To solve the problem of fugitive cement dust, the use of cement slurry, prepared by combining cement powder and water, has been proposed to allow this process to be utilized in urban areas. However, using cement slurry introduces several factors not associated with using dry cement, and the influence of these factors on road base strength is unknown. While other researchers have investigated how factors such as cement content, material type, cement-treated base (CTB) aging time, source and quantity of recycled asphalt pavement (RAP), and compaction delay time affect the compressive strength of CTB (Guthrie et al. 2007a, Guthrie et al. 2007b, Guthrie et al. 2009, Lim and Zollinger 2003, Sebesta et al. 2009, Taha et al. 2002), limited research has addressed factors unique to cement slurry that may influence CTB strength. 
Furthermore, the strength attained by the use of cement slurry has not been compared to that achieved by the use of dry cement.

Therefore, the objectives of this research were to 1) identify construction-related factors that influence the strength of road base treated with cement slurry in conjunction with FDR and quantify the effects of these factors and 2) compare the strength of road base treated with cement slurry with that of road base treated with dry cement. The results of this research will help pavement engineers prepare specifications that properly address potential construction issues associated with the use of cement slurry and more confidently apply cement stabilization in urban environments.

\subsection{Scope}

This research involved extensive laboratory testing of a base material obtained from an FDR project on Redwood Drive in Salt Lake City, Utah, in August 2008. Treatments with both cement slurry and dry cement were evaluated in full-factorial experimentation with three replicates of each unique treatment. The 7-day unconfined compressive strength (UCS), dry density (DD), and moisture content (MC) were measured as dependent variables, while independent variables included cement content; slurry water batching temperature; cement slurry aging temperature; cement slurry aging time; presence of a set-retarding, water-reducing admixture; and aggregate-slurry mixing time. Statistical analyses, including analysis of variance (ANOVA), were performed to address the objectives of this research. 


\subsection{Outline of Report}

This report contains five chapters. Chapter 1 presents the problem statement and scope of the research. Chapter 2 provides background information on FDR and construction factors affecting CTB. Chapter 3 describes the experimental design, laboratory procedures, and data analysis methods. Chapter 4 reports the results of the investigation and interprets the findings. Chapter 5 summarizes the results and offers recommendations. 


\section{BACKGROUND}

\subsection{Overview}

This chapter explains the process of construction with FDR in conjunction with cement stabilization and describes construction factors that may affect the strength of CTB.

\subsection{Construction Process}

FDR in conjunction with cement stabilization includes several general construction steps. A reclaimer first grinds the failed asphalt pavement and combines the newly formed RAP with the underlying road base, as shown in Figures 2.1 and 2.2. After the layer is graded to remove any excess material, cement is added, either in dry or slurry form. While dry cement requires no previous preparation before placement, cement slurry is prepared at a batch plant by mixing cement powder and water in correct proportions; after batching at the plant, the slurry is transported to the project site. When in dry form, cement is typically distributed over the newly formed road base using a pneumatic spreader as shown in Figure 2.3, which also depicts the associated fugitive cement dust common to this distribution technique. Figure 2.4 shows distribution of dry cement using a conventional pneumatic spreader modified with an enclosure to reduce fugitive dust. Complete elimination of fugitive dust is achieved with the application of a cement slurry as illustrated in Figure 2.5; this particular patent-pending slurry spreader attaches 


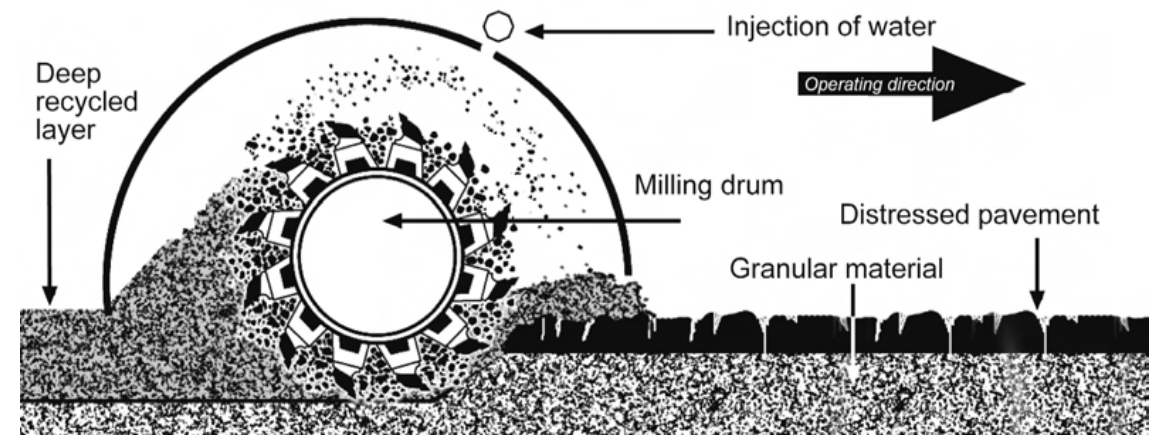

Figure 2.1 Schematic showing a reclaimer drum grinding distressed asphalt pavement and mixing with underlying road base (Luhr et al. 2005).

directly to the chute of a standard ready-mix truck. In the absence of a spreader, cement slurry can also be distributed directly from the ready-mix truck as shown in Figure 2.6.

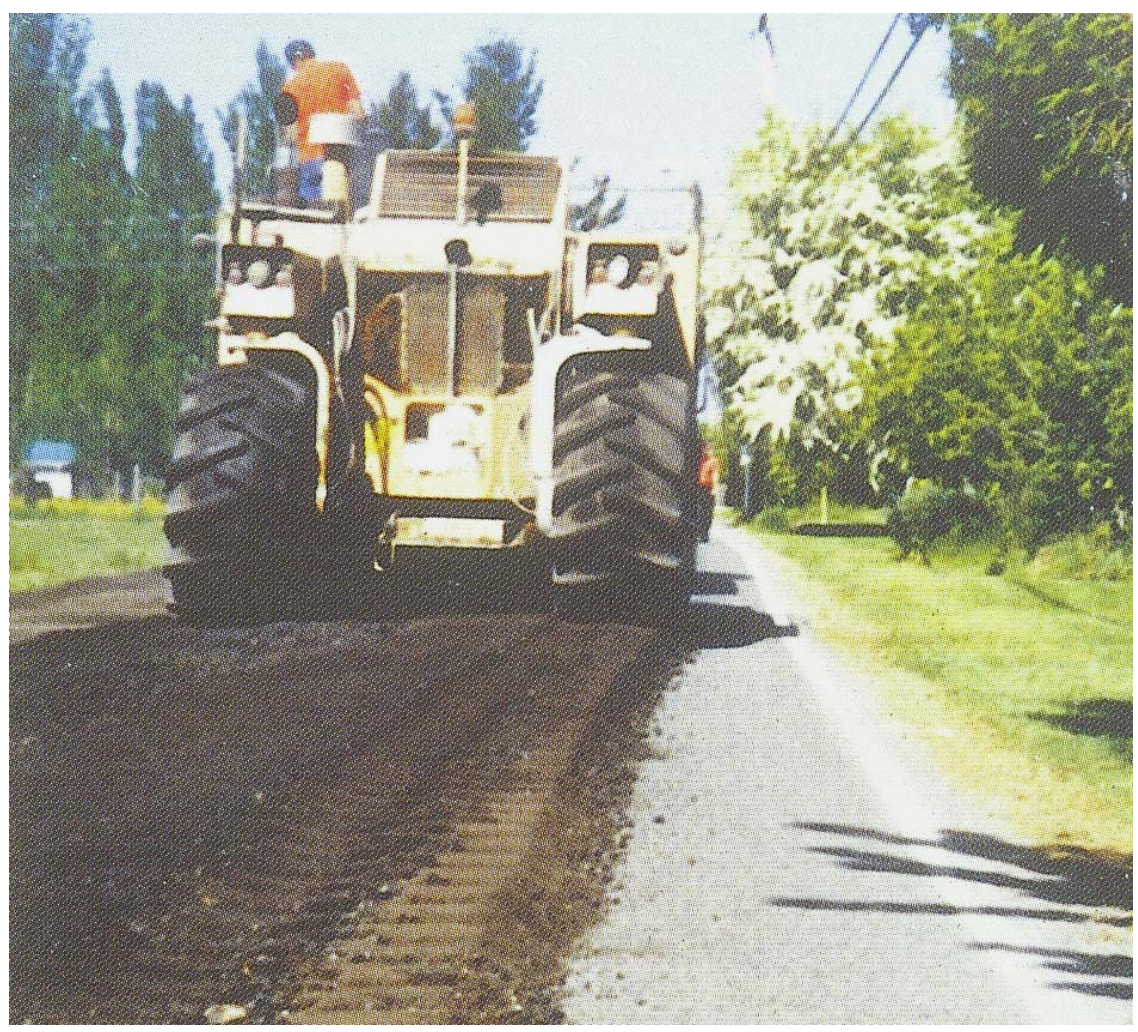

Figure 2.2 Grinding a failed asphalt pavement and mixing with underlying road base (PCA 2002). 


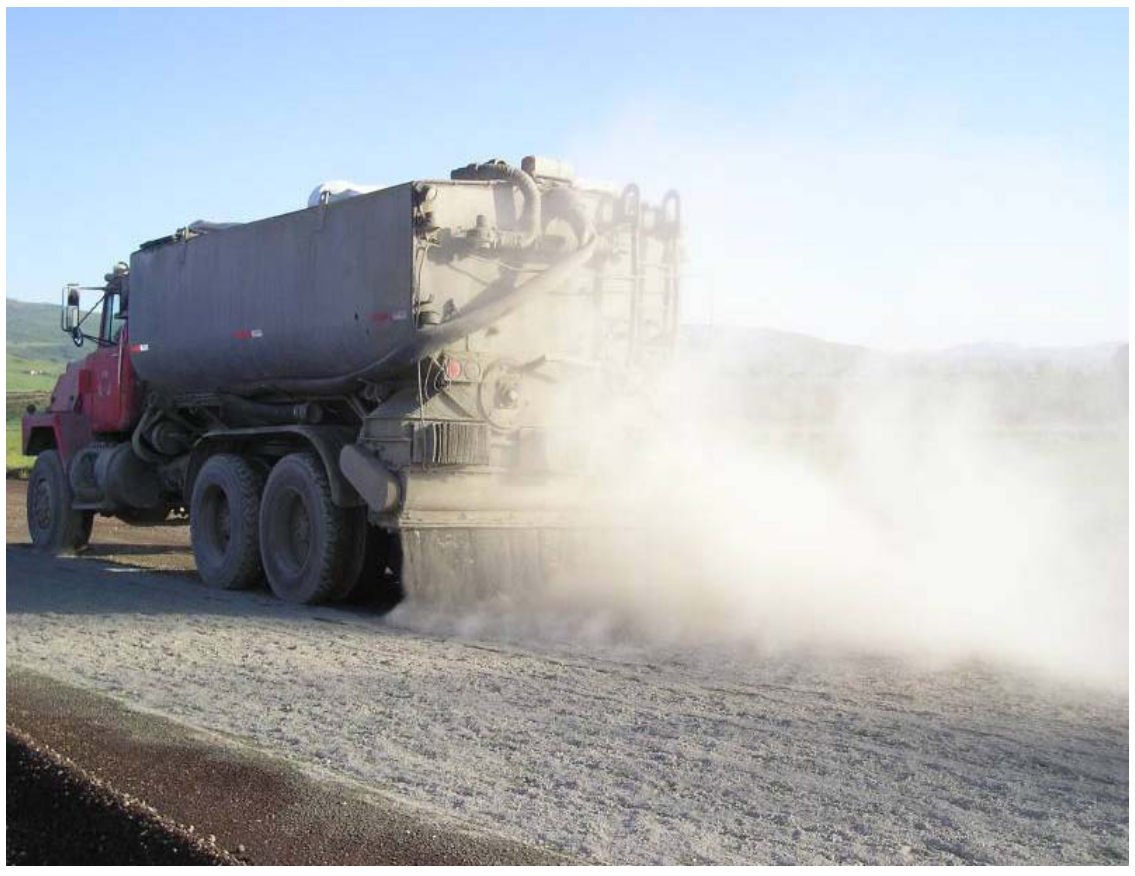

Figure 2.3 Fugitive cement dust associated with applying dry cement using a pneumatic spreader.

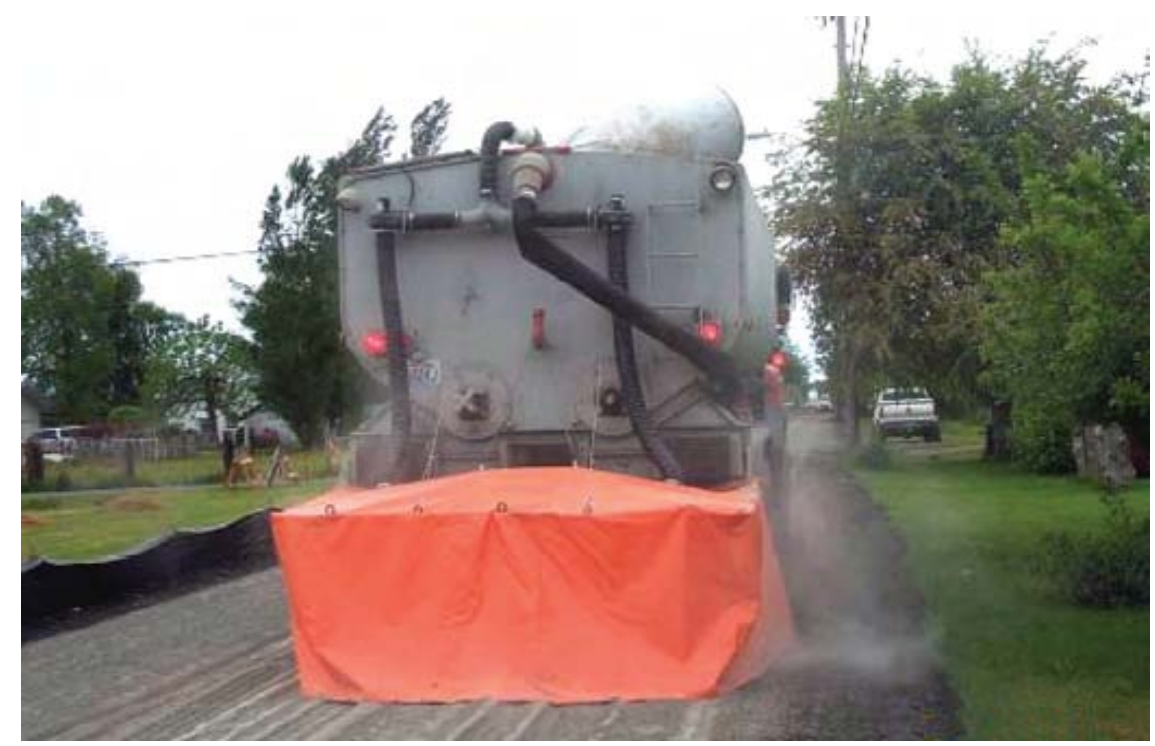

Figure 2.4 Spreading dry cement using a pneumatic spreader with an enclosure for dust reduction (Luhr et al. 2005). 


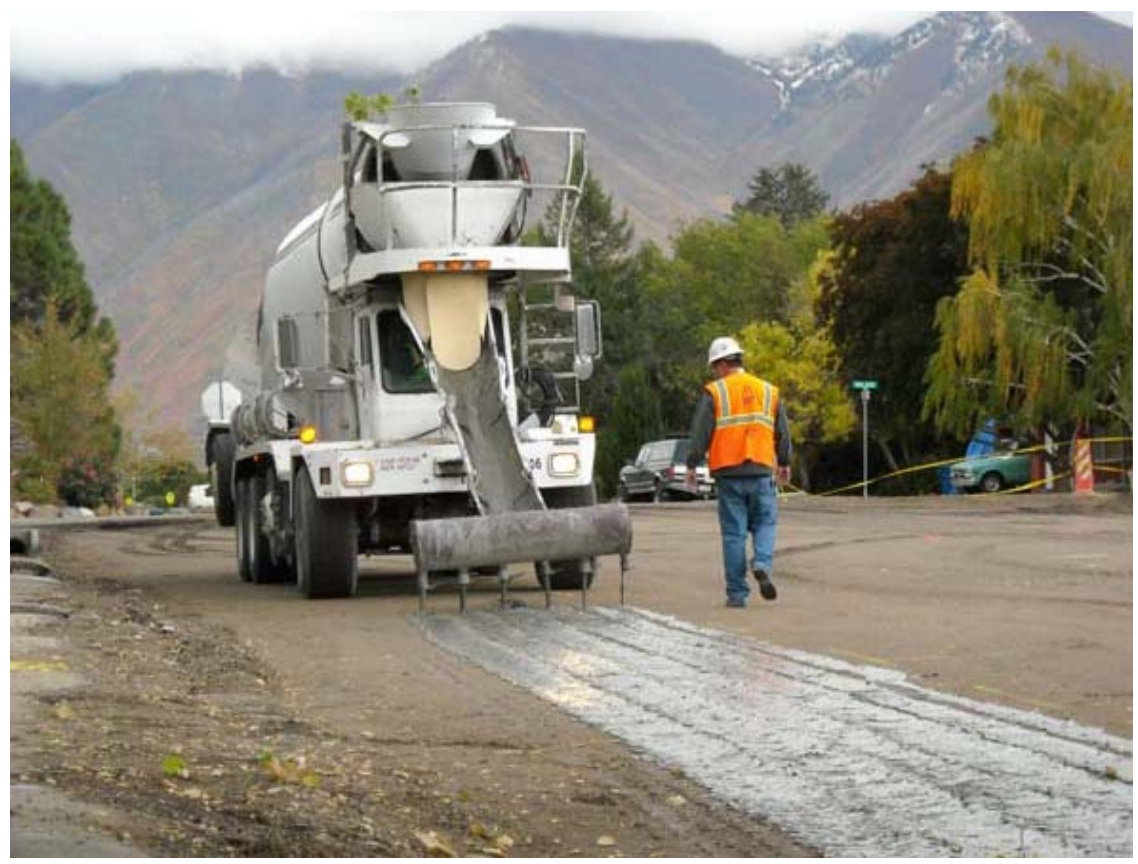

Figure 2.5 Application of cement slurry in an FDR project using a slurry spreader.

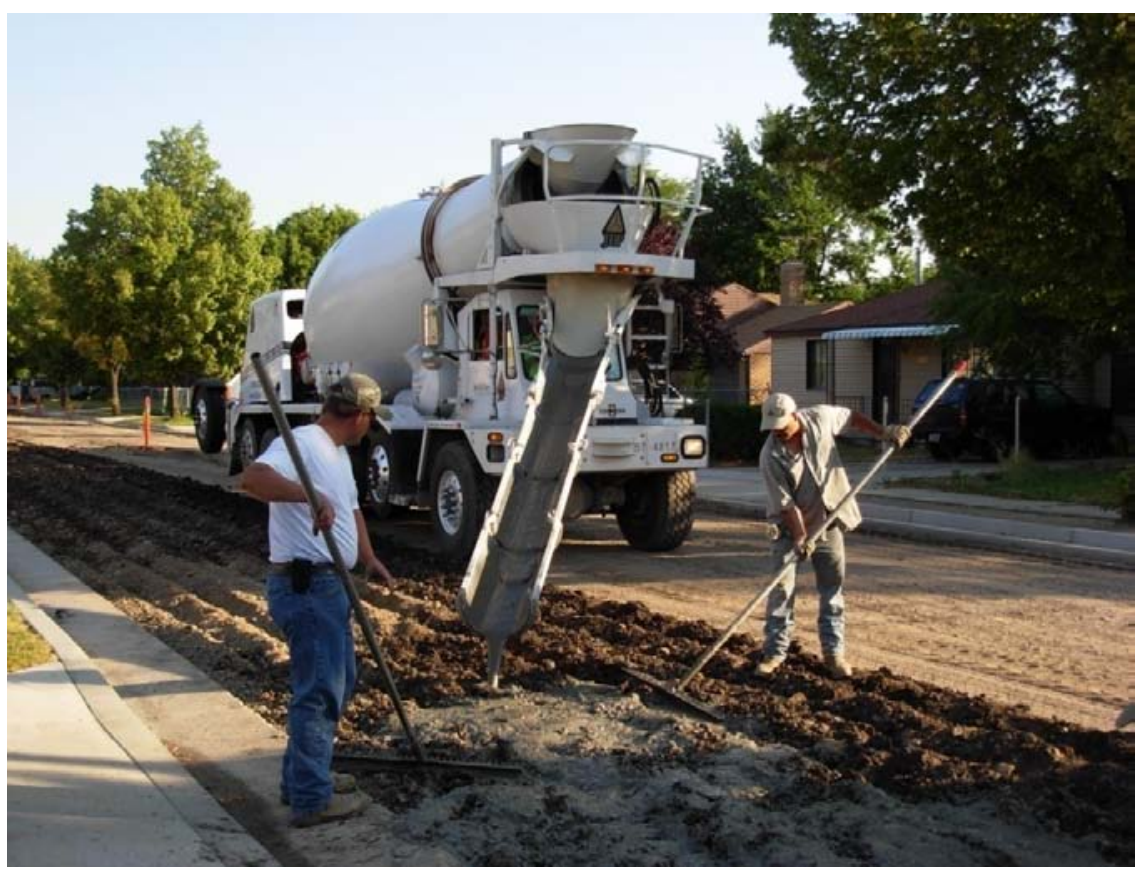

Figure 2.6 Application of cement slurry in an FDR project directly from the chute of a ready-mix truck. 
After the cement is applied, whether in dry or slurry form, water may be applied to the road base if insufficient moisture exists relative to optimum moisture content (OMC) (PCA 1995). In this case, as illustrated in Figure 2.7, the water can be metered directly into the mixing drum of the reclaimer as the cement is blended with the road base.

After the cement and road base are mixed, the resulting CTB is then compacted as shown in Figure 2.8. After compaction, the CTB should be maintained moist by light watering or misting for at least 7 days so that the cement can hydrate. Alternatively, a curing compound may be applied to seal in the moisture. A bituminous prime coat, for example, can serve satisfactorily as a curing compound (Halsted et al. 2006). Light traffic may be allowed on the completed soilcement immediately following compaction provided the traffic loads do not damage the curing compound or cause permanent deformation. Heavy truck trafficking, however, is allowed only after sufficient curing time, usually 7 days (ACI 1990, Kearney et al. 1999). The wearing course

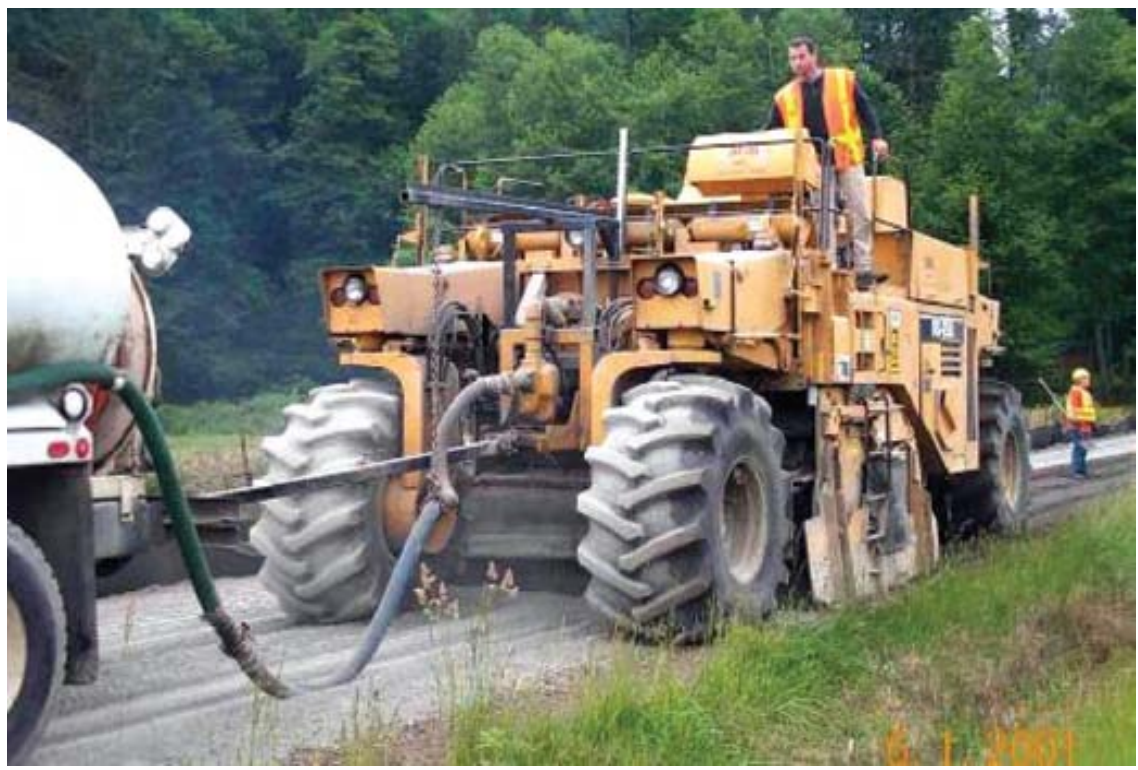

Figure 2.7 Mixing cement with road base while injecting water (Luhr et al. 2005). 


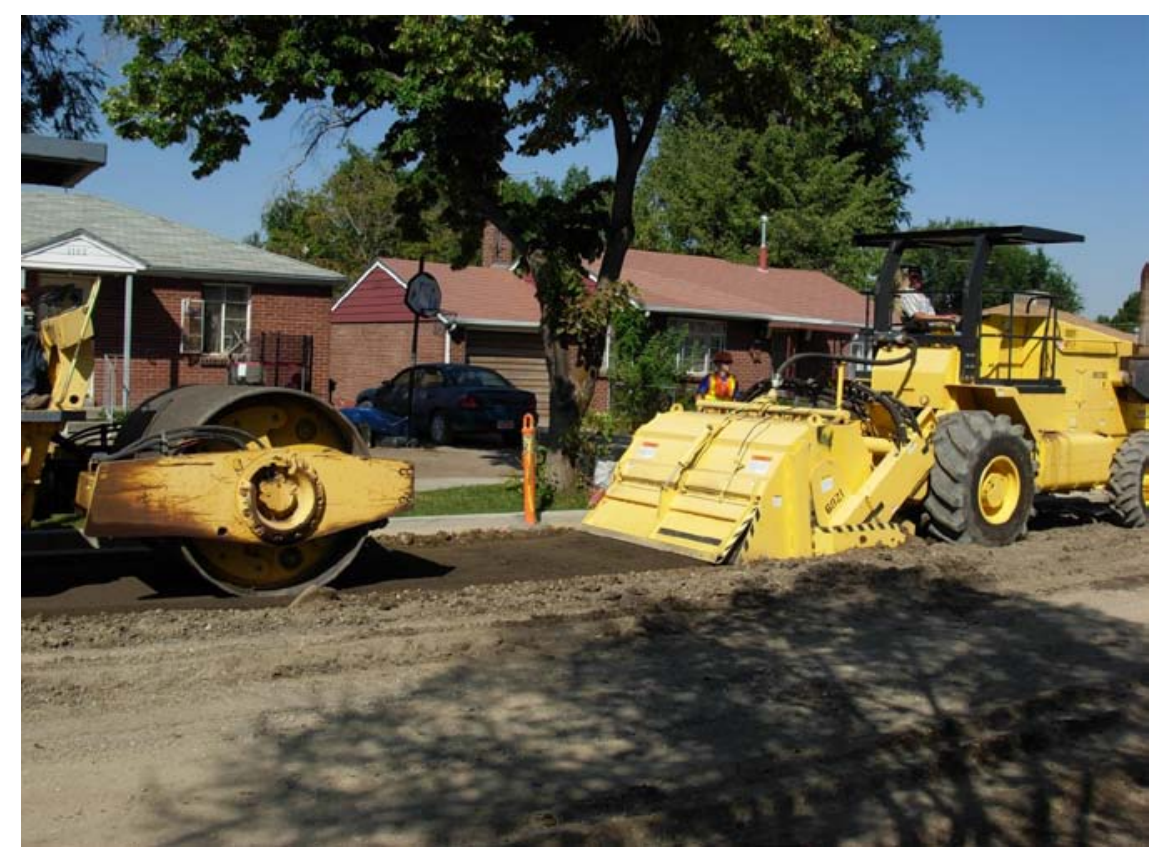

Figure 2.8 Compaction following mixing of cement and road base.

may be applied as soon as the CTB is stable under construction traffic, usually between 4 and 48 hours (Halsted 2006).

\subsection{Construction Factors}

Several factors affect the strength of CTB. The most important factors are cement proportioning and its blending with soil, water proportioning and its blending with soil, and soilcement compaction to proper density before the cement hydrates (PCA 1992). The proper cement content for a CTB construction project is determined by preparing laboratory specimens with varying amounts of cement. Following PCA protocols, the specimens are subjected to strength and durability testing, and the cement content that satisfies minimum strength and durability requirements is then specified (PCA 1992). 
The proper water content for a CTB project is determined from a moisture-density curve prepared at the specified cement content. Soil-cement should be prepared as close to possible to OMC in order to be compacted to maximum density and exhibit the desired strength (Halsted et al. 2006). Laboratory tests are typically based on one of two compaction procedures, ASTM D698 (Standard Test Methods for Laboratory Compaction Characteristics of Soil Using Standard Effort) and ASTM D1557 (Standard Test Methods for Laboratory Compaction Characteristics of Soil Using Modified Effort). Research suggests that greater compaction than that achieved through the modified compaction method is not practically possible in the field (Burmister 1965, Lee et al. 2007, Miller et al. 2002).

Cement undergoes a hydration reaction when combined with water. This exothermic chemical reaction is very complex and involves several reactants and products. However, the reaction that typically governs the setting and hardening times of fresh concrete and cement paste is the conversion of tricalcium silicate, $\mathrm{C}_{3} \mathrm{~S}$, to a calcium silicate hydrate (CSH) (FitzGerald et al. 1998). Figure 2.9 shows the reactivity of $\mathrm{C}_{3} \mathrm{~S}$ as a function of time as evidenced by the rate of heat evolution.

Hydration occurs in five stages. Initial hydrolysis, consisting of the release of calcium and hydroxide ions from $\mathrm{C}_{3} \mathrm{~S}$ grains, occurs during stage one. The reaction quickly slows but still continues into the dormant/induction period, stage two. The relative inactivity of portland cement during the induction period is what allows portland cement concrete to remain in the plastic state for several hours (Mindess 2003). The induction period may last 0.5 to 3 hours (Double et al. 1978). Initial set occurs at the end of the induction period, marking the time when the cement paste is no longer moldable. After critical concentrations of calcium and hydroxide are reached, the acceleration period, stage three, begins. The reaction products, including CSH, 


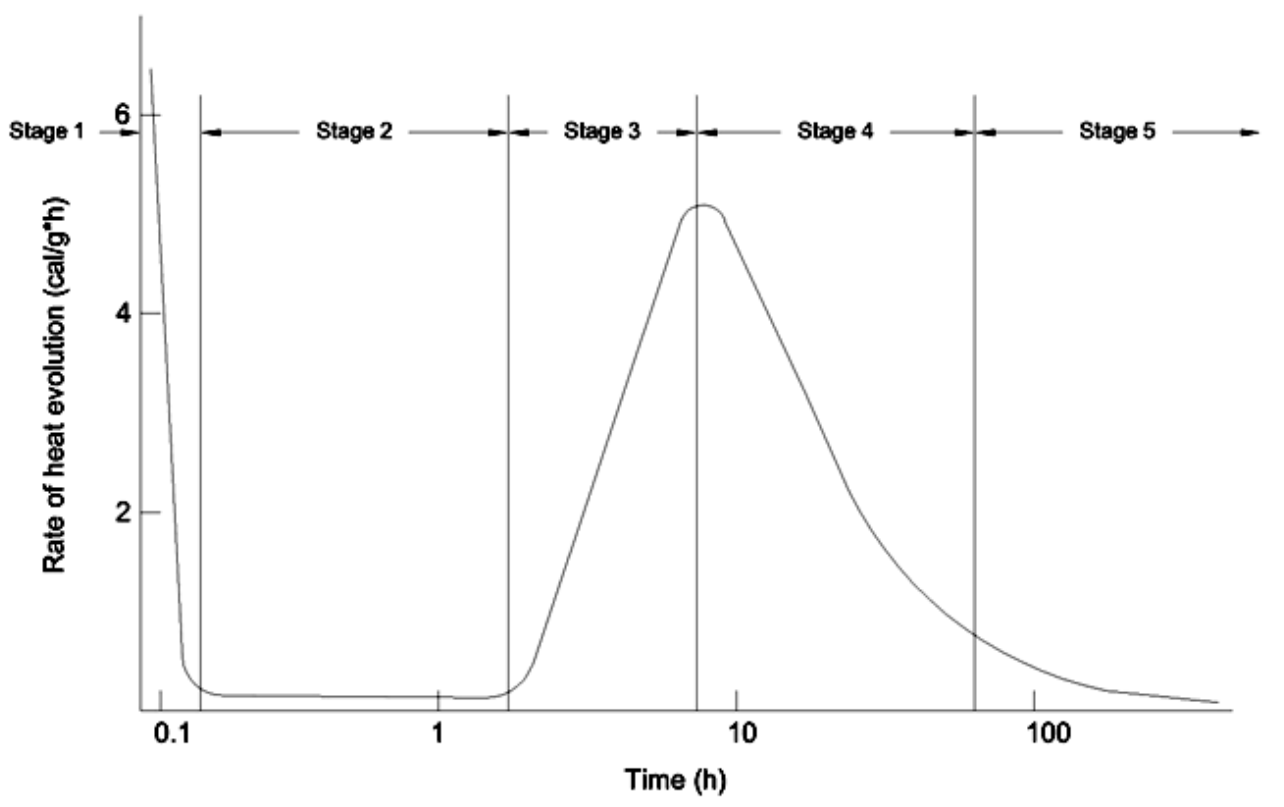

Figure 2.9 Rate of heat evolution during hydration of $C_{3} S$ (after Mindess 2003).

begin forming during this stage. The end of stage three and the beginning of stage four, the deceleration period, are characterized by final set and early hardening. The hydration reaction slows in stage four and becomes diffusion-controlled in stage five (Mindess 2003).

Using cement slurry to treat road base introduces several factors that are not present when cement powder is used. These factors, which possibly affect the strength of the stabilized road base, include greater time between initial hydration and cement-aggregate mixing, environmental temperature, water batching temperature, cement slurry age, use of chemical admixtures, and effectiveness of cement-aggregate mixing time.

CTB stabilized with cement slurry could exhibit a different strength from that stabilized with dry cement because water is introduced to cement slurry earlier than to dry cement for FDR applications. An earlier initiation of cement hydration could thus potentially alter the strength of 
road base stabilized with aggregate, especially since the length of the induction phase, stage two, can vary.

Environmental temperatures could affect the strength of CTB, as temperature is known to affect the rate of cement hydration. Increasing the temperature of hydration shortens the dormant period (Double et al. 1978). Cement can be subjected to a wide range of environmental temperatures while being transported from a batch plant to a construction site. The effect of environmental temperatures is well understood regarding the transportation of fresh concrete. For example, during hot seasons in Texas, fresh concrete may be injected with liquid nitrogen to cool it before being transported, prolonging the induction phase and delaying initial set (Juenger et al. 2008). Excessively hot or cold environmental temperatures may also be offset by preparing slurry with prescribed water temperatures. Batch plants will commonly prepare fresh concrete with cold water for hot-weather placement and with hot water for cold-weather placement to lengthen and shorten initial set times, respectively. Departments of transportation even have specifications governing how much time a contractor is allowed to place fresh concrete once it arrives at a construction site, depending on environmental temperatures. For example, the Utah Department of Transportation (UDOT) specification 03055 requires that the temperature of fresh concrete be between 50 and $90^{\circ} \mathrm{F}$ when placed in forms (UDOT 2011). In theory, temperature may affect CTB in similar ways.

The strength of road base stabilized with cement slurry could differ according to slurry age at the time of application. Because portland cement hydrates with time, ready-mix truck drivers must plan their delivery routes carefully, as unexpected traffic delays can lead to premature setting of concrete, even before unloading. Temporal limits, depending on environmental conditions, are therefore often included in construction specifications for concrete 
projects. For example, UDOT specifies that concrete must be placed within 90 min of batching when the air temperature is below $80^{\circ} \mathrm{F}$, within $75 \mathrm{~min}$ of batching when the air temperature is between 80 and $85^{\circ} \mathrm{F}$, and within 60 min of batching when the air temperature is above $85^{\circ} \mathrm{F}$ (UDOT 2011). Thus, the amount of time that passes between slurry preparation and application may influence the properties of the resulting CTB.

Chemical admixtures, such as set retarders and water reducers, could influence the strength of road base treated with cement slurry. Set retarders prolong the induction phase, slowing down the rate of early $\mathrm{C}_{3} \mathrm{~S}$ hydration and early strength development (Mindess 2003). Water reducers cause cement particles to electrostastically repel each other, increasing strength by making the cement work more efficiently (Mindess 2003). The benefits of these admixtures in concrete construction may also be realized in CTB construction.

Cement-aggregate mixing time may affect the strength of CTB. Studies from as early as the 1930s have shown that increasing the mixing time of concrete increases its compressive strength (PCA 1953). Guides to CTB construction emphasize the importance of thorough mixing (ACI 1990, PCA 1992). Therefore, a similar increase in strength in CTB may be observed by increasing mixing time.

\subsection{Summary}

FDR in conjunction with cement stabilization is a method for rehabilitating failed asphalt pavements. The process involves grinding the failed asphalt pavement with a reclaimer, mixing the newly formed RAP with the underlying road base, grading, adding cement in either dry or slurry form, blending the cement with the RAP-road base mixture, compacting, curing, and 
paving with a wearing course. When dry cement is used, care must be taken to minimize fugitive cement dust; the problem is avoided entirely when cement slurry is used.

Several factors affect the strength of CTB. The literature indicates that the most important factors are cement proportioning and its blending with soil, water proportioning and its blending with soil, and soil-cement compaction to proper density before the cement hydrates. Compacting the cement-treated material to proper density is more easily accomplished when the cement-treated material is at or near OMC.

Using cement slurry in conjunction with FDR is a relatively new practice that introduces several factors not present when cement powder is used. Such factors, which are expected to affect the strength of the stabilized road base, include greater time between initial hydration and cement-aggregate mixing, environmental temperature, water batching temperature, cement slurry age, use of chemical admixtures, and effectiveness of cement-aggregate mixing time. 


\section{PROCEDURES}

\subsection{Overview}

This chapter presents the experimental design developed for this research and then describes the processes that were employed in material characterization, specimen preparation, specimen testing, and data analysis.

\subsection{Experimental Design}

Seven factors influencing the 7-day UCS, DD, and MC of cement-treated road base were investigated in this research, namely cement content, slurry water batching temperature, admixture use, slurry aging temperature, slurry aging time, cement-aggregate mixing time, and cement form as described in Table 3.1. The first six factors can apply to road base treated with cement in slurry form; however, only cement content and cement-aggregate mixing time apply to specimens prepared with dry cement. Consequently, two full-factorial designs were implemented, one for each cement form.

Slurry water batching temperature refers to the temperature of water when first mixed with cement powder. In practice, batch plants commonly adjust this temperature according to outside temperature. Water batching temperature was controlled in this research by conditioning deionized water for at least 24 hours in an environmental chamber set to either 60 or $90^{\circ} \mathrm{F}$. The water batching temperatures and slurry aging temperatures were chosen to fall within the 50 to 
Table 3.1 Experimental Design

\begin{tabular}{c|cc}
\hline Cement Slurry & \multicolumn{2}{|c}{ Levels } \\
\hline Slurry Water BatchingTemperature $\left({ }^{\circ} \mathrm{F}\right)$ & 60 & 90 \\
Slurry Admixture & yes & no \\
Slurry Aging Temperature $\left({ }^{\circ} \mathrm{F}\right)$ & 60 & 90 \\
Slurry Aging Time (min) & 30 & 90 \\
Cement Content $(\%)$ & 2 & 6 \\
Cement-Aggregate Mixing Time (sec) & 5 & 15 \\
\hline Dry Cement & \multicolumn{2}{|c}{ Levels } \\
\hline Cement Content $(\%)$ & 2 & 6 \\
Cement-Aggregate Mixing Time (sec) & 5 & 15 \\
\hline
\end{tabular}

$90^{\circ} \mathrm{F}$ range that UDOT requires for fresh concrete upon arrival at a job site, as stated in Chapter

2. The slurry admixture used in this research possessed both set-retarding and water-reducing properties consistent with the requirements specified for Type D in ASTM C494 (Standard Specification for Chemical Admixtures for Concrete). Slurry aging temperature was the air temperature to which cement slurry was subjected after it was batched but before it was mixed into the road base. This temperature was provided by aging the cement slurry under continuous mixing in an environmental chamber set to either 60 or $90^{\circ} \mathrm{F}$. This arrangement simulated the conditions inside a ready-mix truck to which cement slurry would be subjected during transportation from a batch plant to a road construction site. Temperatures inside a ready-mix truck may vary according to factors such as outside temperature and solar radiation.

While every effort was made in this research to maintain separate cool and warm environmental chambers at 60 and $90^{\circ} \mathrm{F}$, respectively, the cool chamber temperature varied from 50 to $61^{\circ} \mathrm{F}$, and the warm chamber temperature varied from 88 to $97^{\circ} \mathrm{F}$. Although using environmental chambers with greater temperature stability would have been advantageous, the observed variation in temperatures was not likely detrimental to the results of this investigation 
because the difference in high and low temperatures at any particular time was always well pronounced.

Slurry aging time was either 30 or 90 min, simulating either a short or long haul from a batch plant to a road rehabilitation site. Cement-aggregate mixing time refers to the number of seconds that the moist road base and cement were mixed together in the laboratory, simulating the mixing time achieved in the field using a reclaimer.

\subsection{Material Characterization}

Redwood Drive, shown in Figure 3.1, is a residential road in Salt Lake City, Utah, that was reconstructed using FDR in the summer of 2008. Approximately 1,500 lb of road base mixed with RAP were collected from the site during reconstruction. The road base was dried in an oven at $140^{\circ} \mathrm{F}$ until it reached constant weight. As shown in Figures 3.2 and 3.3, a bulk

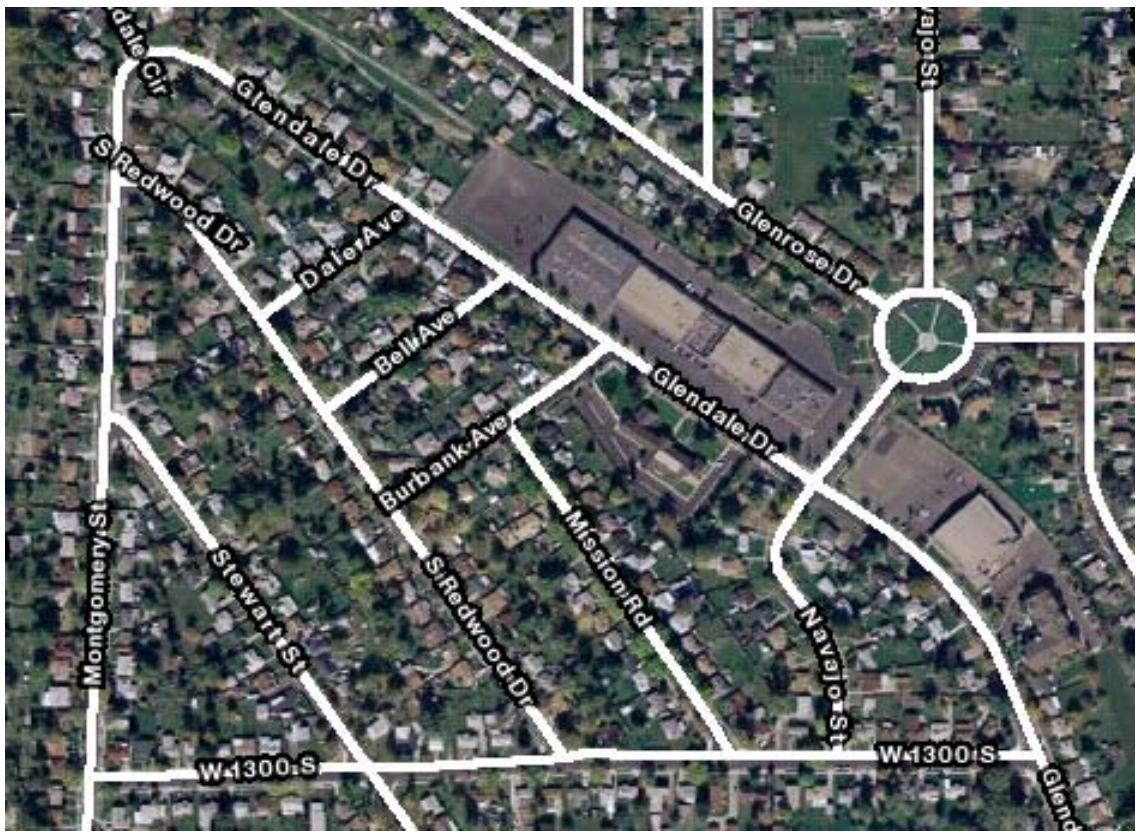

Figure 3.1 Aerial view of Redwood Drive and surrounding area (MapQuest 2011). 


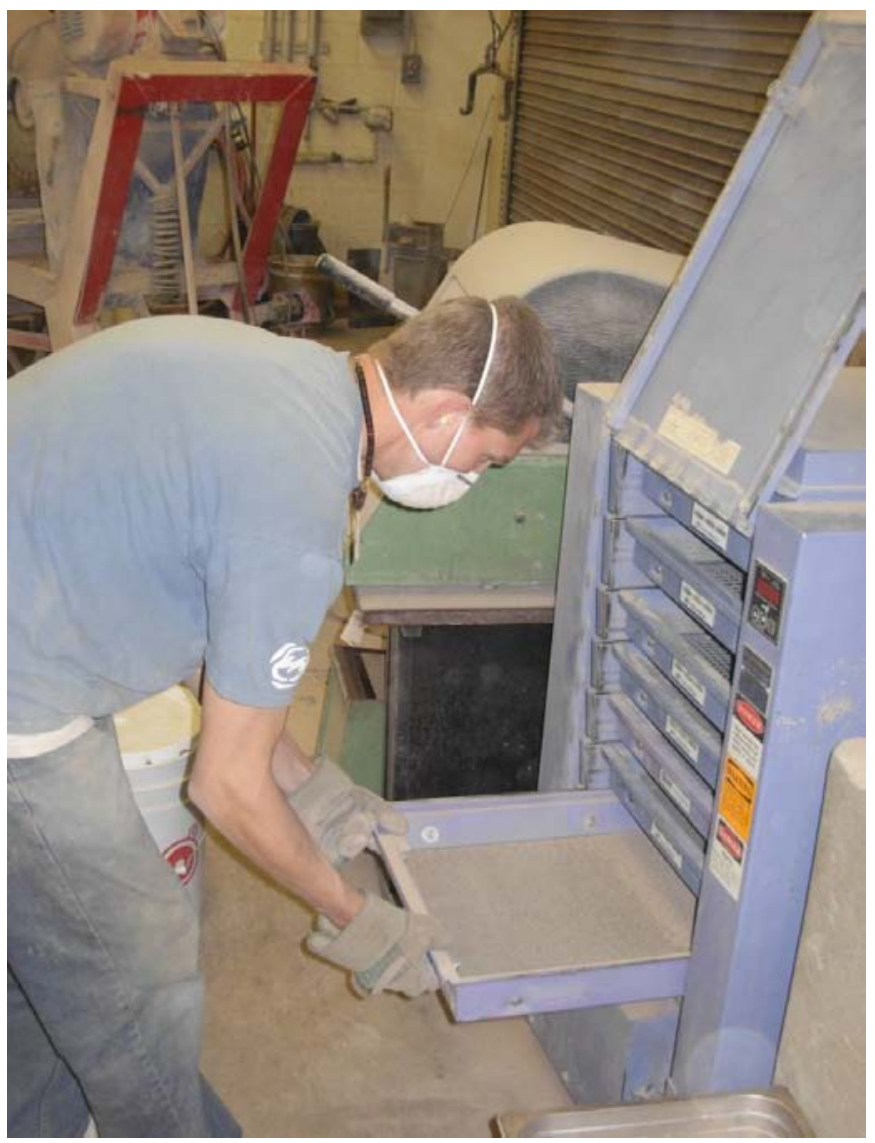

Figure 3.2 Operation of the sieving machine for bulk material separation.

separation of the material was then performed over the following sieves: 2 in., $3 / 4$ in., $1 / 2$ in., 3/8 in., No. 4, No. 8, No. 16, No. 30, No. 50, No. 100, and No. 200. The particles retained on the 2-in. and 3/4-in. sieves were excluded from subsequent analysis or testing, consistent with PCA guidelines (PCA 1992).

To classify the material, washed sieve and hydrometer analyses were performed as shown in Figures 3.4 and 3.5 to obtain a particle-size distribution. Atterberg limits were evaluated in general accordance with ASTM D4318 (Standard Practice for Classification of Soils and Soil Aggregate Mixtures for Highway Construction Purposes). Both the Unified Soil 


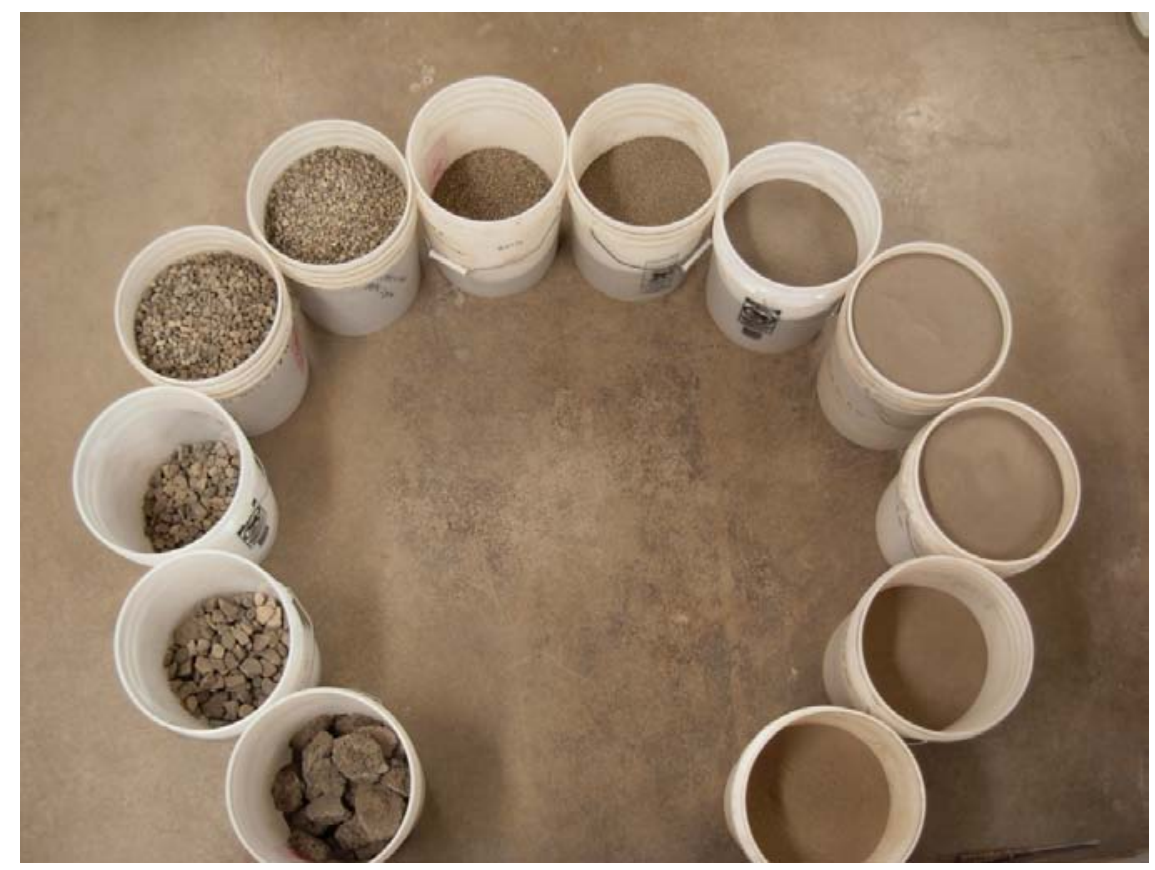

Figure 3.3 Road base separated after bulk sieving.

Classification System (USCS) and the American Association of State Highway and Transportation Officials (AASHTO) method were used. Following classification, moisturedensity curves were developed following ASTM D1557 for the road base prepared at each cement content selected for evaluation in this research.

\subsection{Specimen Preparation}

Specimen preparation consisted of aggregate and water proportioning, slurry preparation when applicable, aggregate and cement mixing, and specimen compaction and curing.

\subsubsection{Aggregate and Water Proportioning}

As shown in Figure 3.6, aggregates retained on the various sieve sizes were weighed out according to the percentages determined from the bulk sieve analysis to yield approximately 4.5- 


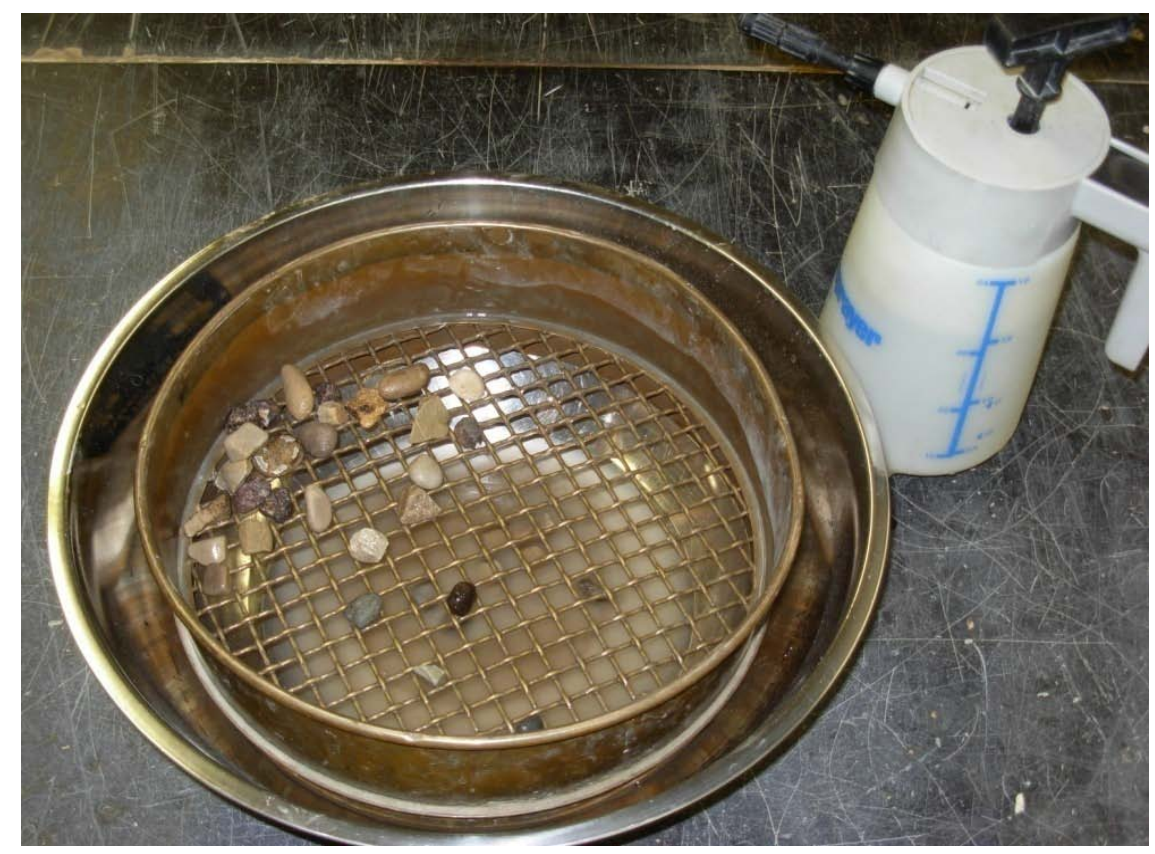

Figure 3.4 Aggregate during washed sieving for road base classification.

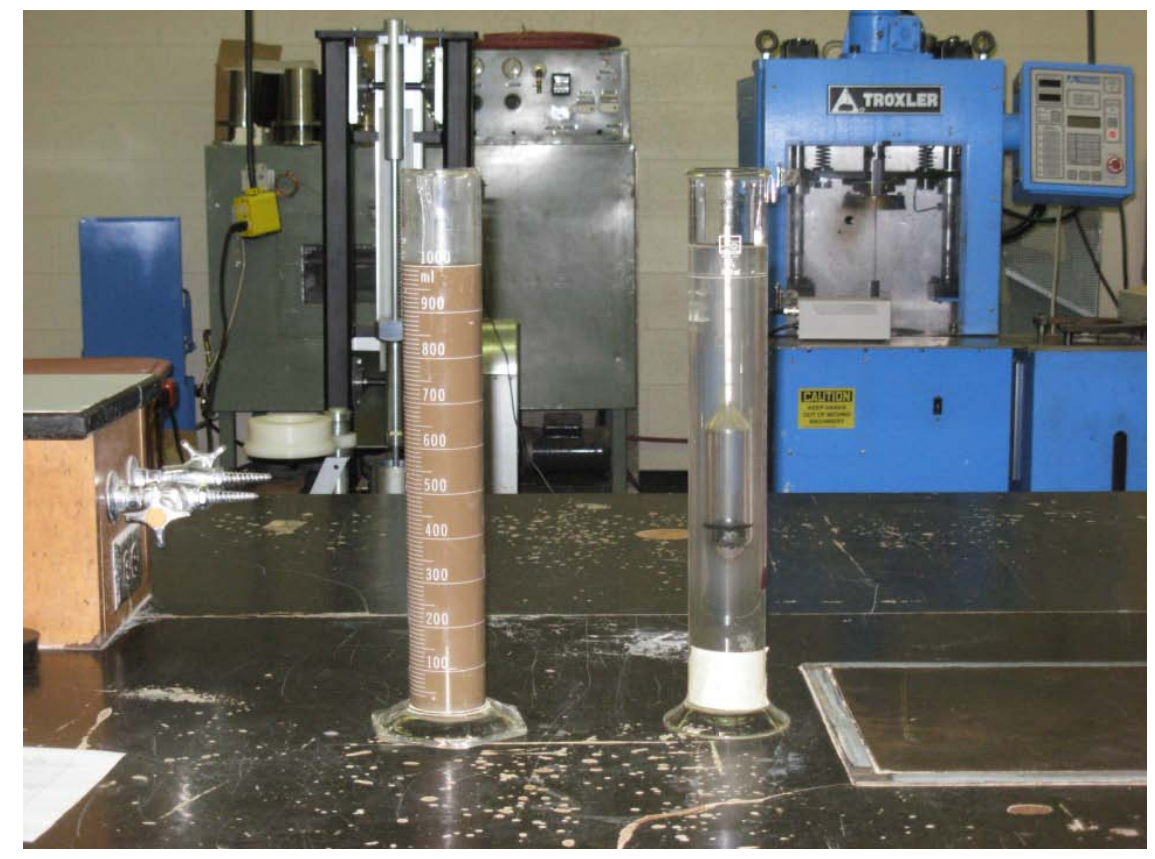

Figure 3.5 Particle separation using hydrometer for road base classification. 


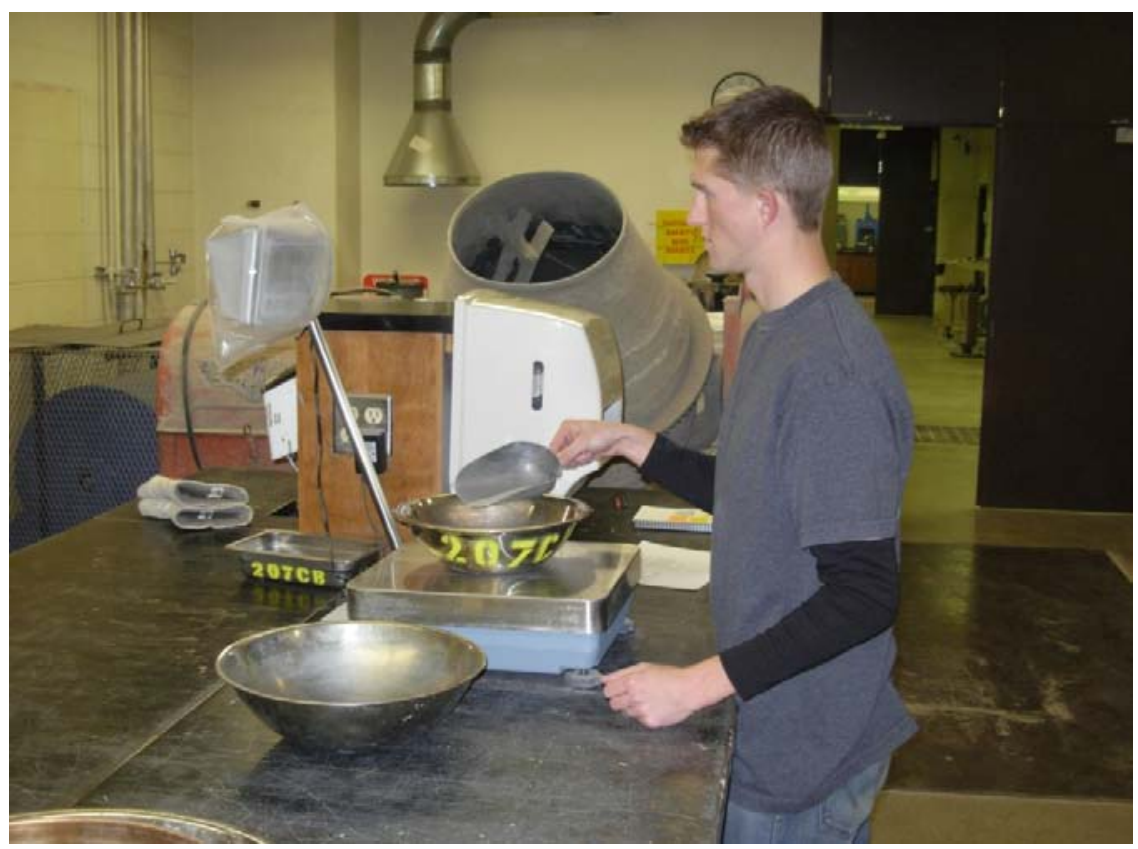

Figure 3.6 Proportioning of road base aggregate for testing.

lb specimens. The aggregates prepared for a given specimen were then placed in a plastic cylinder 6 in. in diameter and 12 in. in height, depicted in Figure 3.7, in the following order to facilitate consistent mixing: No. 8 , No. 16 , No. 30 , No. 50, No. 100 , No. 200 , pan, $1 / 2$ in. $3 / 8$ in., and No. 4. Sufficient deionized water was then poured over the aggregates to provide the correct amount of moisture to achieve maximum dry density (MDD) after compaction. When cement slurry was used, less water was added to account for the water contained in the cement slurry. After the water was added, the cylinders were sealed with a lid to prevent water loss from evaporation. The aggregates were left to absorb water for at least 24 hours before specimens were compacted. 


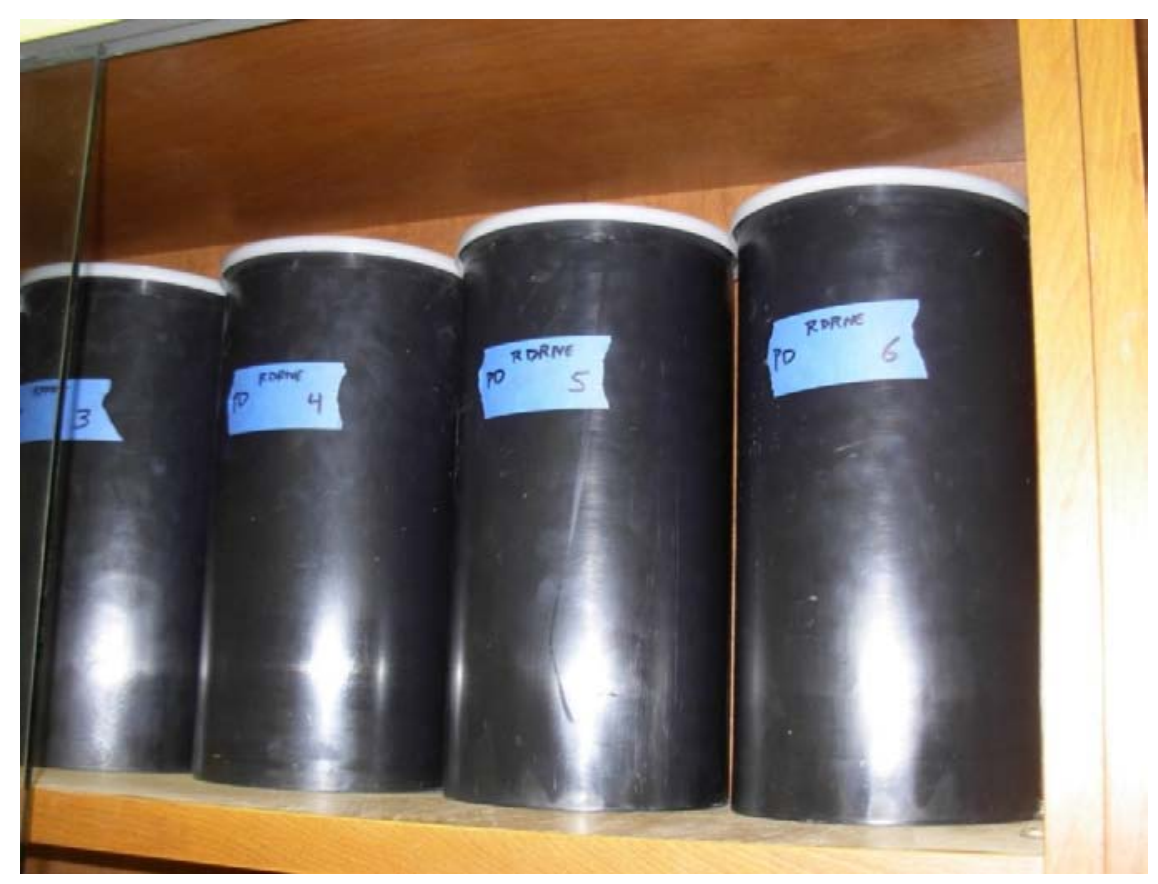

Figure 3.7 Road base moistening in sealed plastic cylinders.

\subsubsection{Cement Slurry Preparation and Aging}

While the dry cement required no special treatment before mixing with the aggregate, special conditioning of the cement slurry was required before it was mixed with the aggregate. Slurry preparation procedures were based on mixing protocols given in ASTM C187 (Standard Test Method for Normal Consistency of Hydraulic Cement). In this research, the water-cement ratio was held constant at 0.50 , a reasonable ratio for cement slurry used in CTB applications. Batching water was conditioned for at least 24 hours in an environmental chamber set to either 60 or $90^{\circ} \mathrm{F}$ and then added to a mixing bowl preconditioned to the temperature of the batching water, as shown in Figure 3.8. When applicable, $6.5 \mathrm{fl} \mathrm{oz}$ of set-retarding, water-reducing admixture per $100 \mathrm{lb}$ of cement was added to the water before cement was added, as shown in Figure 3.9. Cement was then added to the batching water and mixed, as shown in Figures 3.10 and 3.11. 


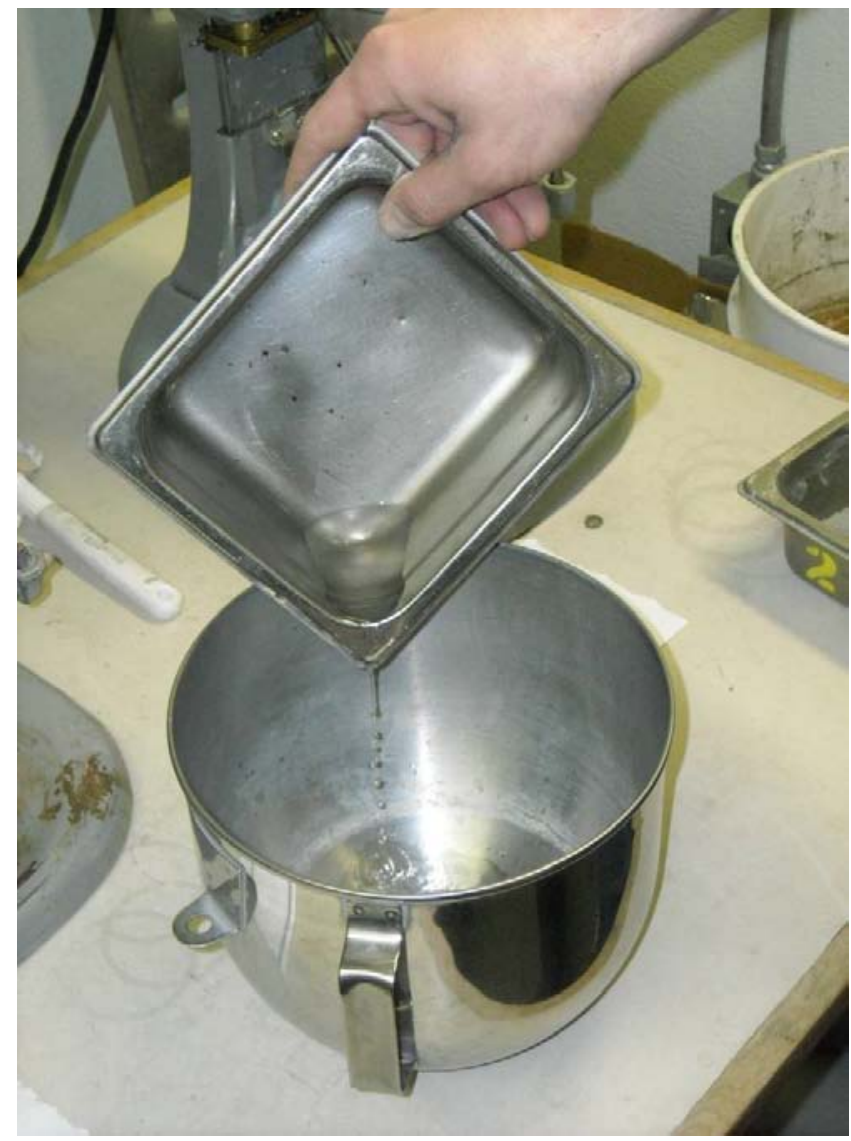

Figure 3.8 Conditioned, deionized water used to make cement slurry. 


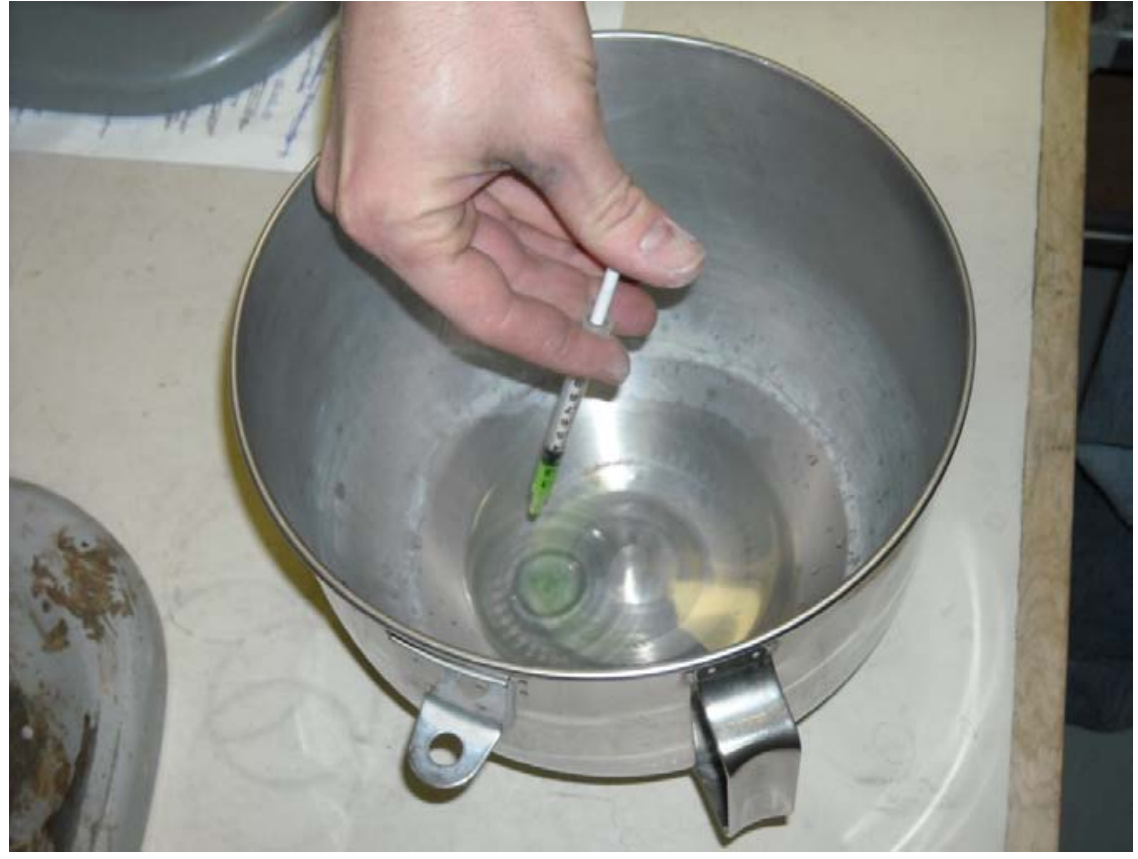

Figure 3.9 Addition of a set-retarding, water-reducing admixture to cement slurry water. 


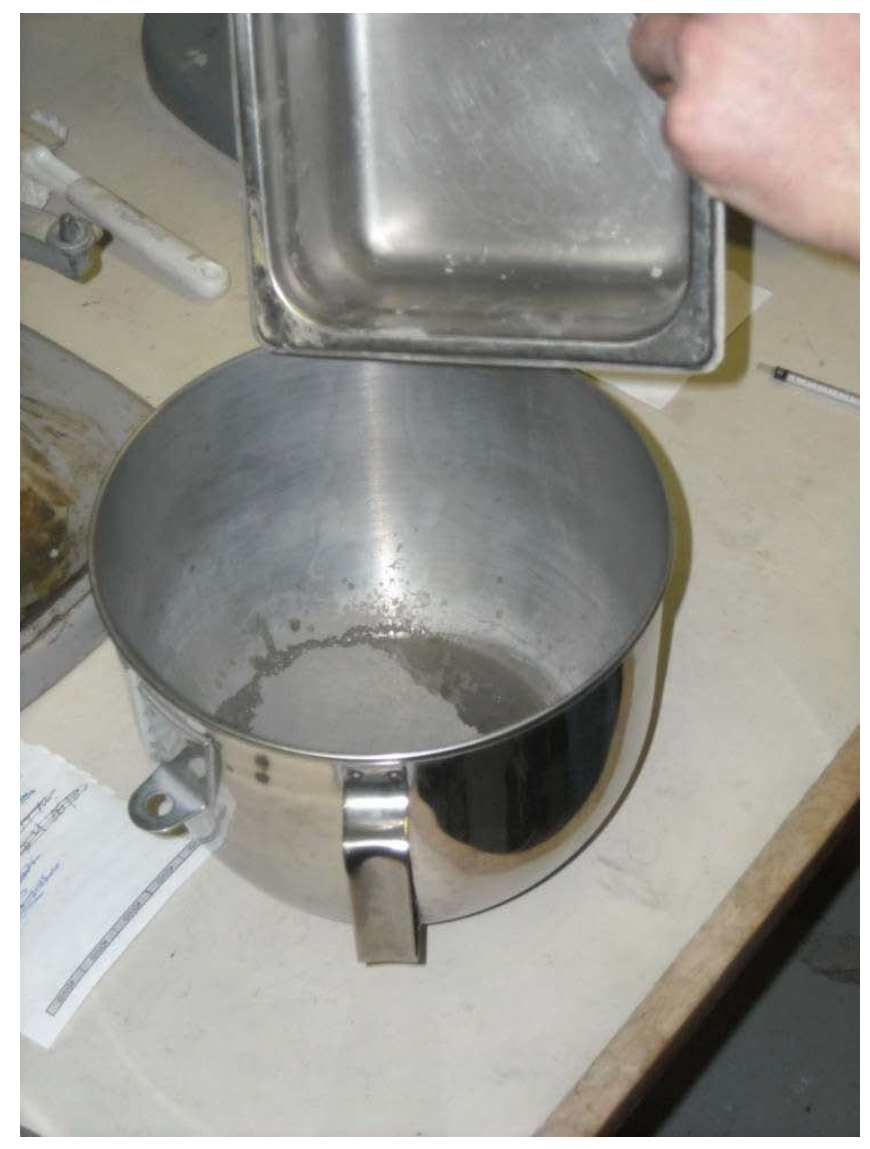

Figure 3.10 Addition of cement to water to prepare cement slurry.

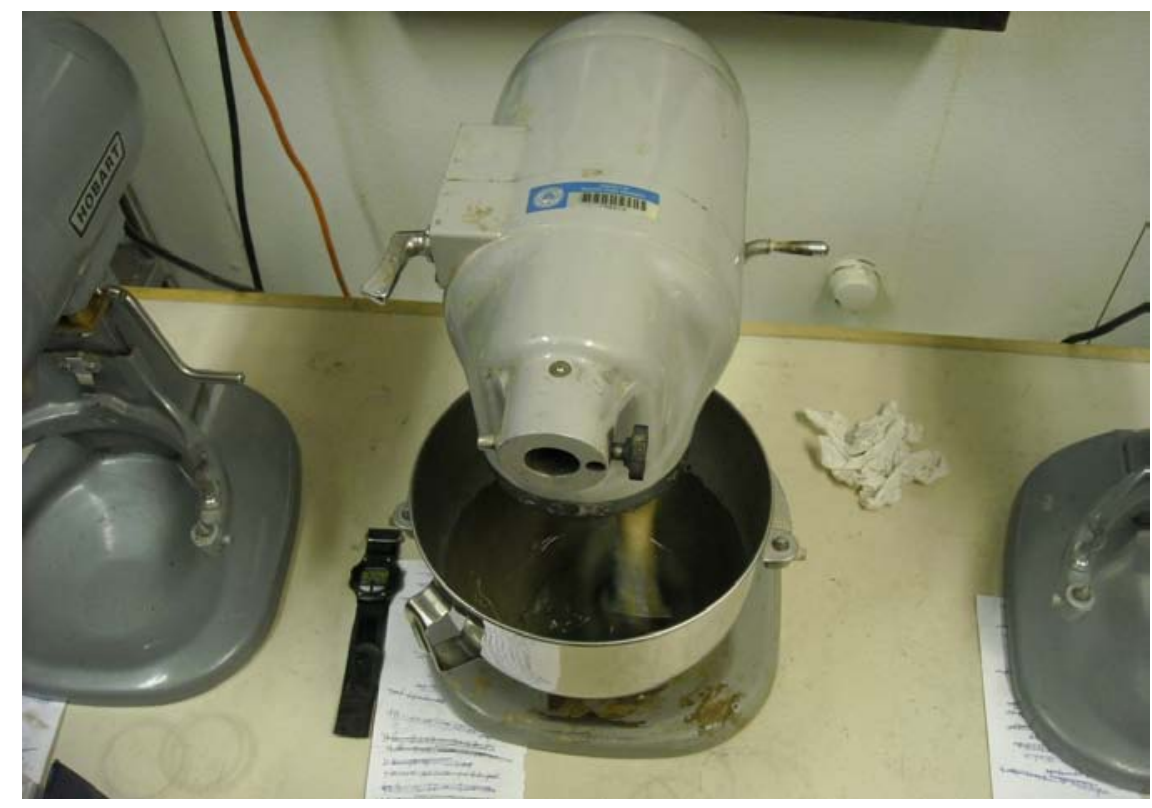

Figure 3.11 Initial mixing to prepare cement slurry. 
After initial mixing, the slurry was then aged for either 30 or $90 \mathrm{~min}$ in an environmental chamber set to either 60 or $90^{\circ} \mathrm{F}$. During aging, the slurry was continuously mixed at approximately $140 \pm 5$ revolutions per minute using a planetary motion mixer. To minimize water evaporation during mixing, the mixer and bowl were wrapped with a plastic covering as shown in Figure 3.12.

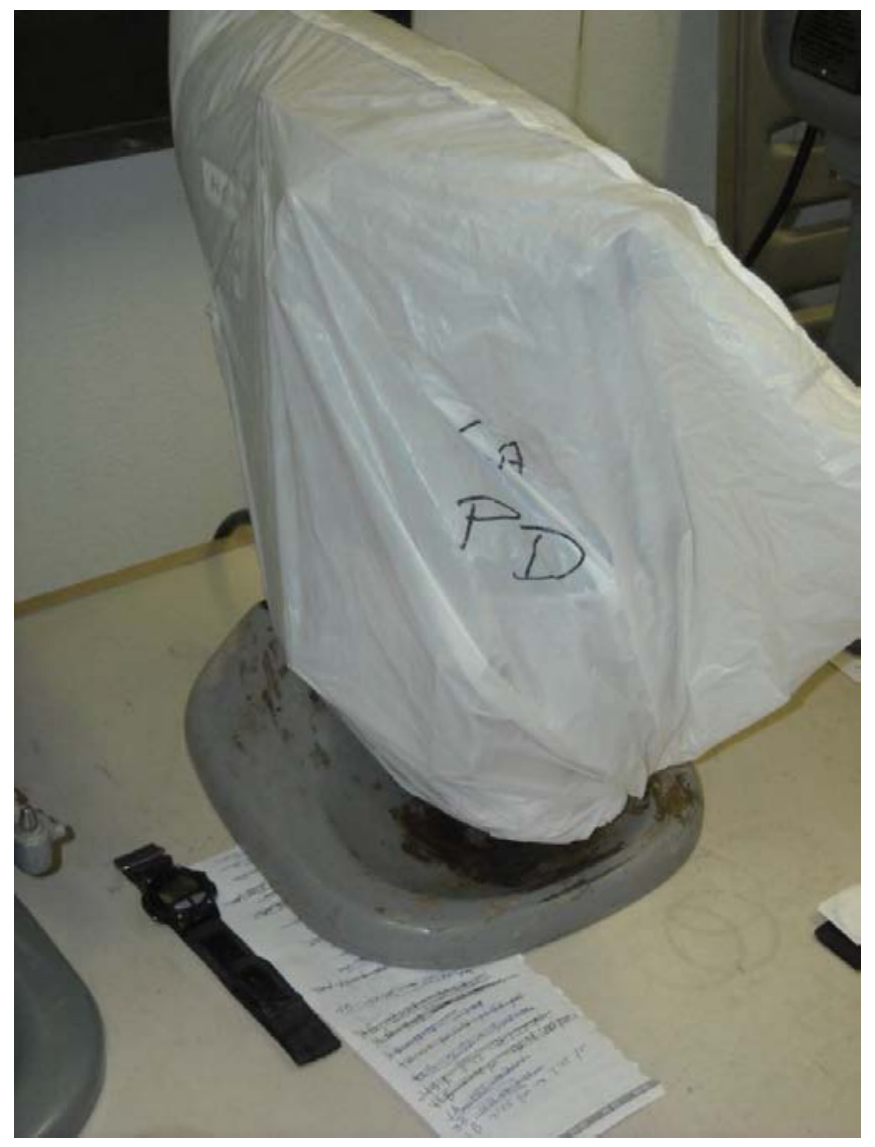

Figure 3.12 Slurry aging in a covered mixer in a temperature-controlled environmental chamber.

\subsubsection{Aggregate and Cement Mixing}

Aggregates were moistened for at least 24 hours before being mixed with cement. For mixing, the moistened aggregate prepared for a given specimen was placed in a 6-in.-diameter metal compaction mold, and either dry cement or cement slurry was then added. Figure 3.13 
shows cement slurry being added to the moistened aggregate after slurry aging, and Figure 3.14 shows the slurry with the aggregate just before mixing. The aggregate and cement were mixed together for either 5 or 15 sec using a cordless drill and mixing rod as illustrated in Figure 3.15. Compaction commenced immediately following cement-aggregate mixing.

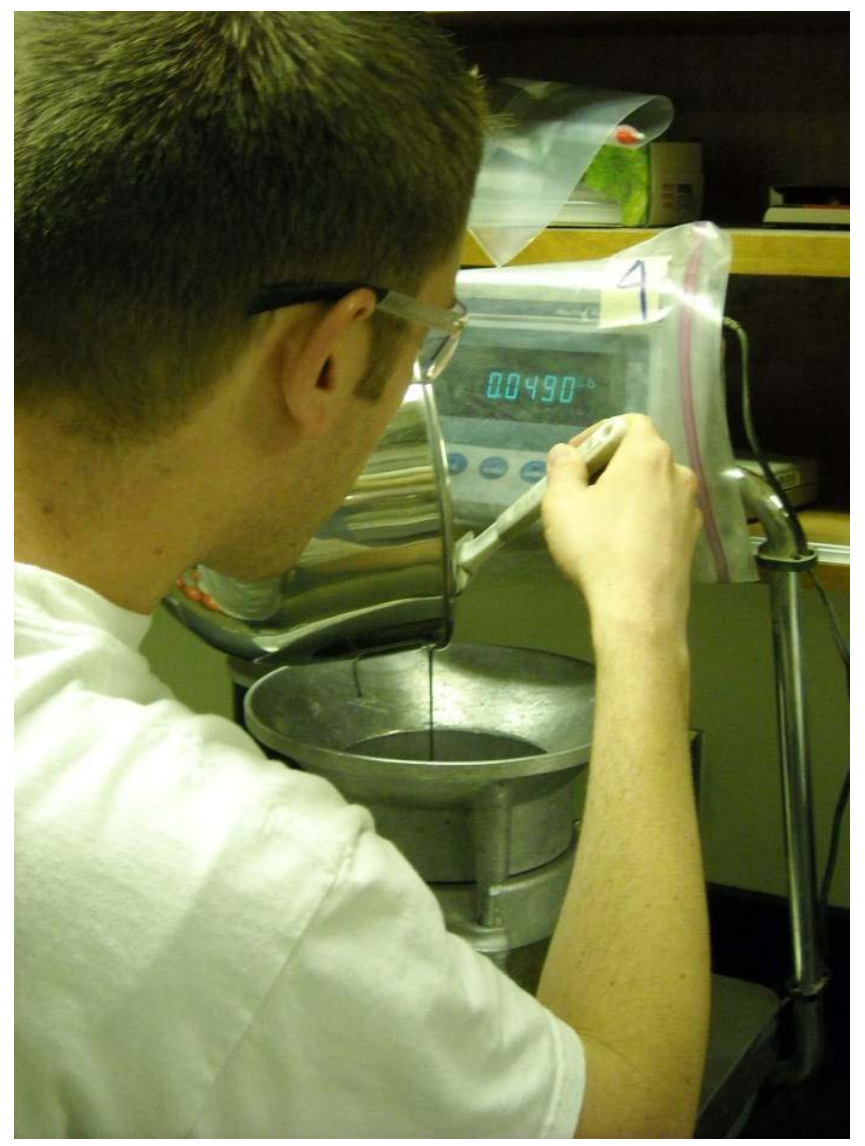

Figure 3.13 Adding cement slurry to aggregate. 


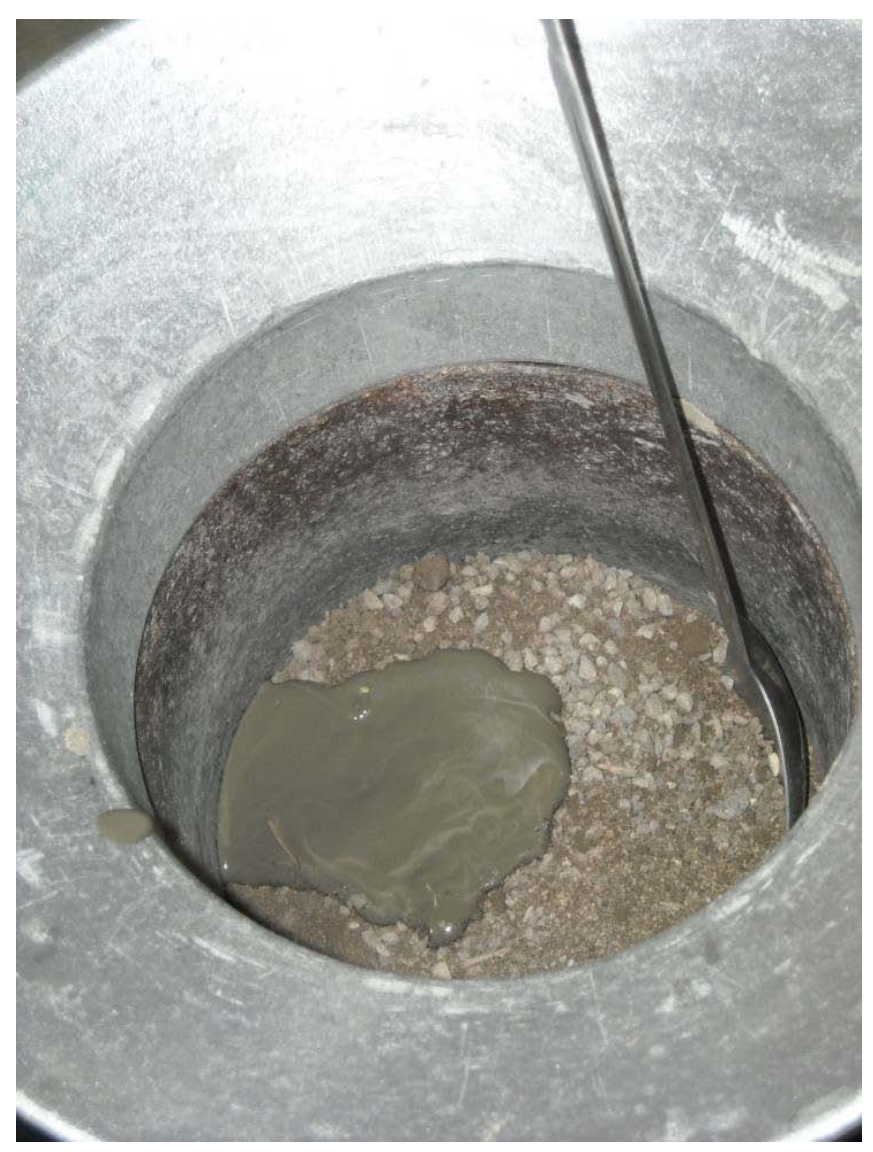

Figure 3.14 Cement slurry with aggregate before mixing. 


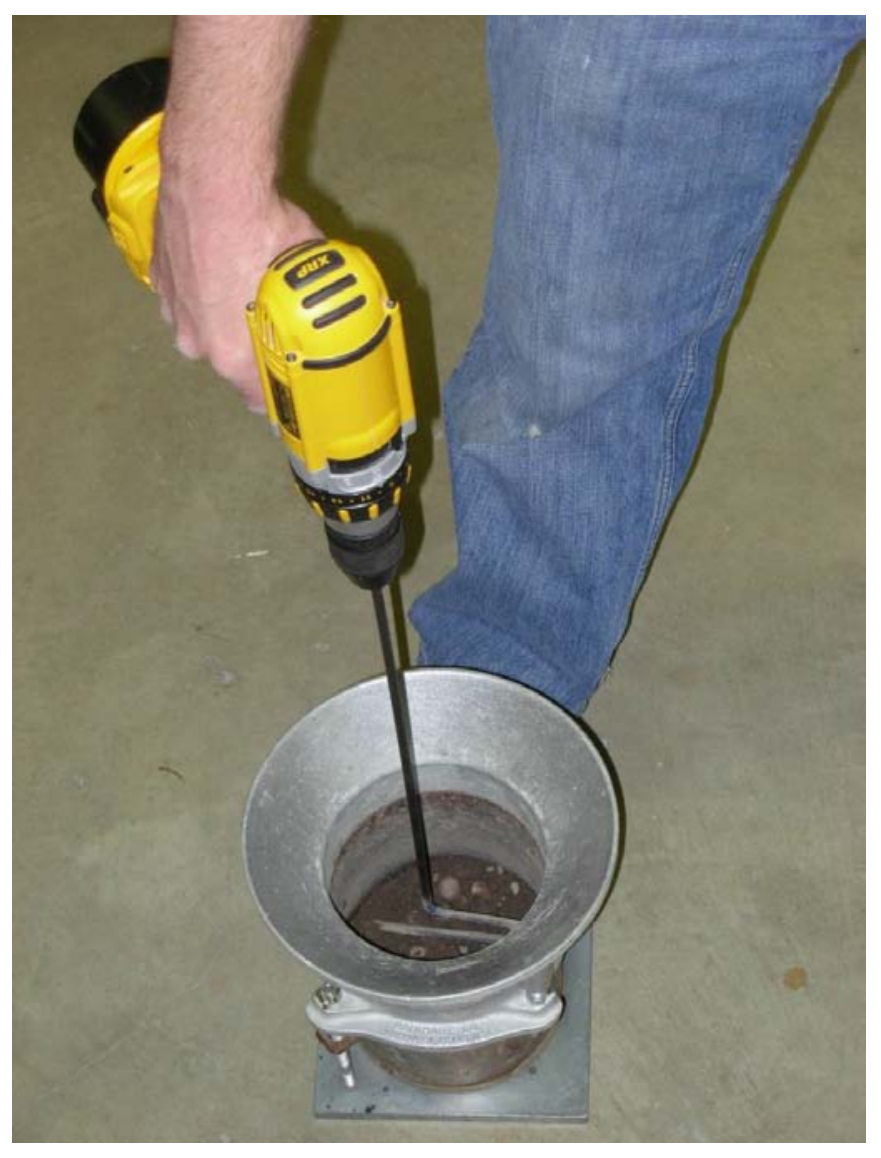

Figure 3.15 Mixing cement with aggregate.

\subsubsection{Specimen Compaction and Curing}

The cement-aggregate mixture was compacted in a 4-in.-diameter, 4.59-in.-tall mold using the modified compaction procedure as shown in Figure 3.16. The compacted specimen was then extruded from the compaction mold, sealed in a plastic bag, and aged at room temperature for 7 days. Placement of compacted specimens in an ice chest, as shown in Figure 3.17, ensured minimal temperature variation during curing. 


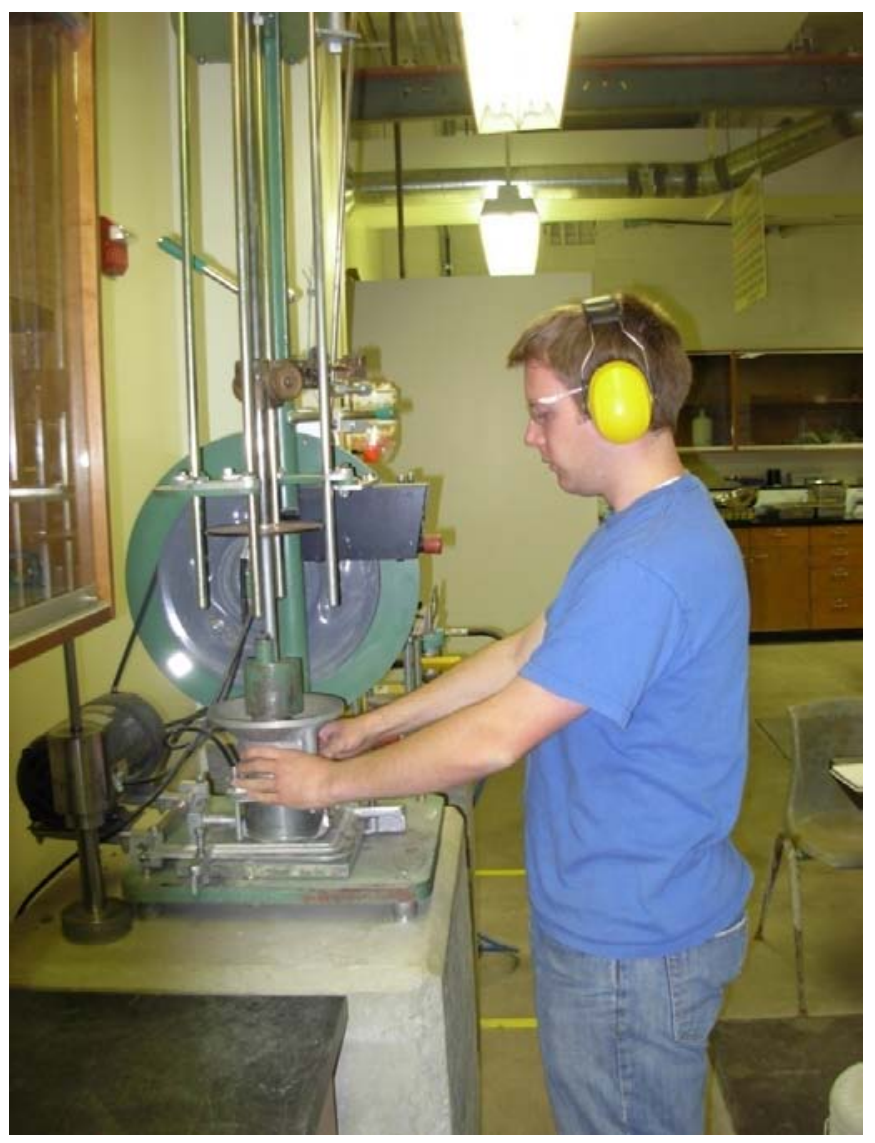

Figure 3.16 Compacting a CTB specimen. 


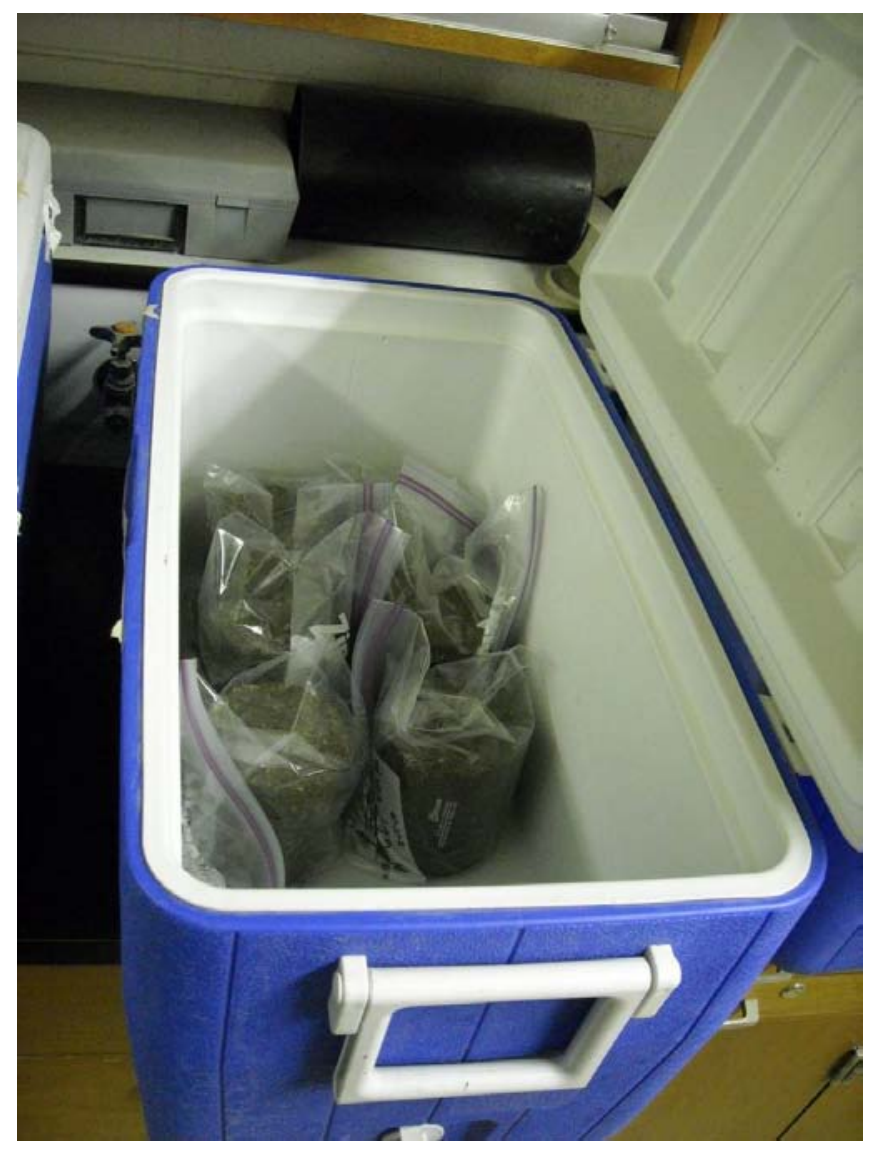

Figure 3.17 CTB specimens ready for 7 days of curing at room temperature.

\subsection{Specimen Testing}

After 7 days of curing, the specimens were removed from their bags, weighed, and capped with gypsum in preparation for UCS testing. The plastic bags were placed over the specimens while the capping compound hardened in order to preserve the moisture content, as shown in Figure 3.18. The UCS of each specimen was then determined at a strain rate of $0.05 \mathrm{in} . / \mathrm{min}$ using a compression machine with a floating bottom platen as shown in Figure 3.19. After UCS testing, the caps were removed, and the specimens were weighed and oven-dried at $140^{\circ} \mathrm{F}$ to facilitate computation of MC and DD. As depicted in Figure 3.20, the remnants of the specimens were dried until they reached constant weight. 


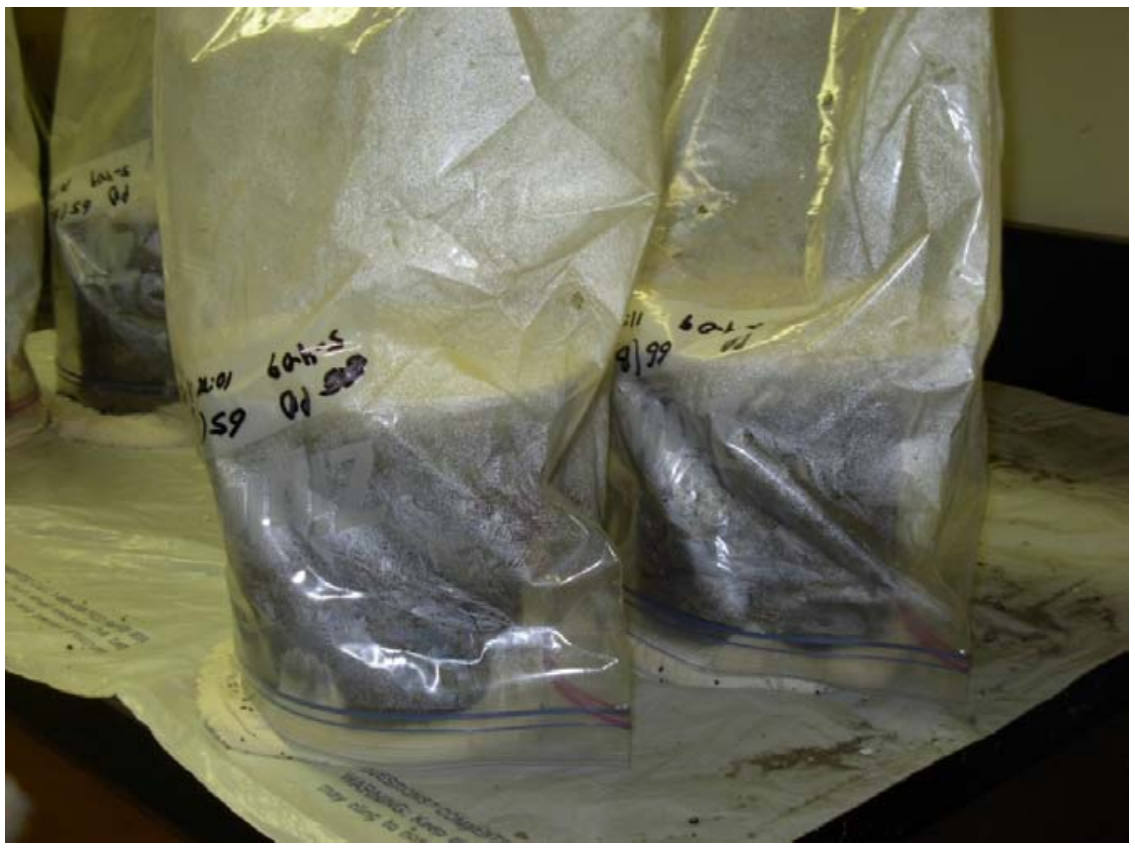

Figure 3.18 Hardening of gypsum caps in preparation for 7-day UCS testing. 


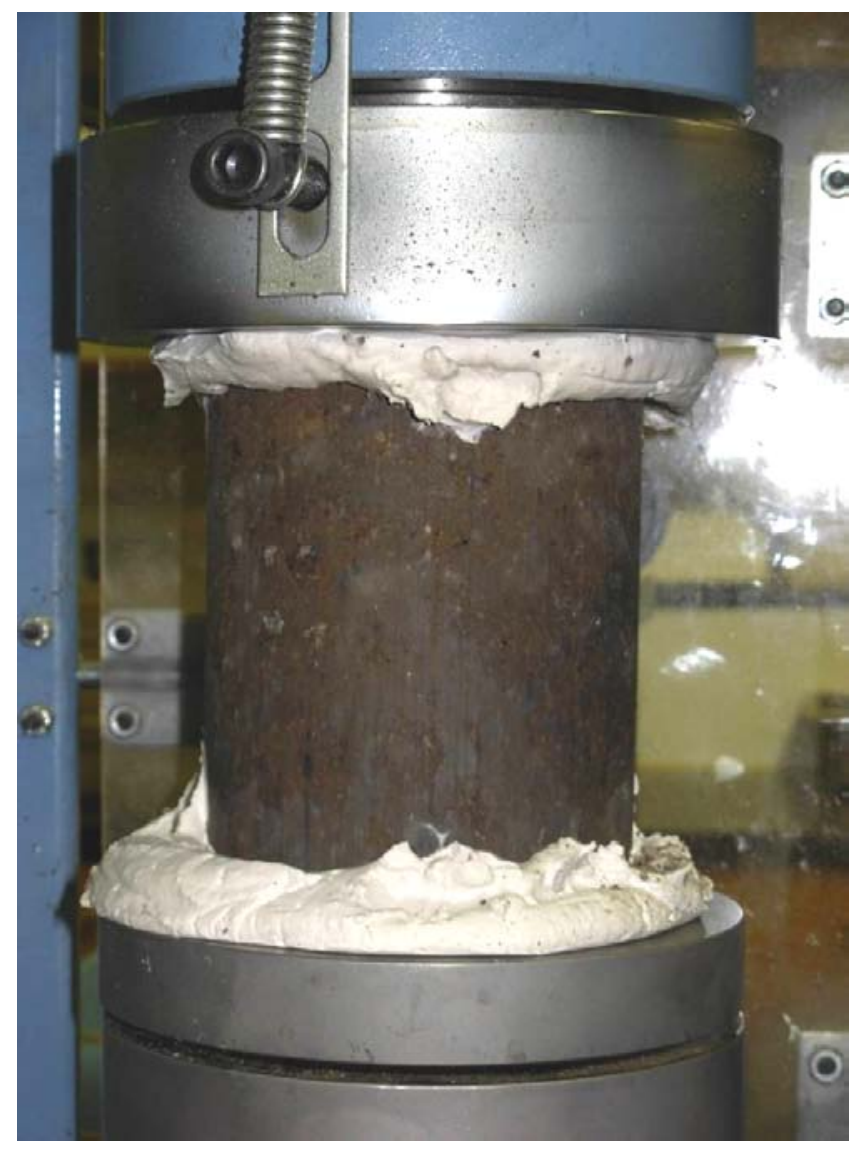

Figure 3.19 CTB specimen undergoing 7-day UCS testing. 


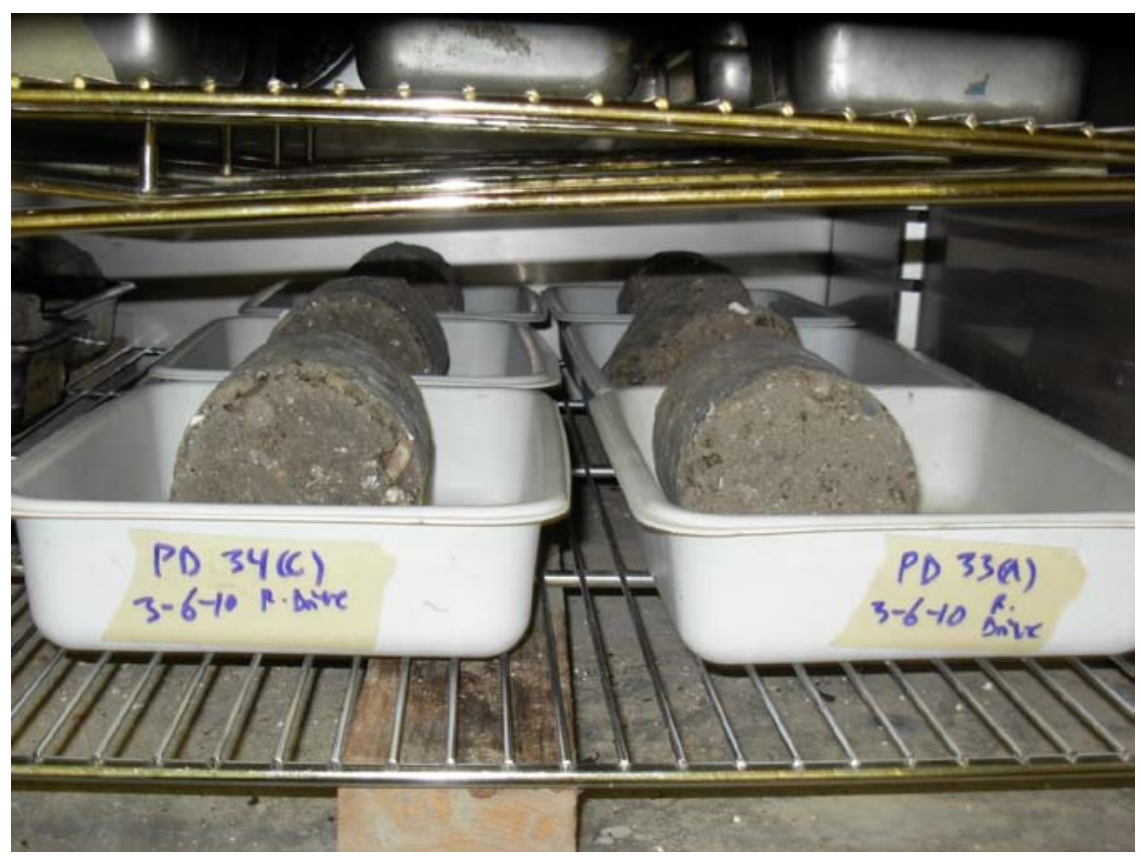

Figure 3.20 Specimens drying in a $140^{\circ} \mathrm{F}$ oven in order to obtain DD and MC.

\subsection{Data Analyses}

An ANOVA was performed to determine whether differences in slurry water batching temperature, slurry admixture, slurry aging temperature, slurry aging time, cement content, cement-aggregate mixing time, and cement form (dry or slurry) affected the 7-day UCS, DD, and MC of cement-treated road base. Two data sets were formed for statistical analysis. For the first analysis, only data from specimens prepared with cement slurry were used to determine the effect of the first six factors on 7-day UCS, DD, and MC. A full model was first produced to examine the effect of these six variables on 7-day UCS. In this model, $p$-values were obtained for the main effects and interactions. A reduced model was then created by sequentially deleting factors with a $p$-value greater than 0.15 so that all remaining factors had a $p$-value less than or equal to 0.15 . The coefficient of determination, or $\mathrm{R}^{2}$ value, was computed for the reduced model. Least squares means for the factors were then computed. Factors in the reduced model 
with a $p$-value less than or equal to 0.05 were considered to be statistically significant. The process was then repeated for DD and MC.

For the second statistical analysis, in order to determine the effect of cement form, data from all specimens were used. In addition to cement form, this second analysis investigated the effect of cement content and mixing time on 7-day UCS, DD, and MC. Again, full and reduced models were generated, and least squares means were determined.

In addition to statistical significance, practical importance was also evaluated. To determine whether differences in least squares means of UCS were practically important, a chart correlating UCS with the structural coefficient $\left(a_{2}\right)$ and resilient modulus of CTB was consulted. The structural coefficient and modulus values of road base serve as inputs in pavement design. The correlation chart indicated that a change in structural coefficient of 0.01 , which is the smallest increment used in practice, would change the 7-day UCS by about 50 psi (Huang 2004). Therefore, a difference in 7-day UCS of less than 50 psi would not result in a different pavement design. Consequently, 50 psi was considered to be the smallest difference in 7-day UCS of practical importance.

To determine whether differences in least squares means of DD were practically important, suggested specifications for compaction density were consulted. Recommended specifications for CTB require that it be compacted to a minimum of 98 percent of MDD (Halsted 2006), or to within 2 percent of the target MDD; a variance of 2 percent was therefore considered to be of practical importance in this research. If the DD associated with a treatment varied by more than 2 percent from the DD of another treatment, the difference was considered to be practically important. 
To determine whether differences in least squares means of MC were practically important, suggested specifications for MC were consulted. Recommended specifications for CTB require that moisture content be within 2 percent of $\mathrm{OMC}$ at the time of compaction (Halsted 2006); therefore, similar to the approach used for determining practical importance for $\mathrm{DD}$, a variance of 2 percent in MC was considered to be of practical importance in this research.

\subsection{Summary}

Seven factors potentially influencing the 7-day UCS, DD, and MC of cement-treated road base were investigated in two full-factorial experiments performed in this research. The factors included cement content, water batching temperature, admixture use, slurry aging temperature, slurry aging time, cement-aggregate mixing time, and cement form. Specimens were compacted using modified compaction effort and then cured at room temperature in sealed plastic bags. Following curing, specimens were subjected to UCS testing and oven-drying to obtain UCS, DD, and MC values. Test results were evaluated in two ANOVAs. The first examined factors pertaining only to specimens prepared using cement slurry, and the second examined factors pertaining to specimens prepared with either dry cement or cement slurry. Significant main effects and interactions were identified in the analyses. 


\section{RESULTS}

\subsection{Overview}

This chapter presents the findings from material characterization, testing, and statistical analyses. All results presented in this chapter are limited in their application to the material type and ranges of the independent variables used in the experimental design in this research.

\subsection{Material Characterization}

The results of the washed sieve analysis are shown in Table 4.1 and Figure 4.1. The Atterberg limits testing indicated that the soil was not plastic. The soil was classified as SP, poorly graded sand with gravel, according to the USCS and as A-1-b according to the AASHTO method.

Two cement contents, 2 and 6 percent, were chosen to yield lightly and heavily stabilized specimens, respectively. Moisture-density curves prepared for each soil-cement combination are shown in Figures 4.2 and 4.3, and the associated OMC and MDD values determined from the graphs are presented in Table 4.2. 
Table 4.1 Particle-Size Distribution

\begin{tabular}{c|c}
\hline $\begin{array}{c}\text { Sieve } \\
\text { Size }\end{array}$ & $\begin{array}{c}\text { Percent } \\
\text { Passing }(\%)\end{array}$ \\
\hline 1/2 in. & 89.3 \\
3/8 in. & 81.0 \\
No. 4 & 64.0 \\
No. 8 & 47.7 \\
No. 16 & 37.2 \\
No. 30 & 30.0 \\
No. 50 & 25.7 \\
No. 100 & 21.4 \\
No. 200 & 15.8 \\
\hline
\end{tabular}

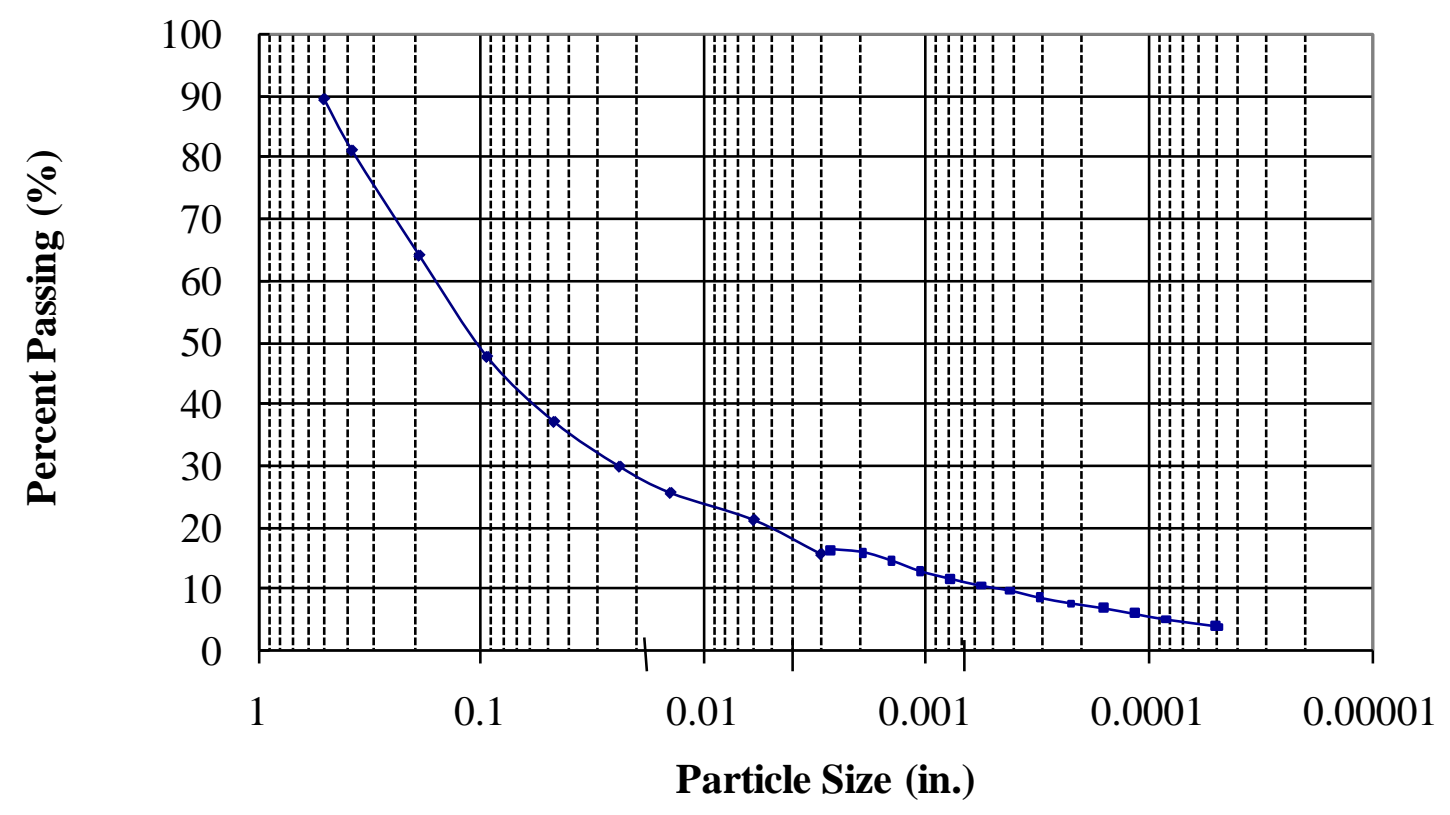

Figure 4.1 Particle-size distribution from washed-sieve analysis. 


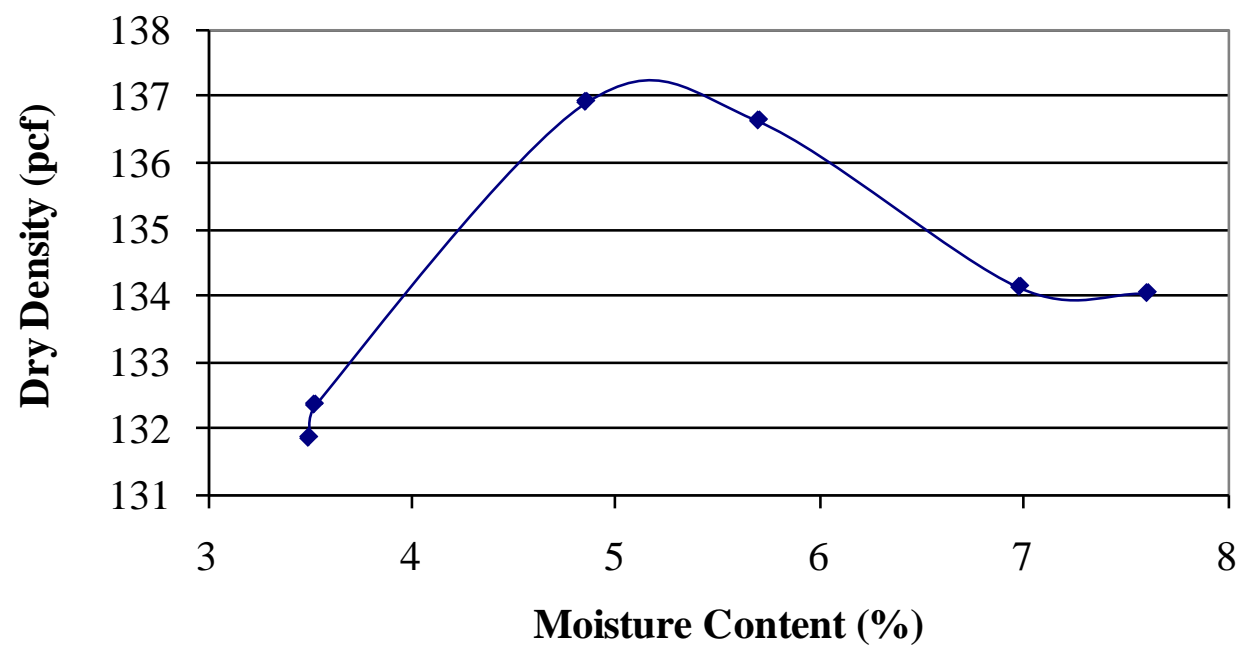

Figure 4.2 Moisture-density curve for road base containing 2 percent cement.

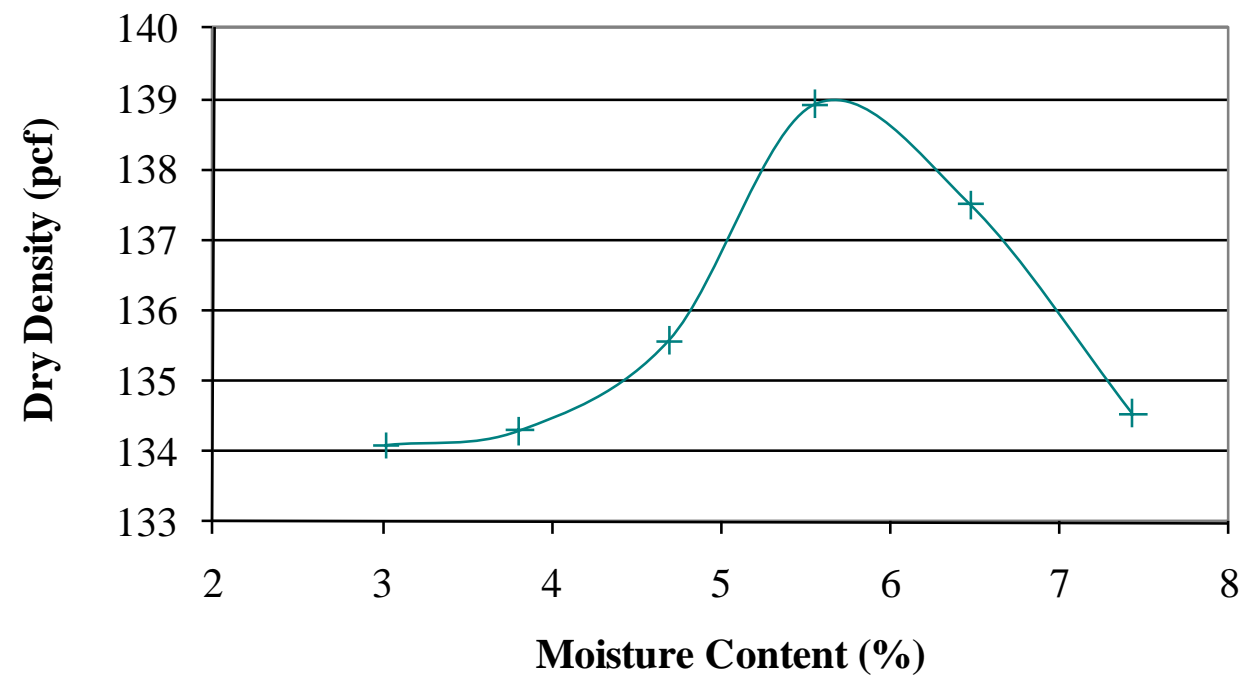

Figure 4.3 Moisture-density curve for road base containing 6 percent cement. 
Table 4.2 OMC and MDD Values

\begin{tabular}{c|c|c}
\hline $\begin{array}{c}\text { Cement } \\
\text { Content (\%) }\end{array}$ & OMC (\%) & MDD (pcf) \\
\hline 2 & 5.2 & 137.2 \\
6 & 5.7 & 138.9 \\
\hline
\end{tabular}

\subsection{Evaluation of Road Base Stabilized with Cement Slurry}

This section gives the results of the first statistical analysis, including main effects and interactions, using only data from specimens prepared using cement slurry. In the analyses, discussion of only statistically significant and practically important factors is given.

\subsubsection{Main Effects}

Table 4.3 shows the main effects and interactions from the reduced ANOVA models associated with road base treated with cement slurry. Interactions are indicated by asterisks. A hyphen indicates that the $p$-value exceeded 0.15 in that case. An $\mathrm{R}^{2}$ value is also given for each of the models.

The least squares means for main effects shown in Table 4.3 to be statistically significant, or those with $p$-values less than or equal to 0.05 , are given in Table 4.4 for 7 -day UCS, DD, and MC of road base stabilized with cement slurry. Among these, only cement content and mixing time affected the 7-day UCS of road base treated with cement slurry in a practically important way as defined in Chapter 3. The data show that, after all factors were considered, increasing cement slurry content from 2 to 6 percent increased UCS by 86 percent, raising it on average by 425 psi; increasing cement content predictably increases 7-day UCS because more CSH is formed to bind the aggregates together. Increasing the mixing time from 5 to 15 sec increased 
Table 4.3 ANOVA Results for Road Base Treated with Cement Slurry

\begin{tabular}{|c|c|c|c|}
\hline \multirow{2}{*}{ Factor } & \multicolumn{3}{|c|}{$p$-value } \\
\hline & 7-Day UCS & DD & MC \\
\hline Cement Content & $<0.0001$ & $<0.0001$ & $<0.0001$ \\
\hline Water Batching Temperature & 0.0429 & 0.0681 & $<0.0001$ \\
\hline Slurry Admixture & 0.0438 & 0.0605 & $<0.0001$ \\
\hline Aging Temperature & 0.1375 & $<0.0001$ & $<0.0001$ \\
\hline Aging Time & 0.0888 & $<0.0001$ & $<0.0001$ \\
\hline Mixing Time & $<0.0001$ & - & $<0.0001$ \\
\hline Cement Content*Aging Temperature & 0.0056 & - & $<0.0001$ \\
\hline Cement Content*Mixing Time & $<0.0001$ & 0.0089 & 0.1323 \\
\hline Water Batching Temperature*Aging Temperature & 0.0874 & 0.0091 & $<0.0001$ \\
\hline Aging Temperature*Slurry Admixture & 0.0182 & $<0.0001$ & $<0.0001$ \\
\hline Aging Temperature*Mixing Time & 0.1367 & - & - \\
\hline Water Batching Temperature*Slurry Admixture & - & 0.0012 & 0.0005 \\
\hline Slurry Admixture*Aging Time & - & 0.1258 & - \\
\hline Cement Content*Water Batching Temperature & - & - & $<0.0001$ \\
\hline Cement Content*Slurry Admixture & - & - & 0.0010 \\
\hline Cement Content*Aging Time & - & - & 0.1306 \\
\hline $\mathrm{R}^{2}$ & 0.9420 & 0.4734 & 0.8925 \\
\hline
\end{tabular}

UCS by 22 percent, raising it on average by $141 \mathrm{psi}$; increased mixing time allows the cement to be dispersed more uniformly throughout the aggregate matrix, minimizing the occurrence of particularly weak zones that would otherwise cause lower UCS values. While the effects of water batching temperature and the presence of a slurry admixture were are statistically significant, they are not practically important, changing the UCS by less than the threshold of 50 psi established for this research. None of the main effects on DD or MC were determined to be both statistically significant and practically important. 
Table 4.4 Least Squares Means for Main Effects of Experimental Factors on UCS, DD, and MC of Road Base Treated with Cement Slurry

\begin{tabular}{c|c|c|c|c}
\hline & & $\begin{array}{c}\text { 7-Day } \\
\text { UCS } \\
\text { Factor }\end{array}$ & & \\
& Level & (psi) & DD (pcf) & MC (\%) \\
\hline \multirow{2}{*}{ Cement Content (\%) } & 2 & 496 & 138.0 & 4.6 \\
& 6 & 921 & 139.0 & 4.4 \\
\hline Water Batching & 60 & 700 & - & 4.5 \\
Temperature ( $\left.{ }^{\circ} \mathrm{F}\right)$ & 90 & 717 & - & 4.5 \\
\hline \multirow{2}{*}{ Slurry Admixture } & No & 717 & - & 4.5 \\
& Yes & 700 & - & 4.5 \\
\hline \multirow{2}{*}{ Aging Temperature ( $\left.{ }^{\circ} \mathrm{F}\right)$} & 60 & - & 138.9 & 4.6 \\
& 90 & - & 138.1 & 4.4 \\
\hline \multirow{2}{*}{ Aging Time (min) } & 30 & - & 138.8 & 4.6 \\
& 90 & - & 138.2 & 4.4 \\
\hline \multirow{2}{*}{ Mixing Time (sec) } & 5 & 638 & - & 4.5 \\
& 15 & 779 & - & 4.5 \\
\hline
\end{tabular}

\subsubsection{Interactions}

Least squares means for interactions shown to be statistically significant in Table 4.3 are given in Table 4.5 for 7-day UCS of road base stabilized with cement slurry. Two-way interactions associated with 7-day UCS are cement content by aging temperature, cement content by mixing time, and aging temperature by slurry admixture, which are shown in Figures 4.4 to 4.6. The lines connecting data points in the figures do not imply that interpolation can be performed; rather, they assist in showing interactions by highlighting slope differences. 
Table 4.5 Least Squares Means for Interactions between Experimental Factors for UCS of Road Base Treated with Cement Slurry

\begin{tabular}{c|c|c}
\hline Cement Content (\%) & Aging Temperature $\left({ }^{\circ} \mathrm{F}\right)$ & UCS (psi) \\
\hline \multirow{2}{*}{2} & 60 & 515 \\
& 90 & 478 \\
\hline \multirow{2}{*}{6} & 60 & 915 \\
& 90 & 926 \\
\hline Cement Content (\%) & Mixing Time (sec) & UCS (psi) \\
\hline \multirow{2}{*}{2} & 5 & 460 \\
& 15 & 532 \\
\hline \multirow{2}{*}{6} & 5 & 816 \\
& 15 & 1025 \\
\hline \multirow{2}{*}{ Aging Temperature ( $\left.{ }^{\circ} \mathrm{F}\right)$} & Slurry Admixture & $\mathrm{UCS}(\mathrm{psi})$ \\
\hline \multirow{2}{*}{60} & No & 713 \\
& Yes & 716 \\
\hline \multirow{2}{*}{90} & No & 721 \\
& Yes & 683 \\
\hline
\end{tabular}

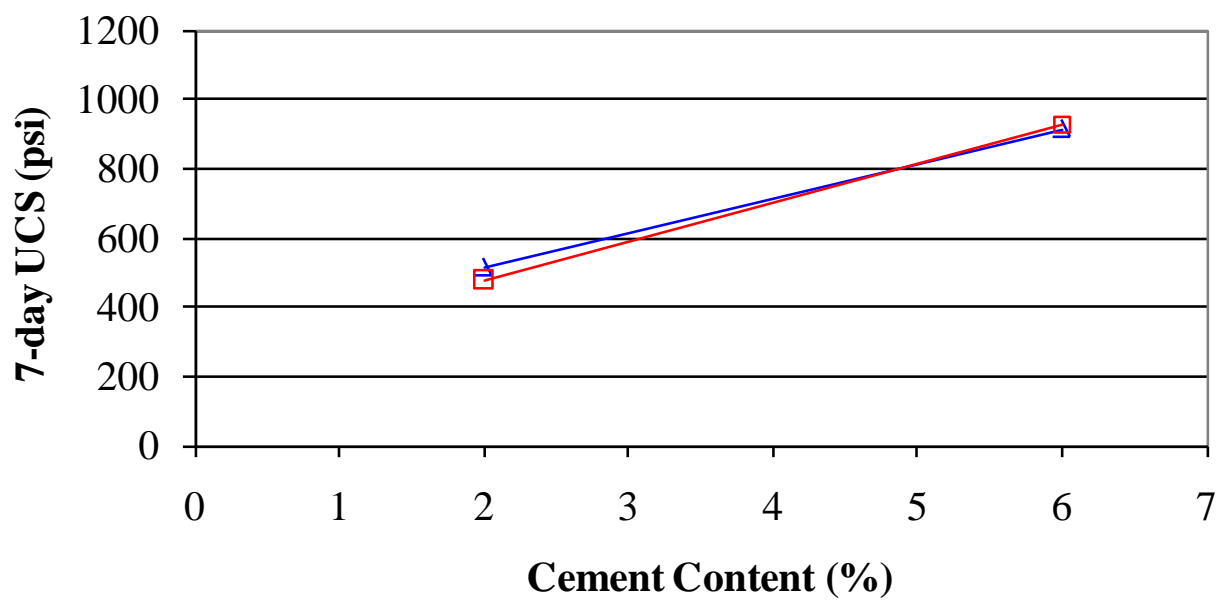

$$
\neg 60^{\circ} \mathrm{F} \text { Aging Temperature } \rightarrow-90^{\circ} \mathrm{F} \text { Aging Temperature }
$$

Figure 4.4 Interaction between cement content and slurry aging temperature. 


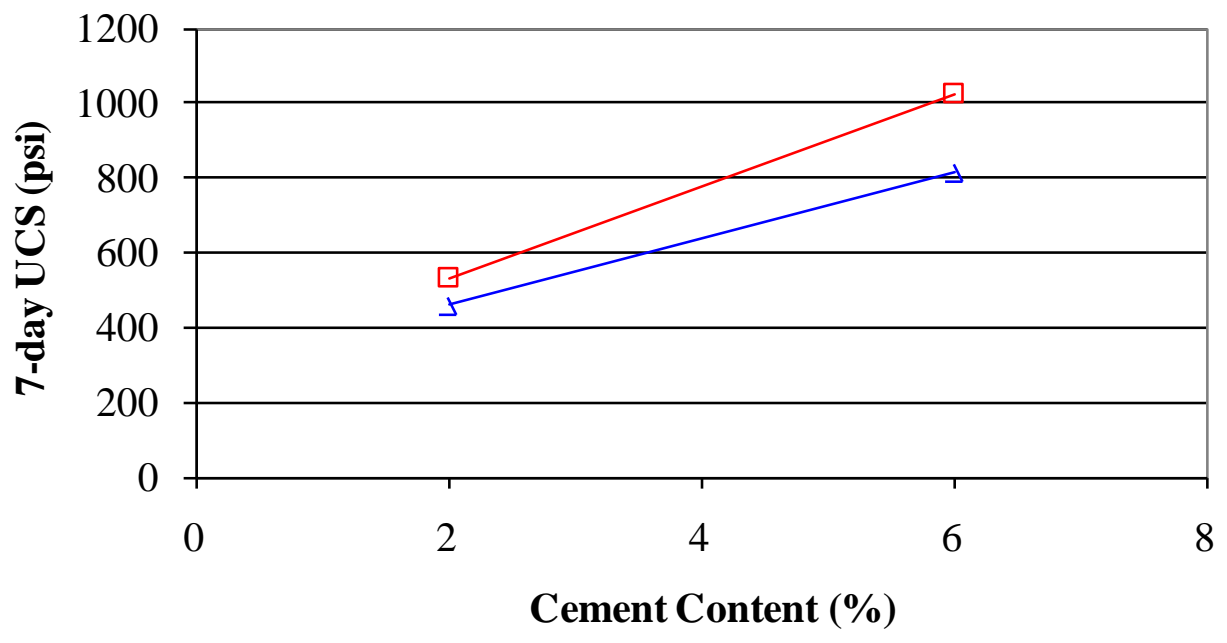

$\neg 5$ sec Mixing Time $\quad \square-15$ sec Mixing Time

Figure 4.5 Interaction between cement content and cement-aggregate mixing time.

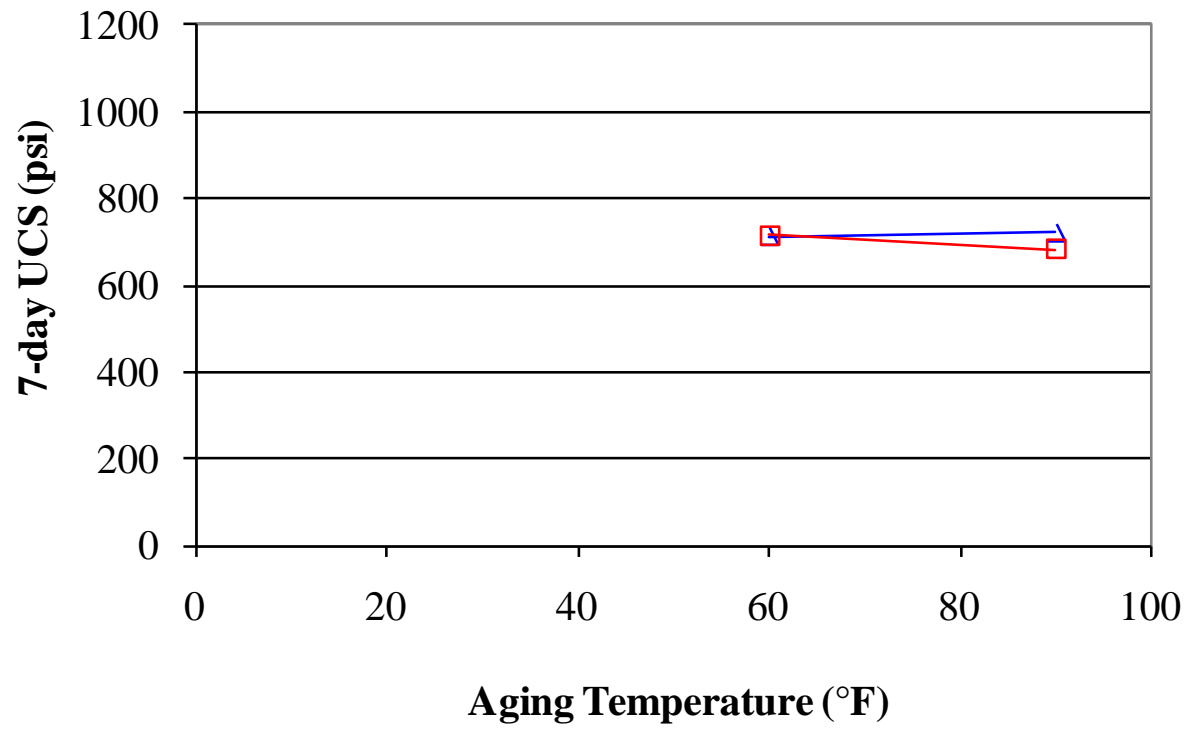

$\rightarrow$ No Slurry Admixture $\quad \square-$ With Slurry Admixture

Figure 4.6 Interaction between slurry aging temperature and slurry admixture. 
The interactions of cement content by slurry aging temperature and slurry aging temperature by cement admixture are slight and are of no practical importance. However, the interaction between cement content and cement-aggregate mixing time, shown in Table 4.5 and Figure 4.5, is practically important. The graph shows that increasing cement content from 2 to 6 percent caused a greater increase in 7-day UCS when the cement is mixed longer with the aggregate. For a mixing time of 5 sec, 7-day UCS increased by 356 psi when cement content was increased from 2 to 6 percent. However, for a mixing time of 15 sec, 7-day UCS increased by 493 psi when cement content was increased by the same amount.

Table 4.6 shows the interactions relating to DD that were statistically significant, and Figures 4.7 to 4.10 show these interactions. Although each factor is statistically significant, none is of practical importance.

Table 4.7 shows the interactions relating to MC that were statistically significant, and Figures 4.11 to 4.16 show these interactions. Again, although each factor is statistically significant, none is of practical importance.

\subsection{Evaluation of Road Base Stabilized with Either Slurry or Dry Cement}

This section presents the results of the second statistical analysis that included data from

all specimens, both those prepared from cement slurry and those prepared from dry cement. As in the previous analyses, discussion of only statistically significant and practically important factors is given. 
Table 4.6 Least Squares Means for Interactions between Experimental Factors for DD of Road Base Treated with Cement Slurry

\begin{tabular}{c|c|c}
\hline Cement Content (\%) & Mixing Time (sec) & DD (pcf) \\
\hline \multirow{2}{*}{2} & 5 & 138.1 \\
& 15 & 137.9 \\
\hline \multirow{2}{*}{6} & 5 & 138.8 \\
& 15 & 139.3 \\
\hline Water Batching & Aging Temperature $\left({ }^{\circ} \mathrm{F}\right)$ & $\mathrm{DD}(\mathrm{pcf})$ \\
Temperature $\left({ }^{\circ} \mathrm{F}\right)$ & 60 & 138.8 \\
\multirow{2}{*}{60} & 90 & 138.4 \\
\hline \multirow{2}{*}{90} & 60 & 138.9 \\
& 90 & 137.8 \\
\hline Aging Temperature $\left({ }^{\circ} \mathrm{F}\right)$ & Slurry Admixture & $\mathrm{DD}(\mathrm{pcf})$ \\
\hline \multirow{2}{*}{60} & No & 138.7 \\
& Yes & 139.0 \\
\hline \multirow{2}{*}{90} & No & 138.6 \\
& Yes & 137.7 \\
\hline Water Batching & Slurry Admixture & DD (pcf) \\
\hline Temperature $\left({ }^{\circ} \mathrm{F}\right)$ & No & 139.0 \\
\multirow{2}{*}{60} & Yes & 138.3 \\
\hline \multirow{2}{*}{90} & No & 138.3 \\
& Yes & 138.5 \\
\hline & &
\end{tabular}




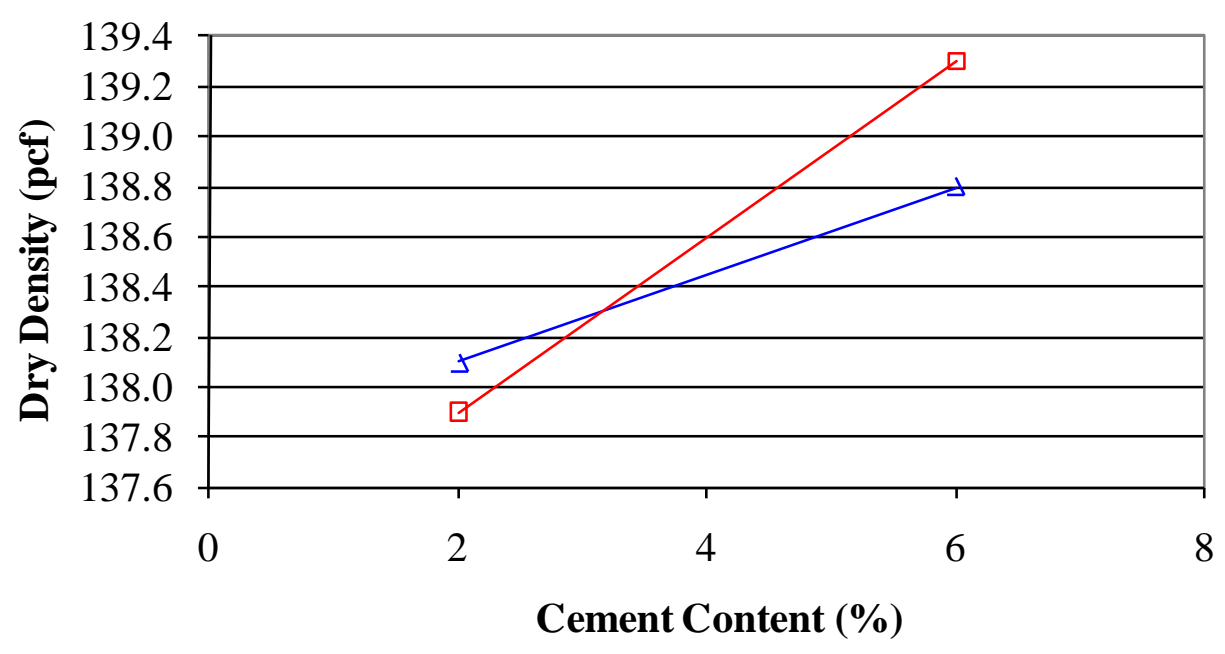

$$
\neg 5 \text { sec Mixing Time } \quad \square \mathbf{1 5} \text { sec Mixing Time }
$$

Figure 4.7 Interaction between cement content and cement-aggregate mixing time.

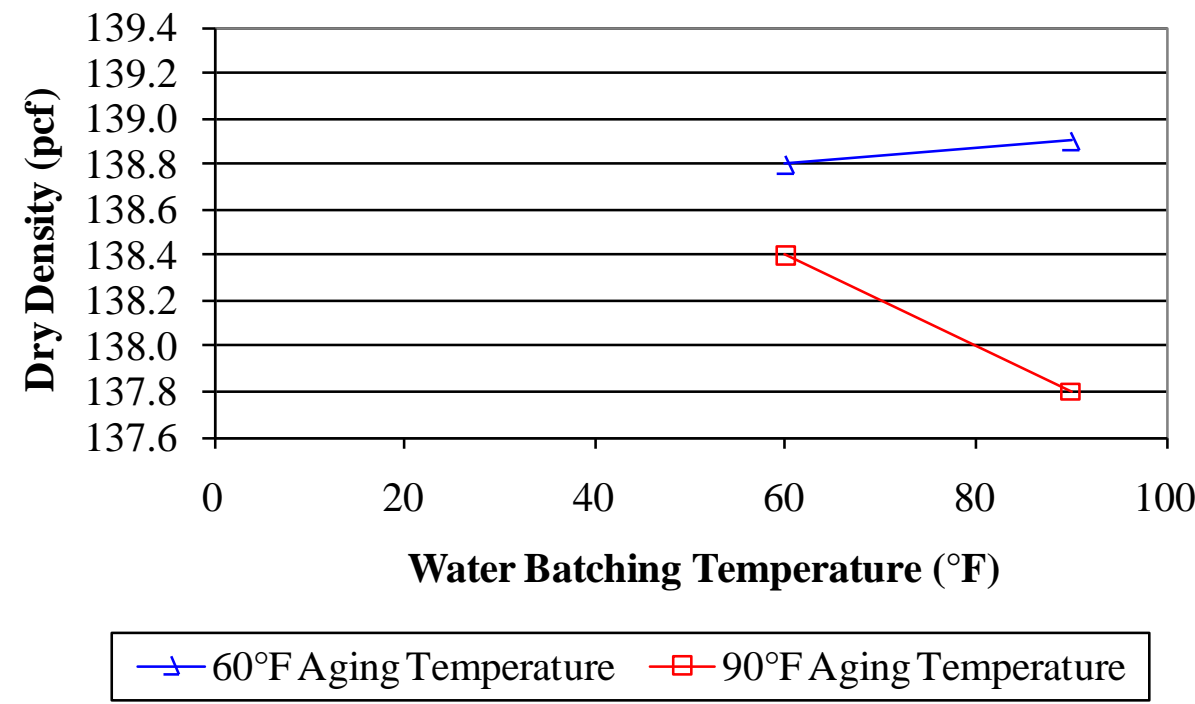

Figure 4.8 Interaction between water batching temperature and slurry aging temperature. 


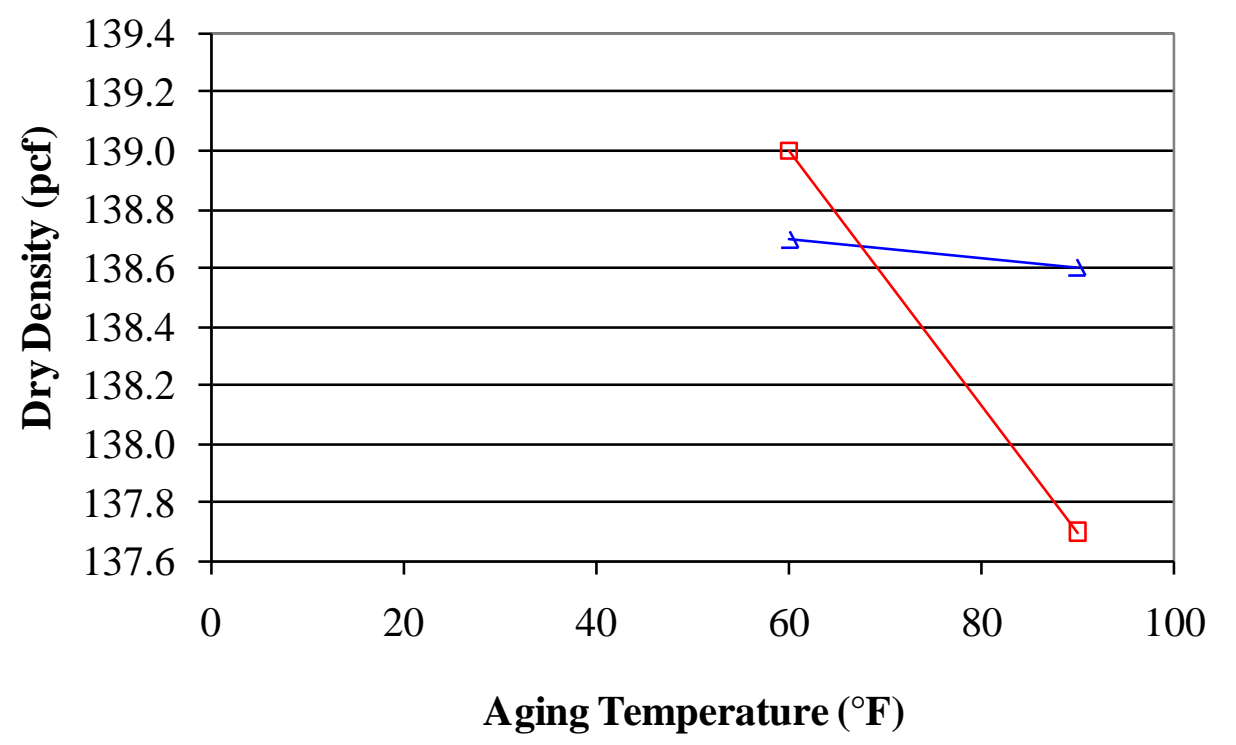

$\rightarrow$ No Slurry Admixture $\quad \square$-With Slurry Admixture

Figure 4.9 Interaction between aging temperature and slurry admixture.

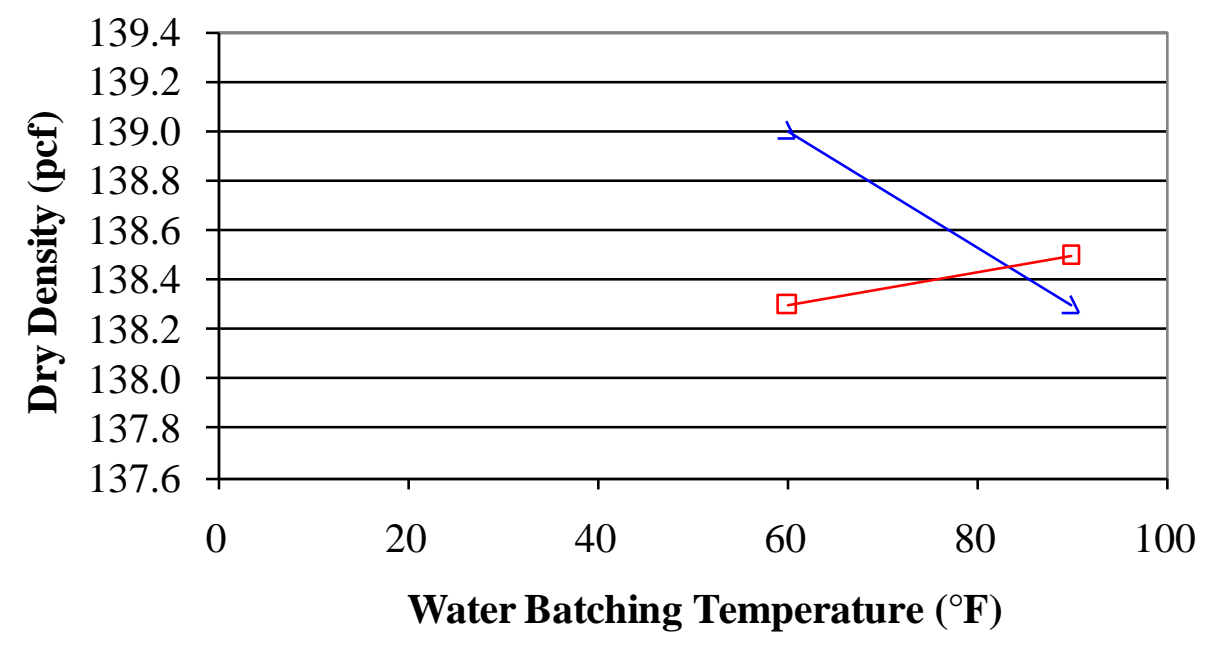

Figure 4.10 Interaction between water batching temperature and slurry admixture. 
Table 4.7 Least Squares Means for Interactions between Experimental Factors for MC of Road Base Treated with Cement Slurry

\begin{tabular}{|c|c|c|}
\hline Cement Content (\%) & Aging Temperature $\left({ }^{\circ} \mathrm{F}\right)$ & MC (\%) \\
\hline \multirow{2}{*}{2} & 60 & 4.7 \\
\hline & 90 & 4.6 \\
\hline \multirow{2}{*}{6} & 60 & 4.5 \\
\hline & 90 & 4.2 \\
\hline Water Batching & & \\
\hline Temperature ( $\left.{ }^{\circ} \mathrm{F}\right)$ & Aging Temperature $\left({ }^{\circ} \mathrm{F}\right)$ & $\mathrm{MC}(\%)$ \\
\hline \multirow{2}{*}{60} & 60 & 4.6 \\
\hline & 90 & 4.5 \\
\hline \multirow{2}{*}{90} & 60 & 4.6 \\
\hline & 90 & 4.3 \\
\hline Aging Temperature $\left({ }^{\circ} \mathrm{F}\right)$ & Slurry Admixture & $\mathrm{MC}(\%)$ \\
\hline \multirow{2}{*}{60} & No & 4.6 \\
\hline & Yes & 4.6 \\
\hline \multirow{2}{*}{90} & No & 4.4 \\
\hline & Yes & 4.5 \\
\hline Water Batching & & \\
\hline Temperature $\left({ }^{\circ} \mathrm{F}\right)$ & Slurry Admixture & $\mathrm{MC}(\%)$ \\
\hline \multirow{2}{*}{60} & No & 4.5 \\
\hline & Yes & 4.6 \\
\hline \multirow{2}{*}{90} & No & 4.5 \\
\hline & Yes & 4.5 \\
\hline Cement Content (\%) & Water Batching Temperature $\left({ }^{\circ} \mathrm{F}\right)$ & $\mathrm{MC}(\%)$ \\
\hline \multirow{2}{*}{2} & 60 & 4.6 \\
\hline & 90 & 4.6 \\
\hline \multirow{2}{*}{6} & 60 & 4.4 \\
\hline & 90 & 4.3 \\
\hline Cement Content (\%) & Slurry Admixture & $\mathrm{MC}(\%)$ \\
\hline \multirow{2}{*}{2} & No & 4.6 \\
\hline & Yes & 4.6 \\
\hline \multirow{2}{*}{6} & No & 4.3 \\
\hline & Yes & 4.4 \\
\hline
\end{tabular}




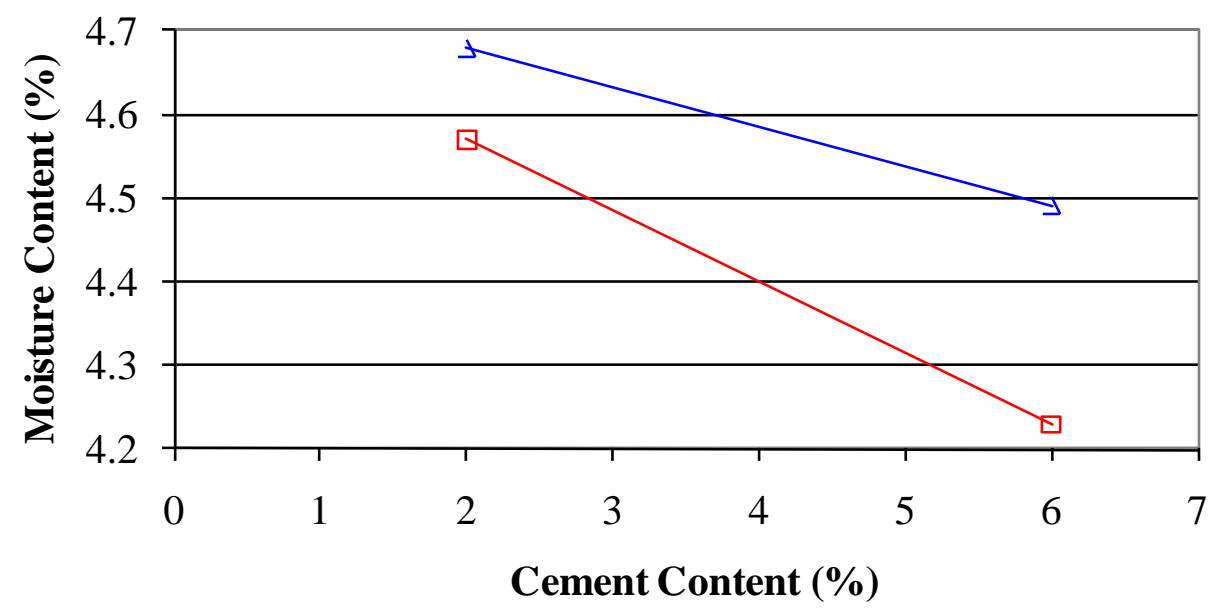

$\neg 60^{\circ} \mathrm{F}$ Aging Temperature $\square-90^{\circ} \mathrm{F}$ Aging Temperature

Figure 4.11 Interaction between slurry aging temperature and cement content.

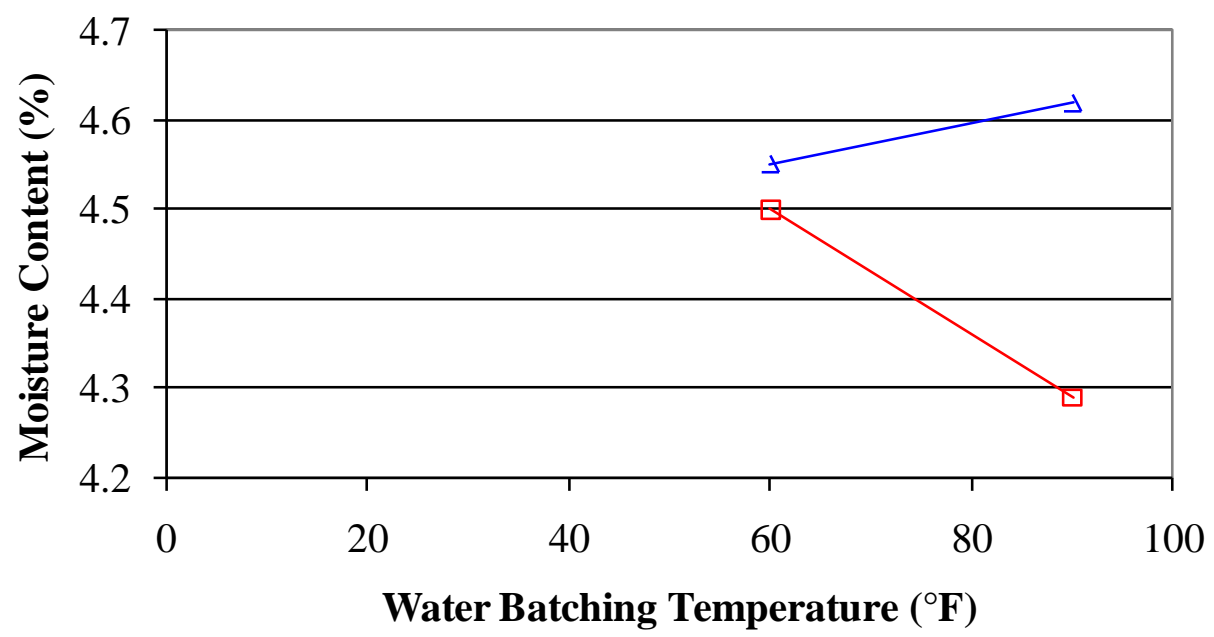

$\neg 60^{\circ} \mathrm{F}$ Aging Temperature $\square-90^{\circ} \mathrm{F}$ Aging Temperature

Figure 4.12 Interaction between slurry aging temperature and water batching temperature. 


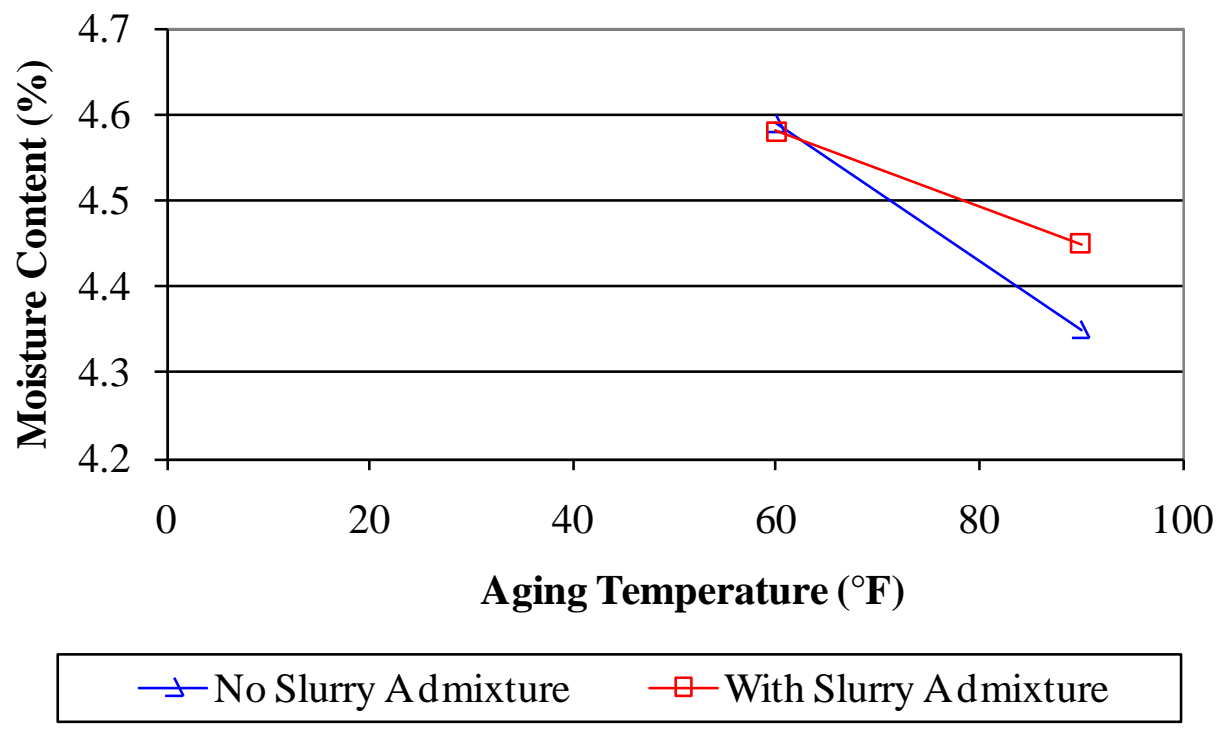

Figure 4.13 Interaction between slurry admixture and slurry aging temperature.

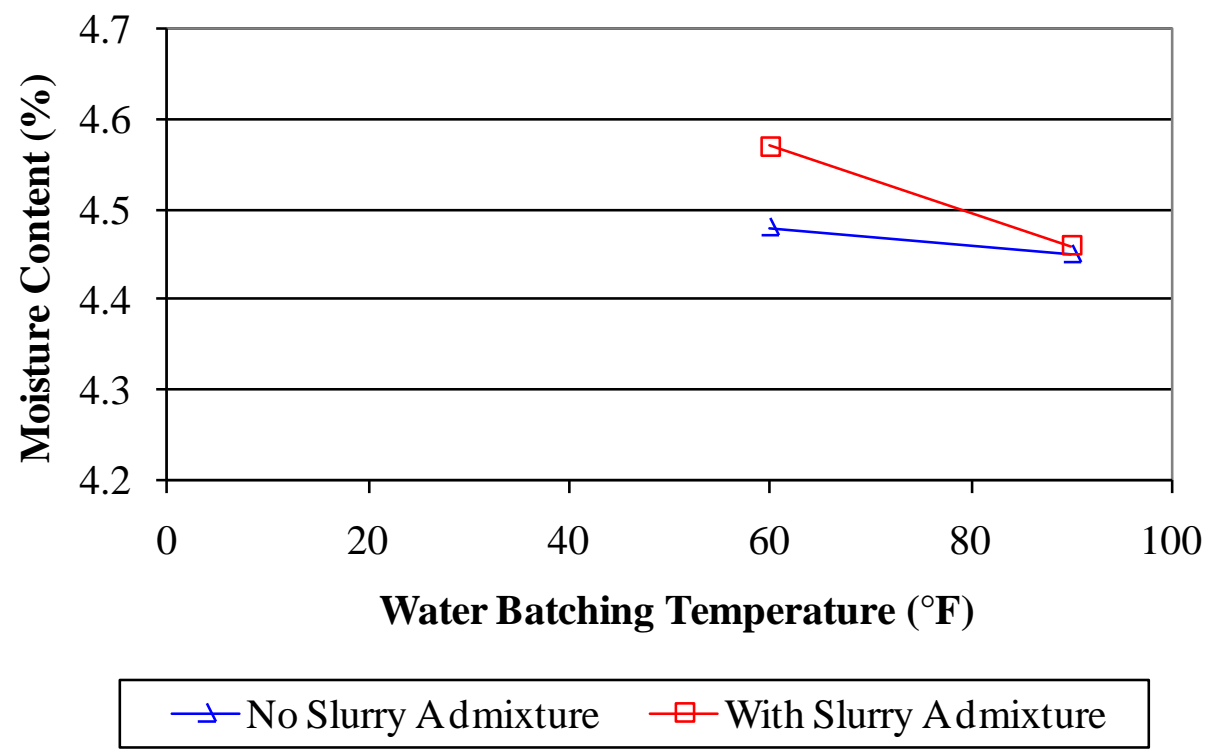

Figure 4.14 Interaction between slurry admixture and water batching temperature. 


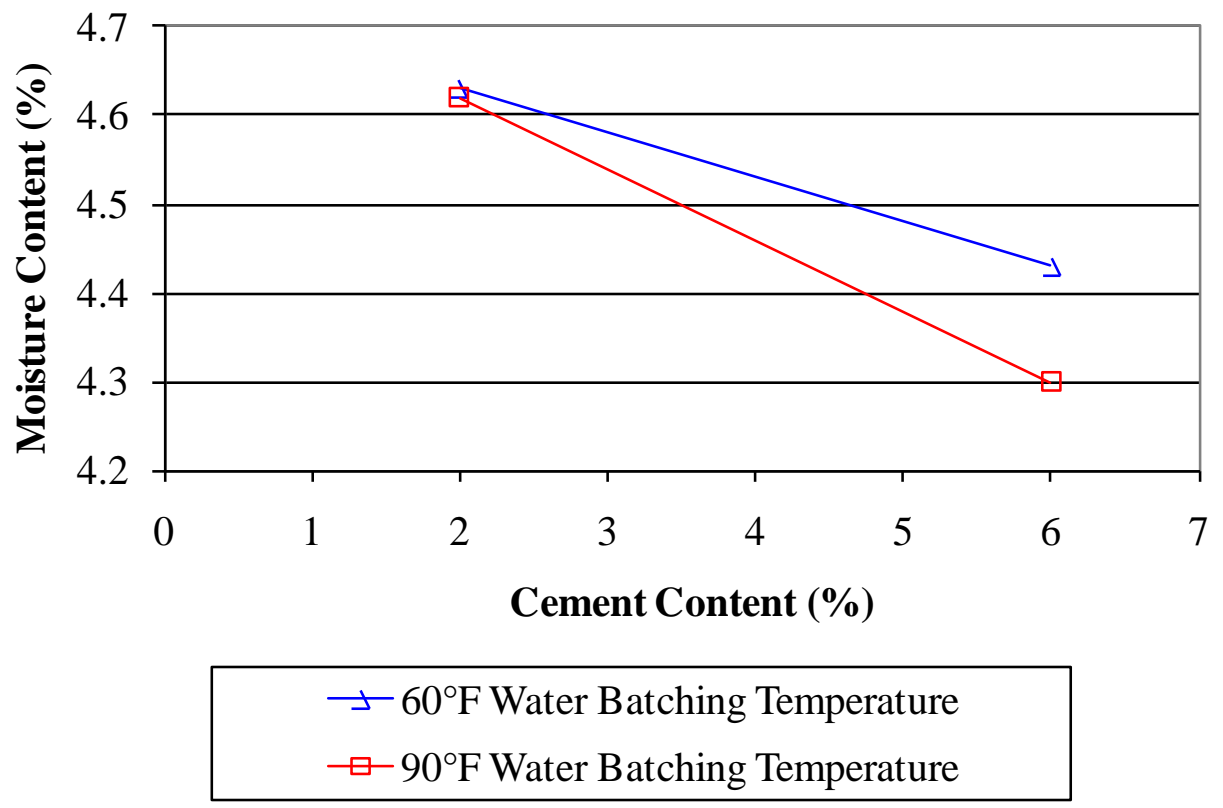

Figure 4.15 Interaction between water batching temperature and cement content.

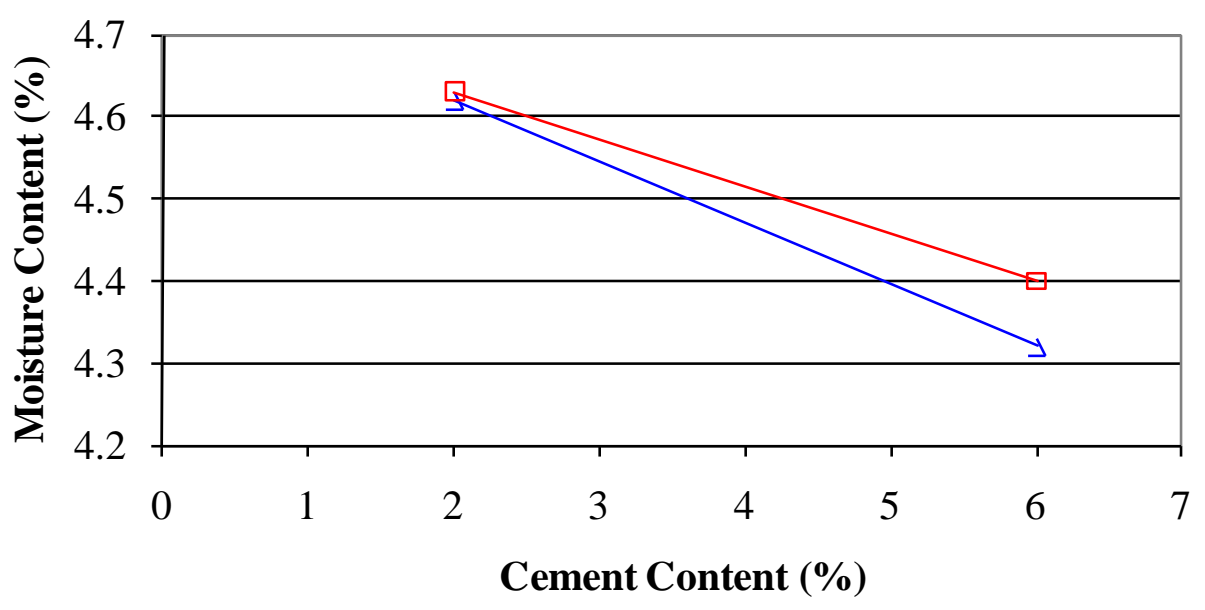

$\neg$ No Slurry Admixture $\quad \square-$ With Slurry Admixture

Figure 4.16 Interaction between slurry admixture and cement content. 


\subsubsection{Main Effects}

Table 4.8 shows the main effects and interactions from the reduced ANOVA models associated with road base treated with either dry cement or cement slurry. As in the first statistical model, interactions are indicated by asterisks, and a hyphen indicates that the $p$-value exceeded 0.15 in that case. An $\mathrm{R}^{2}$ value is also given for each of the models.

The least squares means for main effects shown in Table 4.8 to be statistically significant are given in Table 4.9 for 7-day UCS, DD, and MC of road base stabilized with either dry cement or cement slurry. All three experimental variables affected the 7-day UCS in a practically important way. The data show that, after all factors were considered, increasing cement content from 2 to 6 percent nearly doubled 7-day UCS, raising it by 493 psi. Mixing

Table 4.8 ANOVA Results for Road Base Treated with Dry Cement or Cement Slurry

\begin{tabular}{c|c|c|c}
\hline \multirow{2}{*}{ Factor } & \multicolumn{3}{|c}{$p$-value } \\
\cline { 2 - 4 } & 7-Day UCS & DD & MC \\
\hline Cement Form & 0.0008 & 0.0048 & - \\
Cement Content & $<0.0001$ & 0.0005 & $<0.0001$ \\
Mixing Time & $<0.0001$ & - & 0.0130 \\
Cement Content*Cement Form & 0.0011 & - & 0.1101 \\
Cement Form*Mixing Time & 0.0656 & - & - \\
Cement Content*Mixing Time & $<0.0001$ & - & - \\
\hline $\mathrm{R}^{2}$ & 0.9192 & 0.2248 & 0.3902 \\
\hline
\end{tabular}


time had the next greatest effect on 7-day UCS; increasing cement-aggregate mixing time from 5 to 15 sec increased 7-day UCS by nearly 15 percent, raising it by 102 psi. Using dry cement over cement slurry increased 7-day UCS by about 10 percent, raising it on average by 71 psi. None of the main effects on DD or MC were determined to be both statistically significant and practically important and are therefore not discussed further in this report.

\subsubsection{Interactions}

Least squares means for interactions shown to be statistically significant in Table 4.8 are given in Table 4.10 for 7-day UCS of road base stabilized with either dry cement or cement slurry. Two-way interactions associated with 7-day UCS are cement content by cement form and cement content by mixing time, which are shown in Figures 4.17 to 4.18 . As before, the lines connecting data points in the figures do not imply that interpolation can be performed; rather, they assist in showing interactions by highlighting slope differences.

Table 4.9 Least Squares Means for Main Effects of Experimental Factors on UCS, DD, and MC of Road Base Treated with Dry Cement or Cement Slurry

\begin{tabular}{|c|c|c|c|c|}
\hline Factor & Level & $\begin{array}{l}\text { 7-Day } \\
\text { UCS } \\
\text { (psi) }\end{array}$ & DD (pcf) & $\mathrm{MC}(\%)$ \\
\hline \multirow{2}{*}{ Cement Form } & Dry & 779 & 137.5 & - \\
\hline & Slurry & 708 & 138.5 & - \\
\hline \multirow{2}{*}{ Cement Content (\%) } & 2 & 497 & 137.4 & 4.7 \\
\hline & 6 & 990 & 138.6 & 4.3 \\
\hline \multirow{2}{*}{ Mixing Time (sec) } & 5 & 693 & - & 4.5 \\
\hline & 15 & 795 & - & 4.5 \\
\hline
\end{tabular}


Table 4.10 Least Squares Means for Interactions between Experimental Factors for UCS of Road Base Treated with Dry Cement or Cement Slurry

\begin{tabular}{c|c|c}
\hline Cement Content (\%) & Cement Form & UCS (psi) \\
\hline \multirow{2}{*}{2} & Dry & 499 \\
& Slurry & 496 \\
\hline \multirow{2}{*}{6} & Dry & 1060 \\
& Slurry & 921 \\
\hline Cement Content (\%) & Mixing Time (sec) & UCS (psi) \\
\hline \multirow{2}{*}{2} & 5 & 481 \\
& 15 & 514 \\
\hline \multirow{2}{*}{6} & 5 & 904 \\
& 15 & 1076 \\
\hline
\end{tabular}

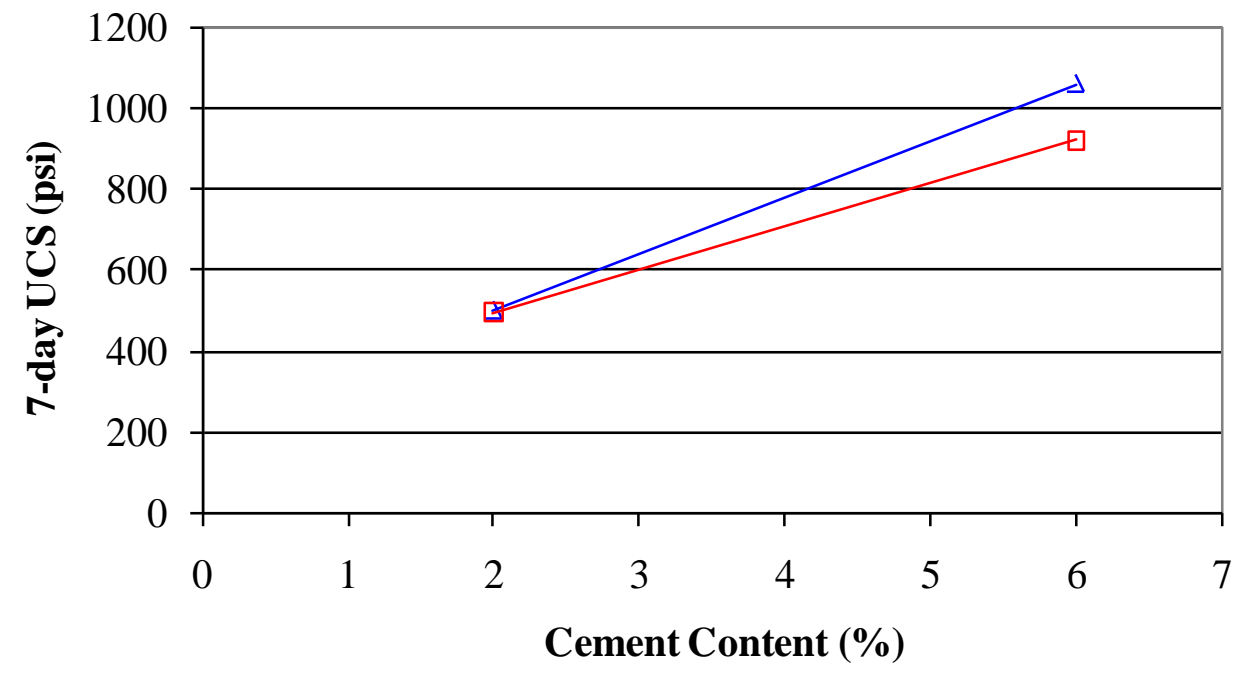

$\neg$ Dry Cement $\square$-Slurry Cement

Figure 4.17 Interaction between cement content and cement form. 


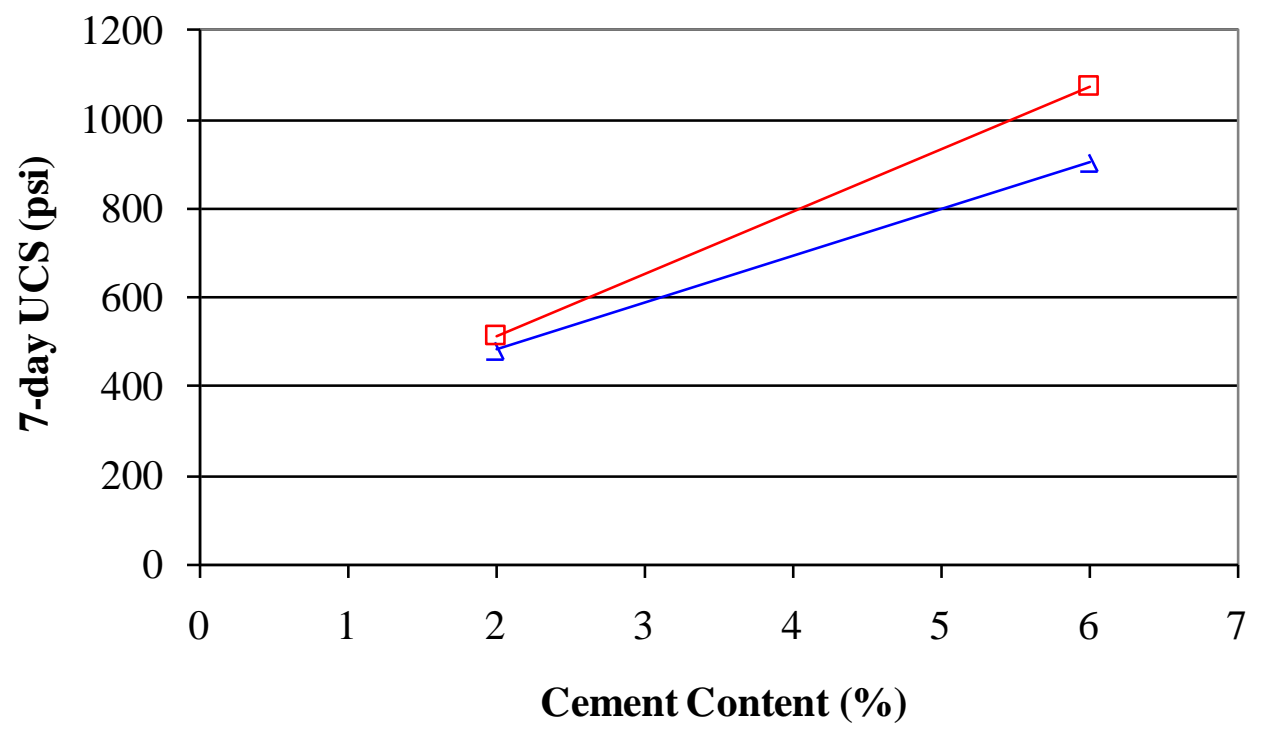

$\neg 5$ sec Mixing Time $\quad \square-15$ sec Mixing Time

Figure 4.18 Interaction between cement content and cement-aggregate mixing time.

In the cement content by cement form interaction, 7-day UCS values of specimens prepared with dry cement increased by 561 psi when cement content was increased from 2 to 6 percent but increased by only 425 psi for specimens prepared with cement slurry when cement content was similarly increased. In the cement content by cement-aggregate mixing time interaction, UCS values of specimens mixed for 5 sec increased by 423 psi when cement content was increased from 2 to 6 percent but increased by 562 psi for specimens mixed for 15 sec when cement content was increased by the same amount. None of the interactions related to DD or MC were determined to be both statistically significant and practically important. 


\subsection{Summary}

For road base treated with cement slurry, only two of the six factors, cement content and cement-aggregate mixing time, affected 7-day UCS in a statistically significant and practically important way. After all factors were considered, increasing cement slurry content from 2 to 6 percent increased 7-day UCS by 86 percent, raising it on average by 425 psi. Increasing the mixing time from 5 to 15 sec increased 7-day UCS by 22 percent, raising it on average by 141 psi. None of the factors affected the DD or MC of road base treated with cement slurry in both a statistically significant and practically important way.

Of the statistically significant interactions relating to 7-day UCS, DD, and MC of road base treated with cement slurry, only one was of practical importance, cement content by mixing time. For a mixing time of 5 sec, 7-day UCS increased by 356 psi when cement content was increased from 2 to 6 percent. However, for a mixing time of 15 sec, 7-day UCS increased by 493 psi when cement content was increased by the same amount.

For road base treated with either dry cement or cement slurry, all three experimental variables affected the 7-day UCS in a statistically significant and practically important way. The data show that, after all factors were considered, increasing cement content from 2 to 6 percent nearly doubled 7-day UCS, raising it by 493 psi. Mixing time had the next greatest effect on 7day UCS; increasing cement-aggregate mixing time from 5 to 15 sec increased 7-day UCS by nearly 15 percent, raising it by 102 psi. Using dry cement over cement slurry increased 7-day UCS by about 10 percent, raising it on average by 71 psi.

Of the statistically significant interactions relating to 7-day UCS, DD, and MC of road base treated with either dry cement or cement slurry, only two interactions, both relating to 7-day UCS, were statistically significant and practically important. These included cement content by 
cement form and cement content by cement-aggregate mixing time. In the cement content by cement form interaction, 7-day UCS values of specimens prepared with dry cement increased by 561 psi when cement content was increased from 2 to 6 percent but increased by only 425 psi for specimens prepared with cement slurry when cement content was increased by the same amount. In the cement content by cement-aggregate mixing time interaction, 7-day UCS values of specimens mixed for $5 \mathrm{sec}$ increased by 423 psi when cement content was increased from 2 to 6 percent but increased by 562 psi for specimens mixed for 15 sec when cement content was increased by the same amount. None of the interactions related to DD or MC were determined to be both statistically significant and practically important. 


\section{CONCLUSION}

\subsection{Summary}

Cement stabilization in conjunction with FDR is an established practice for rehabilitating deteriorating asphalt roads. Using dry cement in the FDR process effectively produces strong and durable road base. However, its application with a pneumatic spreader creates undesirable fugitive cement dust. The cement dust poses a nuisance and, when inhaled, a health threat. Therefore, despite the numerous benefits of cement treatment, FDR in conjunction with conventional cement stabilization cannot generally be used in urban areas.

To solve the problem of fugitive cement dust, the use of cement slurry, prepared by combining cement powder and water, has been proposed to allow cement stabilization to be utilized in urban areas. However, using cement slurry introduces several factors not associated with using dry cement, and the influence of these factors on road base strength is unknown. Furthermore, the strength attained by the use of cement slurry has not been compared to that achieved by the use of dry cement. Therefore, the objectives of this research were to 1) identify construction-related factors that influence the strength of road base treated with cement slurry in conjunction with FDR and quantify the effects of these factors and 2) compare the strength of road base treated with cement slurry with that of road base treated with dry cement. The results of this research will help pavement engineers prepare specifications that properly address 
potential construction issues associated with the use of cement slurry and more confidently apply cement stabilization in urban environments.

In order to achieve the objectives of this research, base material was obtained from an FDR project and subjected to extensive laboratory testing. Treatments with both cement slurry and dry cement were evaluated in full-factorial experimentation with three replicates of each unique treatment. The 7-day UCS, DD, and MC were measured as dependent variables, while independent variables included cement content; slurry water batching temperature; cement slurry aging temperature; cement slurry aging time; presence of a set-retarding, water-reducing admixture; and aggregate-slurry mixing time. Statistical analyses, including ANOVA, were performed to address the objectives of this research.

\subsection{Findings}

This research suggests that, when road base is stabilized with cement slurry in conjunction with FDR, the slurry water batching temperature; haul time; environmental temperature; and presence of a set-retarding, water-reducing admixture will not significantly affect the strength of CTB, provided that those factors fall within the limits explored in this research and are applied to a road base with similar properties. Cement content and cementaggregate mixing time are positively correlated with the strength of CTB regardless of cement form. Additionally, using cement slurry will result in slightly lower strength values than using dry cement. 


\subsection{Recommendations}

Pavement engineers should consider developing and implementing mixing requirements in FDR specifications when cement is used to ensure that the effect of cement stabilization is fully realized. Furthermore, because a slight reduction in CTB strength can be expected when cement slurry is used, engineers should design accordingly, perhaps by specifying a slight increase in cement to compensate for the difference.

Future research in this field may focus on repeating these tests using different levels of the experimental factors investigated in this research and with different types of road base. Additionally, the effect of the experimental variables on road base durability may be evaluated. 


\section{REFERENCES}

American Concrete Institute, "State-of-the-Art Report on Soil Cement," ACI Materials Journal, Vol. 87, No. 4, July/August 1990, pages 395 to 417.

Asphalt Recycling and Reclaiming Association, Basic Asphalt Recycling Manual, Publication NHIO1-022, Annapolis, Maryland, USA, 2001, 270 pages.

Bemanian, S.; Polish, P.; and Maurer, G., “Cold In-Place Recycling and Full-Depth Reclamation Projects by Nevada Department of Transportation: State of the Practice,” Transportation Research Record: Journal of the Transportation Research Board, No. 1949, Transportation Research Board of the National Academies, Washington, D.C., 2006, pages 54 to 71 .

Burmister, D. M., Compaction of Soils, American Society of Testing and Materials, Baltimore, Maryland, 1965, 135 pages.

Double, D. D.; Hellawell, A.; and Perry, S. J., “The Hydration of Portland Cement,” Proceedings of the Royal Society of London. Series A, Mathematical and Physical Sciences. Vol. 359, No. 1699, March 17, 1978, pages 435 to 451.

FitzGerald, S. A.; Neumann, D. A.; and Rush, J. J., "In Situ Quasi-elastic Neutron Scattering Study of the Hydration of Tricalcium Silicate,” Chemistry of Materials, Vol. 10, No. 1, 1998, pages 397 to 402 .

Guthrie, W. S.; Brown, A. V.; and Eggett, D. L., "Cement Stabilization of Aggregate Base Material Blended with Reclaimed Asphalt Pavement,” Transportation Research Record: Journal of the Transportation Research Board, No. 2026, Transportation Research Board of the National Academies, Washington, D.C., 2007, pages 47 to 53.

Guthrie, W. S.; Cooley, D.; and Eggett, D. L., "Effects of Reclaimed Asphalt Pavement on Mechanical Properties of Base Materials,” Transportation Research Record: Journal of the Transportation Research Board, No. 2005, Transportation Research Board of the National Academies, Washington, D.C., 2007, pages 44 to 52.

Guthrie, W. S.; Michener, J. E.; Wilson, B. T., and Eggett, D. L., "Effects of Environmental Factors on Construction of Soil-Cement Pavement Layers," Transportation Research Record: Journal of the Transportation Research Board, No. 2104, Transportation Research Board of the National Academies, Washington, D.C., 2009, pages 71 to 79. 
Halsted, G. E.; Luhr, D. R.; and Adaska, W. S., Guide to Cement-Treated Base (CTB), EB236.01, Portland Cement Association, Skokie, Illinois, USA, 2006, 20 pages.

Huang, Y. H., Pavement Analysis and Design, Pearson Prentice Hall, Upper Saddle River, New Jersey, USA, 2004, 775 pages.

Juenger, M. C. G.; Hema, J.; and Solt, S., "The Effects of Liquid Nitrogen on Concrete Properties," Center for Transportation Research, The University of Texas at Austin, Austin, Texas, USA, 2008, 109 pages.

Kearney, E. J. and Huffman, J. E., "Full-Depth Reclamation Process,” Transportation Research Record: Journal of the Transportation Research Board, No. 1684, Transportation Research Board, National Research Council, Washington, D.C., 1999, pages 203 to 209.

Lee, K.; Prezzi, M.; and Kim, N., "Subgrade Design Parameters from Samples Prepared with Different Compaction Methods,” Journal of Transportation Engineering, Vol. 133, No. 2, February 2007, pages 82 to 89.

Lim, S. and Zollinger, D. G., "Estimation of the Compressive Strength and Modulus of Elasticity of Cement-Treated Aggregate Base Materials," Transportation Research Record: Journal of the Transportation Research Board," No. 1837, Transportation Research Board of the National Academies, 2003, pages 30 to 38.

Luhr, D. R.; Adaska, W. S.; and Halsted, G. E., Guide to Full-Depth Reclamation (FDR) with Cement, EB234.02, Portland Cement Association, Skokie, Illinois, USA, 2005, 15 pages.

MapQuest, www.mapquest.com, accessed February 11, 2011, 1 page.

Miller, C. J.; Yesiller, N.; Yaldo, K.; and Merayyan, S., "Impact of Soil Type and Compaction Conditions on Soil Water Characteristic," Journal of Geotechnical and Geoenvironmental Engineering, Vol. 128, No. 9, September 2002, pages 733 to 742.

Mindess, S.; Young, J. F.; and Darwin, D., Concrete, Prentice Hall, Upper Saddle River, New Jersey, USA, 2003, 644 pages.

Portland Cement Association, Effect of Long-Time Mixing of Concrete, ST15-2, Skokie, Illinois, USA, March 1953, 1 page.

Portland Cement Association, Full-Depth Recycling with Cement, SR995, Skokie, Illinois, USA, 2002, 8 pages.

Portland Cement Association, Recycling Failed Flexible Pavements with Cement, IS197.01S, Skokie, Illinois, USA, 1976, 4 pages.

Portland Cement Association, Soil-Cement Construction Handbook, EB003.10S, Skokie, Illinois, USA, 1995, 40 pages. 
Portland Cement Association, Soil-Cement Laboratory Handbook, EB052.07S, Skokie, Illinois, USA, 1992, 59 pages.

Sebesta, S. and Harris, J. P., Slurry Stabilization and Reaction Chemistry of Cement-Treated Soils, SN3108, Portland Cement Association, Skokie, Illinois, USA, 2009, 63 pages.

Taha, R.; Al-Harthy, A.; and Al-Shamsi, K., “Cement Stabilization of Recycled Asphalt Pavement Aggregate for Road Bases and Subbases,” Journal of Materials in Civil Engineering, Vol. 14, No. 3, May/June 2002, pages 239-245.

Utah Department of Transportation, Supplemental Specifications for 2008 Standard Specifications for Road and Bridge Construction, http://www.udot.utah.gov/main/uconowner.gf?n=5905332050502068, Accessed February 17, 2011, 25 pages. 


\section{APPENDIX: RAW DATA}

Table A.1 Raw Data

\begin{tabular}{|c|c|c|c|c|c|c|c|c|c|c|}
\hline $\begin{array}{c}\text { Cement } \\
\text { Type }\end{array}$ & $\begin{array}{c}\text { Cement } \\
\text { Amount } \\
(\%)\end{array}$ & $\begin{array}{c}\text { Slurry Water } \\
\text { Batching } \\
\text { Temperature } \\
\left({ }^{\circ} \mathrm{F}\right)\end{array}$ & $\begin{array}{c}\text { Slurry } \\
\text { Additive }\end{array}$ & $\begin{array}{c}\text { Slurry Aging } \\
\text { Temperature } \\
\left({ }^{\circ} \mathrm{F}\right)\end{array}$ & $\begin{array}{c}\text { Slurry } \\
\text { Aging } \\
\text { Time } \\
\text { (min) }\end{array}$ & $\begin{array}{c}\text { Mixing } \\
\text { Time } \\
\text { (sec) }\end{array}$ & Specimen & $\begin{array}{c}\text { 7-day UCS } \\
\text { (psi) }\end{array}$ & DD (pcf) & MC (\%) \\
\hline Slurry & 2 & 60 & Yes & 60 & 30 & 5 & 1 & 440 & 137.0 & 4.7 \\
\hline Slurry & 2 & 60 & Yes & 60 & 30 & 5 & 2 & 457 & 137.7 & 4.6 \\
\hline Slurry & 2 & 60 & Yes & 60 & 30 & 5 & 3 & 439 & 138.7 & 4.7 \\
\hline Slurry & 2 & 60 & Yes & 60 & 30 & 15 & 1 & 538 & 138.5 & 4.6 \\
\hline Slurry & 2 & 60 & Yes & 60 & 30 & 15 & 2 & 592 & 140.3 & 4.6 \\
\hline Slurry & 2 & 60 & Yes & 60 & 30 & 15 & 3 & 539 & 137.4 & 4.5 \\
\hline Slurry & 2 & 60 & Yes & 60 & 90 & 5 & 1 & 433 & 137.2 & 4.6 \\
\hline Slurry & 2 & 60 & Yes & 60 & 90 & 5 & 2 & 445 & 138.3 & 4.6 \\
\hline Slurry & 2 & 60 & Yes & 60 & 90 & 5 & 3 & 463 & 138.2 & 4.5 \\
\hline Slurry & 2 & 60 & Yes & 60 & 90 & 15 & 1 & 505 & 136.9 & 4.6 \\
\hline Slurry & 2 & 60 & Yes & 60 & 90 & 15 & 2 & 562 & 138.2 & 4.6 \\
\hline Slurry & 2 & 60 & Yes & 60 & 90 & 15 & 3 & 485 & 138.5 & 4.6 \\
\hline Slurry & 2 & 60 & Yes & 90 & 30 & 5 & 1 & 503 & 138.1 & 4.5 \\
\hline Slurry & 2 & 60 & Yes & 90 & 30 & 5 & 2 & 410 & 137.5 & 4.7 \\
\hline Slurry & 2 & 60 & Yes & 90 & 30 & 5 & 3 & 473 & 138.4 & 4.6 \\
\hline Slurry & 2 & 60 & Yes & 90 & 30 & 15 & 1 & 466 & 137.9 & 4.7 \\
\hline Slurry & 2 & 60 & Yes & 90 & 30 & 15 & 2 & 481 & 137.5 & 4.7 \\
\hline Slurry & 2 & 60 & Yes & 90 & 30 & 15 & 3 & 528 & 138.1 & 4.8 \\
\hline Slurry & 2 & 60 & Yes & 90 & 90 & 5 & 1 & 430 & 137.3 & 4.7 \\
\hline Slurry & 2 & 60 & Yes & 90 & 90 & 5 & 2 & 362 & 136.2 & 4.8 \\
\hline Slurry & 2 & 60 & Yes & 90 & 90 & 5 & 3 & 438 & 137.1 & 4.7 \\
\hline Slurry & 2 & 60 & Yes & 90 & 90 & 15 & 1 & 528 & 136.8 & 4.7 \\
\hline Slurry & 2 & 60 & Yes & 90 & 90 & 15 & 2 & 492 & 136.1 & 4.6 \\
\hline Slurry & 2 & 60 & Yes & 90 & 90 & 15 & 3 & 494 & 135.9 & 4.7 \\
\hline Slurry & 2 & 60 & No & 60 & 30 & 5 & 1 & 523 & 139.1 & 4.8 \\
\hline Slurry & 2 & 60 & No & 60 & 30 & 5 & 2 & 494 & 138.9 & 4.8 \\
\hline Slurry & 2 & 60 & No & 60 & 30 & 5 & 3 & 553 & 140.3 & 4.8 \\
\hline Slurry & 2 & 60 & No & 60 & 30 & 15 & 1 & 513 & 137.1 & 4.6 \\
\hline Slurry & 2 & 60 & No & 60 & 30 & 15 & 2 & 537 & 138.0 & 4.6 \\
\hline Slurry & 2 & 60 & No & 60 & 30 & 15 & 3 & 536 & 138.5 & 4.6 \\
\hline Slurry & 2 & 60 & No & 60 & 90 & 5 & 1 & 474 & 137.6 & 4.6 \\
\hline Slurry & 2 & 60 & No & 60 & 90 & 5 & 2 & 473 & 138.1 & 4.5 \\
\hline Slurry & 2 & 60 & No & 60 & 90 & 5 & 3 & 465 & 137.5 & 4.6 \\
\hline Slurry & 2 & 60 & No & 60 & 90 & 15 & 1 & 542 & 138.1 & 4.6 \\
\hline Slurry & 2 & 60 & No & 60 & 90 & 15 & 2 & 584 & 138.6 & 4.6 \\
\hline Slurry & 2 & 60 & No & 60 & 90 & 15 & 3 & 543 & 137.7 & 4.6 \\
\hline
\end{tabular}


Table A.1 (cont.)

\begin{tabular}{|c|c|c|c|c|c|c|c|c|c|c|}
\hline $\begin{array}{c}\text { Cement } \\
\text { Type }\end{array}$ & $\begin{array}{c}\text { Cement } \\
\text { Amount } \\
(\%) \\
\end{array}$ & \begin{tabular}{|c|} 
Slurry Water \\
Batching \\
Temperature \\
$\left({ }^{\circ} \mathrm{F}\right)$ \\
\end{tabular} & $\begin{array}{c}\text { Slurry } \\
\text { Additive }\end{array}$ & $\begin{array}{c}\text { Slurry Aging } \\
\text { Temperature } \\
\left({ }^{\circ} \mathrm{F}\right) \\
\end{array}$ & $\begin{array}{l}\text { Slurry } \\
\text { Aging } \\
\text { Time } \\
\text { (min) }\end{array}$ & $\begin{array}{l}\text { Mixing } \\
\text { Time } \\
\text { (sec) } \\
\end{array}$ & Specimen & $\begin{array}{c}\text { 7-day UCS } \\
\text { (psi) }\end{array}$ & DD (pcf) & MC (\%) \\
\hline Slurry & 2 & 60 & No & \begin{tabular}{|c|}
90 \\
\end{tabular} & 30 & 5 & 1 & 592 & 140.4 & 4.7 \\
\hline Slurry & 2 & 60 & No & 90 & 30 & 5 & 2 & 467 & 140.1 & 4.6 \\
\hline Slurry & 2 & 60 & No & 90 & 30 & 5 & 3 & 457 & 138.9 & 4.7 \\
\hline Slurry & 2 & 60 & No & 90 & 30 & 15 & 1 & 545 & 138.1 & 4.6 \\
\hline Slurry & 2 & 60 & No & 90 & 30 & 15 & 2 & 556 & 137.4 & 4.7 \\
\hline Slurry & 2 & 60 & No & 90 & 30 & 15 & 3 & 565 & 138.3 & 4.5 \\
\hline Slurry & 2 & 60 & No & 90 & 90 & 5 & 1 & 384 & 138.7 & 4.7 \\
\hline Slurry & 2 & 60 & No & 90 & 90 & 5 & 2 & 389 & 138.9 & 4.6 \\
\hline Slurry & 2 & 60 & No & 90 & 90 & 5 & 3 & 469 & 138.1 & 4.5 \\
\hline Slurry & 2 & 60 & No & 90 & 90 & 15 & 1 & 502 & 138.4 & 4.5 \\
\hline Slurry & 2 & 60 & No & 90 & 90 & 15 & 2 & 502 & 138.4 & 4.5 \\
\hline Slurry & 2 & 60 & No & 90 & 90 & 15 & 3 & 454 & 138.4 & 4.4 \\
\hline Slurry & 2 & 90 & Yes & 60 & 30 & 5 & 1 & 507 & 137.7 & 4.8 \\
\hline Slurry & 2 & 90 & Yes & 60 & 30 & 5 & 2 & 491 & 146.1 & 4.9 \\
\hline Slurry & 2 & 90 & Yes & 60 & 30 & 5 & 3 & 507 & 138.2 & 4.9 \\
\hline Slurry & 2 & 90 & Yes & 60 & 30 & 15 & 1 & 548 & 138.7 & 4.9 \\
\hline Slurry & 2 & 90 & Yes & 60 & 30 & 15 & 2 & 421 & 139.6 & 4.5 \\
\hline Slurry & 2 & 90 & Yes & 60 & 30 & 15 & 3 & 487 & 137.6 & 4.9 \\
\hline Slurry & 2 & 90 & Yes & 60 & 90 & 5 & 1 & 453 & 137.2 & 4.7 \\
\hline Slurry & 2 & 90 & Yes & 60 & 90 & 5 & 2 & 460 & 138.9 & 4.8 \\
\hline Slurry & 2 & 90 & Yes & 60 & 90 & 5 & 3 & 460 & 138.0 & 4.8 \\
\hline Slurry & 2 & 90 & Yes & 60 & 90 & 15 & 1 & 548 & 138.5 & 4.8 \\
\hline Slurry & 2 & 90 & Yes & 60 & 90 & 15 & 2 & 514 & 138.4 & 4.8 \\
\hline Slurry & 2 & 90 & Yes & 60 & 90 & 15 & 3 & 561 & 138.9 & 4.7 \\
\hline Slurry & 2 & 90 & Yes & 90 & 30 & 5 & 1 & 398 & 137.1 & 4.6 \\
\hline Slurry & 2 & 90 & Yes & 90 & 30 & 5 & 2 & 424 & 137.7 & 4.6 \\
\hline Slurry & 2 & 90 & Yes & 90 & 30 & 5 & 3 & 412 & 137.5 & 4.6 \\
\hline Slurry & 2 & 90 & Yes & 90 & 30 & 15 & 1 & 584 & 138.8 & 4.6 \\
\hline Slurry & 2 & 90 & Yes & 90 & 30 & 15 & 2 & 558 & 137.3 & 4.5 \\
\hline Slurry & 2 & 90 & Yes & 90 & 30 & 15 & 3 & 516 & 137.8 & 4.4 \\
\hline Slurry & 2 & 90 & Yes & 90 & 90 & 5 & 1 & 522 & 138.3 & 4.3 \\
\hline Slurry & 2 & 90 & Yes & 90 & 90 & 5 & 2 & 342 & 137.2 & 4.6 \\
\hline Slurry & 2 & 90 & Yes & 90 & 90 & 5 & 3 & 436 & 135.3 & 4.4 \\
\hline Slurry & 2 & 90 & Yes & 90 & 90 & 15 & 1 & 542 & 137.8 & 4.2 \\
\hline Slurry & 2 & 90 & Yes & 90 & 90 & 15 & 2 & 550 & 136.9 & 4.2 \\
\hline Slurry & 2 & 90 & Yes & 90 & 90 & 15 & 3 & 499 & 138.2 & 4.2 \\
\hline Slurry & 2 & 90 & No & 60 & 30 & 5 & 1 & 486 & 137.3 & 4.8 \\
\hline Slurry & 2 & 90 & No & 60 & 30 & 5 & 2 & 584 & 136.2 & 4.8 \\
\hline Slurry & 2 & 90 & No & 60 & 30 & 5 & 3 & 516 & 137.9 & 4.7 \\
\hline Slurry & 2 & 90 & No & 60 & 30 & 15 & 1 & 595 & 138.3 & 4.7 \\
\hline Slurry & 2 & 90 & No & 60 & 30 & 15 & 2 & 543 & 137.8 & 4.7 \\
\hline Slurry & 2 & 90 & No & 60 & 30 & 15 & 3 & 624 & 139.3 & 4.8 \\
\hline Slurry & 2 & 90 & No & 60 & 90 & 5 & 1 & 417 & 137.3 & 4.8 \\
\hline Slurry & 2 & 90 & No & 60 & 90 & 5 & 2 & 524 & 138.9 & 4.6 \\
\hline Slurry & 2 & 90 & No & 60 & 90 & 5 & 3 & 497 & 138.8 & 4.6 \\
\hline
\end{tabular}


Table A.1 (cont.)

\begin{tabular}{|c|c|c|c|c|c|c|c|c|c|c|}
\hline $\begin{array}{c}\text { Cement } \\
\text { Type }\end{array}$ & \begin{tabular}{|c|} 
Cement \\
Amount \\
$(\%)$ \\
\end{tabular} & \begin{tabular}{|c|} 
Slurry Water \\
Batching \\
Temperature \\
$\left({ }^{\circ} \mathrm{F}\right)$
\end{tabular} & $\begin{array}{c}\text { Slurry } \\
\text { Additive } \\
\end{array}$ & $\begin{array}{c}\text { Slurry Aging } \\
\text { Temperature } \\
\left({ }^{\circ} \mathrm{F}\right) \\
\end{array}$ & $\begin{array}{l}\text { Slurry } \\
\text { Aging } \\
\text { Time } \\
\text { (min) }\end{array}$ & $\begin{array}{l}\text { Mixing } \\
\text { Time } \\
\text { (sec) } \\
\end{array}$ & Specimen & $\begin{array}{c}\text { 7-day UCS } \\
\text { (psi) }\end{array}$ & $\mathrm{DD}$ (pcf) & MC (\%) \\
\hline Slurry & 2 & 90 & No & 60 & 90 & 15 & 1 & 588 & 137.5 & 4.6 \\
\hline Slurry & 2 & 90 & No & 60 & 90 & 15 & 2 & 620 & 137.6 & 4.6 \\
\hline Slurry & 2 & 90 & No & 60 & 90 & 15 & 3 & 633 & 139.2 & 4.6 \\
\hline Slurry & 2 & 90 & No & 90 & 30 & 5 & 1 & 424 & 137.1 & 4.5 \\
\hline Slurry & 2 & 90 & No & 90 & 30 & 5 & 2 & 454 & 139.0 & 4.6 \\
\hline Slurry & 2 & 90 & No & 90 & 30 & 5 & 3 & 395 & 137.7 & 4.6 \\
\hline Slurry & 2 & 90 & No & 90 & 30 & 15 & 1 & 505 & 136.7 & 4.5 \\
\hline Slurry & 2 & 90 & No & 90 & 30 & 15 & 2 & 494 & 136.3 & 4.6 \\
\hline Slurry & 2 & 90 & No & 90 & 30 & 15 & 3 & 581 & 137.5 & 4.7 \\
\hline Slurry & 2 & 90 & No & 90 & 90 & 5 & 1 & 469 & 138.1 & 4.5 \\
\hline Slurry & 2 & 90 & No & 90 & 90 & 5 & 2 & 419 & 136.4 & 4.7 \\
\hline Slurry & 2 & 90 & No & 90 & 90 & 5 & 3 & 461 & 137.2 & 4.6 \\
\hline Slurry & 2 & 90 & No & 90 & 90 & 15 & 1 & 425 & 136.3 & 4.7 \\
\hline Slurry & 2 & 90 & No & 90 & 90 & 15 & 2 & 494 & 136.3 & 4.4 \\
\hline Slurry & 2 & 90 & No & 90 & 90 & 15 & 3 & 531 & 137.7 & 4.4 \\
\hline Slurry & 6 & 60 & Yes & 60 & 30 & 5 & 1 & 887 & 139.7 & 4.5 \\
\hline Slurry & 6 & 60 & Yes & 60 & 30 & 5 & 2 & 893 & 139.5 & 4.6 \\
\hline Slurry & 6 & 60 & Yes & 60 & 30 & 5 & 3 & 921 & 139.6 & 4.5 \\
\hline Slurry & 6 & 60 & Yes & 60 & 30 & 15 & 1 & 1058 & 139.1 & 4.4 \\
\hline Slurry & 6 & 60 & Yes & 60 & 30 & 15 & 2 & 1123 & 140.2 & 4.5 \\
\hline Slurry & 6 & 60 & Yes & 60 & 30 & 15 & 3 & 1077 & 140.3 & 4.4 \\
\hline Slurry & 6 & 60 & Yes & 60 & 90 & 5 & 1 & 662 & 139.8 & 4.5 \\
\hline Slurry & 6 & 60 & Yes & 60 & 90 & 5 & 2 & 806 & 139.2 & 4.5 \\
\hline Slurry & 6 & 60 & Yes & 60 & 90 & 5 & 3 & 851 & 139.0 & 4.4 \\
\hline Slurry & 6 & 60 & Yes & 60 & 90 & 15 & 1 & 1088 & 138.6 & 4.4 \\
\hline Slurry & 6 & 60 & Yes & 60 & 90 & 15 & 2 & 1053 & 140.3 & 4.3 \\
\hline Slurry & 6 & 60 & Yes & 60 & 90 & 15 & 3 & 1087 & 140.2 & 4.4 \\
\hline Slurry & 6 & 60 & Yes & 90 & 30 & 5 & 1 & 708 & 138.7 & 4.7 \\
\hline Slurry & 6 & 60 & Yes & 90 & 30 & 5 & 2 & 766 & 137.6 & 4.7 \\
\hline Slurry & 6 & 60 & Yes & 90 & 30 & 5 & 3 & 670 & 139.7 & 4.8 \\
\hline Slurry & 6 & 60 & Yes & 90 & 30 & 15 & 1 & 876 & 137.5 & 4.6 \\
\hline Slurry & 6 & 60 & Yes & 90 & 30 & 15 & 2 & 836 & 139.4 & 4.7 \\
\hline Slurry & 6 & 60 & Yes & 90 & 30 & 15 & 3 & 970 & 139.5 & 4.6 \\
\hline Slurry & 6 & 60 & Yes & 90 & 90 & 5 & 1 & 745 & 136.5 & 4.5 \\
\hline Slurry & 6 & 60 & Yes & 90 & 90 & 5 & 2 & 688 & 137.2 & 4.4 \\
\hline Slurry & 6 & 60 & Yes & 90 & 90 & 5 & 3 & 757 & 136.1 & 4.6 \\
\hline Slurry & 6 & 60 & Yes & 90 & 90 & 15 & 1 & 945 & 138.6 & 4.5 \\
\hline Slurry & 6 & 60 & Yes & 90 & 90 & 15 & 2 & 942 & 137.6 & 4.3 \\
\hline Slurry & 6 & 60 & Yes & 90 & 90 & 15 & 3 & 1024 & 139.2 & 4.4 \\
\hline Slurry & 6 & 60 & Yes & 60 & 30 & 5 & 1 & 892 & 140.0 & 4.7 \\
\hline Slurry & 6 & 60 & Yes & 60 & 30 & 5 & 2 & 787 & 139.6 & 4.7 \\
\hline Slurry & 6 & 60 & Yes & 60 & 30 & 5 & 3 & 824 & 138.9 & 4.7 \\
\hline Slurry & 6 & 60 & Yes & 60 & 30 & 15 & 1 & 922 & 139.0 & 4.5 \\
\hline Slurry & 6 & 60 & Yes & 60 & 30 & 15 & 2 & 984 & 139.3 & 4.5 \\
\hline Slurry & 6 & 60 & Yes & 60 & 30 & 15 & 3 & 978 & 140.8 & 4.5 \\
\hline
\end{tabular}


Table A.1 (cont.)

\begin{tabular}{|c|c|c|c|c|c|c|c|c|c|c|}
\hline $\begin{array}{l}\text { Cement } \\
\text { Type }\end{array}$ & $\begin{array}{c}\text { Cement } \\
\text { Amount } \\
(\%)\end{array}$ & $\begin{array}{l}\text { Slurry Water } \\
\text { Batching } \\
\text { Temperature } \\
\left({ }^{\circ} \mathrm{F}\right)\end{array}$ & $\begin{array}{c}\text { Slurry } \\
\text { Additive }\end{array}$ & \begin{tabular}{|c|} 
Slurry Aging \\
Temperature \\
$\left({ }^{\circ} \mathrm{F}\right)$
\end{tabular} & $\begin{array}{l}\text { Slurry } \\
\text { Aging } \\
\text { Time } \\
\text { (min) }\end{array}$ & $\begin{array}{l}\text { Mixing } \\
\text { Time } \\
\text { (sec) }\end{array}$ & Specimen & $\begin{array}{c}\text { 7-day UCS } \\
\text { (psi) }\end{array}$ & DD (pcf) & MC (\%) \\
\hline Slurry & 6 & 60 & No & 60 & 90 & 5 & 1 & 785 & 138.3 & 4.5 \\
\hline Slurry & 6 & 60 & No & 60 & 90 & 5 & 2 & 775 & 139.3 & 4.4 \\
\hline Slurry & 6 & 60 & No & 60 & 90 & 5 & 3 & 715 & 138.1 & 4.4 \\
\hline Slurry & 6 & 60 & No & 60 & 90 & 15 & 1 & 1009 & 139.7 & 4.4 \\
\hline Slurry & 6 & 60 & No & 60 & 90 & 15 & 2 & 976 & 138.7 & 4.4 \\
\hline Slurry & 6 & 60 & No & 60 & 90 & 15 & 3 & 962 & 139.6 & 4.4 \\
\hline Slurry & 6 & 60 & No & 90 & 30 & 5 & 1 & 750 & 139.3 & 4.1 \\
\hline Slurry & 6 & 60 & No & 90 & 30 & 5 & 2 & 641 & 138.7 & 4.2 \\
\hline Slurry & 6 & 60 & No & 90 & 30 & 5 & 3 & 822 & 140.7 & 4.2 \\
\hline Slurry & 6 & 60 & No & 90 & 30 & 15 & 1 & 1206 & 140.1 & 4.2 \\
\hline Slurry & 6 & 60 & No & 90 & 30 & 15 & 2 & 1138 & 139.6 & 4.2 \\
\hline Slurry & 6 & 60 & No & 90 & 30 & 15 & 3 & 1110 & 140.8 & 4.2 \\
\hline Slurry & 6 & 60 & No & 90 & 90 & 5 & 1 & 937 & 139.4 & 4.3 \\
\hline Slurry & 6 & 60 & No & 90 & 90 & 5 & 2 & 951 & 139.5 & 4.1 \\
\hline Slurry & 6 & 60 & No & 90 & 90 & 5 & 3 & 763 & 137.4 & 4.4 \\
\hline Slurry & 6 & 60 & No & 90 & 90 & 15 & 1 & 1142 & 139.0 & 4.2 \\
\hline Slurry & 6 & 60 & No & 90 & 90 & 15 & 2 & 1000 & 140.3 & 4.0 \\
\hline Slurry & 6 & 60 & No & 90 & 90 & 15 & 3 & 1030 & 142.2 & 4.2 \\
\hline Slurry & 6 & 90 & Yes & 60 & 30 & 5 & 1 & 818 & 138.2 & 4.5 \\
\hline Slurry & 6 & 90 & Yes & 60 & 30 & 5 & 2 & 906 & 140.2 & 4.6 \\
\hline Slurry & 6 & 90 & Yes & 60 & 30 & 5 & 3 & 837 & 139.2 & 4.5 \\
\hline Slurry & 6 & 90 & Yes & 60 & 30 & 15 & 1 & 1046 & 138.9 & 4.5 \\
\hline Slurry & 6 & 90 & Yes & 60 & 30 & 15 & 2 & 1012 & 140.3 & 4.5 \\
\hline Slurry & 6 & 90 & Yes & 60 & 30 & 15 & 3 & 1052 & 141.7 & 4.6 \\
\hline Slurry & 6 & 90 & Yes & 60 & 90 & 5 & 1 & 887 & 139.7 & 4.5 \\
\hline Slurry & 6 & 90 & Yes & 60 & 90 & 5 & 2 & 834 & 139.2 & 4.5 \\
\hline Slurry & 6 & 90 & Yes & 60 & 90 & 5 & 3 & 787 & 138.1 & 4.5 \\
\hline Slurry & 6 & 90 & Yes & 60 & 90 & 15 & 1 & 1045 & 139.2 & 4.4 \\
\hline Slurry & 6 & 90 & Yes & 60 & 90 & 15 & 2 & 952 & 139.1 & 4.5 \\
\hline Slurry & 6 & 90 & Yes & 60 & 90 & 15 & 3 & 851 & 138.8 & 4.5 \\
\hline Slurry & 6 & 90 & Yes & 90 & 30 & 5 & 1 & 828 & 138.4 & 4.3 \\
\hline Slurry & 6 & 90 & Yes & 90 & 30 & 5 & 2 & 967 & 139.4 & 4.3 \\
\hline Slurry & 6 & 90 & Yes & 90 & 30 & 5 & 3 & 873 & 138.6 & 4.4 \\
\hline Slurry & 6 & 90 & Yes & 90 & 30 & 15 & 1 & 961 & 138.1 & 4.2 \\
\hline Slurry & 6 & 90 & Yes & 90 & 30 & 15 & 2 & 1051 & 138.5 & 4.0 \\
\hline Slurry & 6 & 90 & Yes & 90 & 30 & 15 & 3 & 1058 & 138.1 & 4.1 \\
\hline Slurry & 6 & 90 & Yes & 90 & 90 & 5 & 1 & 816 & 139.0 & 3.8 \\
\hline Slurry & 6 & 90 & Yes & 90 & 90 & 5 & 2 & 873 & 137.4 & 4.1 \\
\hline Slurry & 6 & 90 & Yes & 90 & 90 & 5 & 3 & 861 & 137.1 & 4.1 \\
\hline Slurry & 6 & 90 & Yes & 90 & 90 & 15 & 1 & 1212 & 137.8 & 3.9 \\
\hline Slurry & 6 & 90 & Yes & 90 & 90 & 15 & 2 & 1058 & 137.4 & 3.9 \\
\hline Slurry & 6 & 90 & Yes & 90 & 90 & 15 & 3 & 892 & 136.4 & 4.1 \\
\hline Slurry & 6 & 90 & No & 60 & 30 & 5 & 1 & 736 & 137.9 & 4.6 \\
\hline Slurry & 6 & 90 & No & 60 & 30 & 5 & 2 & 857 & 139.7 & 4.5 \\
\hline Slurry & 6 & 90 & No & 60 & 30 & 5 & 3 & 885 & 138.7 & 4.6 \\
\hline
\end{tabular}


Table A.1 (cont.)

\begin{tabular}{|c|c|c|c|c|c|c|c|c|c|c|}
\hline $\begin{array}{c}\text { Cement } \\
\text { Type }\end{array}$ & $\begin{array}{c}\text { Cement } \\
\text { Amount } \\
(\%)\end{array}$ & $\begin{array}{c}\text { Slurry Water } \\
\text { Batching } \\
\text { Temperature } \\
\left({ }^{\circ} \mathrm{F}\right) \\
\end{array}$ & $\begin{array}{c}\text { Slurry } \\
\text { Additive }\end{array}$ & \begin{tabular}{|c} 
Slurry Aging \\
Temperature \\
$\left({ }^{\circ} \mathrm{F}\right)$
\end{tabular} & $\begin{array}{l}\text { Slurry } \\
\text { Aging } \\
\text { Time } \\
\text { (min) }\end{array}$ & $\begin{array}{l}\text { Mixing } \\
\text { Time } \\
\text { (sec) } \\
\end{array}$ & Specimen & $\begin{array}{c}\text { 7-day UCS } \\
\text { (psi) }\end{array}$ & $\mathrm{DD}$ (pcf) & MC (\%) \\
\hline Slurry & 6 & 90 & No & 60 & 30 & 15 & 1 & 864 & 141.7 & 4.7 \\
\hline Slurry & 6 & 90 & No & 60 & 30 & 15 & 2 & 916 & 140.0 & 4.6 \\
\hline Slurry & 6 & 90 & No & 60 & 30 & 15 & 3 & 1100 & 139.4 & 4.4 \\
\hline Slurry & 6 & 90 & No & 60 & 90 & 5 & 1 & 652 & 138.2 & 4.6 \\
\hline Slurry & 6 & 90 & No & 60 & 90 & 5 & 2 & 894 & 139.1 & 4.5 \\
\hline Slurry & 6 & 90 & No & 60 & 90 & 5 & 3 & 809 & & \\
\hline Slurry & 6 & 90 & No & 60 & 90 & 15 & 1 & 962 & 139.6 & 4.5 \\
\hline Slurry & 6 & 90 & No & 60 & 90 & 15 & 2 & 1089 & 139.7 & 4.4 \\
\hline Slurry & 6 & 90 & No & 60 & 90 & 15 & 3 & 1005 & 138.9 & 4.4 \\
\hline Slurry & 6 & 90 & No & 90 & 30 & 5 & 1 & 883 & 139.1 & 4.3 \\
\hline Slurry & 6 & 90 & No & 90 & 30 & 5 & 2 & 836 & 138.2 & 4.1 \\
\hline Slurry & 6 & 90 & No & 90 & 30 & 5 & 3 & 875 & 139.2 & 4.1 \\
\hline Slurry & 6 & 90 & No & 90 & 30 & 15 & 1 & 1138 & 138.5 & 4.0 \\
\hline Slurry & 6 & 90 & No & 90 & 30 & 15 & 2 & 1078 & 138.9 & 4.1 \\
\hline Slurry & 6 & 90 & No & 90 & 30 & 15 & 3 & 1045 & 139.3 & 4.0 \\
\hline Slurry & 6 & 90 & No & 90 & 90 & 5 & 1 & 762 & 138.2 & 4.1 \\
\hline Slurry & 6 & 90 & No & 90 & 90 & 5 & 2 & 814 & 138.3 & 4.1 \\
\hline Slurry & 6 & 90 & No & 90 & 90 & 5 & 3 & 896 & 138.2 & 4.0 \\
\hline Slurry & 6 & 90 & No & 90 & 90 & 15 & 1 & 1153 & 138.6 & 3.9 \\
\hline Slurry & 6 & 90 & No & 90 & 90 & 15 & 2 & 1137 & 138.8 & 3.9 \\
\hline Slurry & 6 & 90 & No & 90 & 90 & 15 & 3 & 971 & 137.6 & 3.9 \\
\hline Dry & 2 & NA & NA & NA & NA & 5 & 1 & 520 & 135.4 & 4.6 \\
\hline Dry & 2 & NA & NA & NA & NA & 5 & 2 & 536 & 136.5 & 4.9 \\
\hline Dry & 2 & NA & NA & NA & NA & 5 & 3 & 480 & 137.1 & 4.7 \\
\hline Dry & 2 & NA & NA & NA & NA & 15 & 1 & 448 & 137.6 & 4.5 \\
\hline Dry & 2 & NA & NA & NA & NA & 15 & 2 & 511 & 136.3 & 4.8 \\
\hline Dry & 2 & NA & NA & NA & NA & 15 & 3 & 497 & 137.9 & 4.7 \\
\hline Dry & 6 & NA & NA & NA & NA & 5 & 1 & 1067 & 138.5 & 4.3 \\
\hline Dry & 6 & NA & NA & NA & NA & 5 & 2 & 848 & 139.3 & 4.3 \\
\hline Dry & 6 & NA & NA & NA & NA & 5 & 3 & 1033 & 138.4 & 4.3 \\
\hline Dry & 6 & NA & NA & NA & NA & 15 & 1 & 1190 & 138.7 & 4.2 \\
\hline Dry & 6 & NA & NA & NA & NA & 15 & 2 & 1099 & 137.1 & 4.2 \\
\hline Dry & 6 & NA & NA & NA & NA & 15 & 3 & 1120 & 137.4 & 4.2 \\
\hline
\end{tabular}


